\title{
OUR PLACE IN MATERIALS
}

Mike Knauer

\author{
A thesis submitted to the Faculty of Graduate and Postdoctoral Affairs in \\ partial fulfillment of the requirements for the degree of
}

\section{Master of Architecture}

\author{
Carleton University \\ Ottawa, Ontario \\ (c) 2014 Mike Knauer
}


Thanks to mom and dad, who gave me everything they had to give.

To nana and papa: if I saw further, it was because of you.

To omi and opa: you showed me what real strength is.

To my brother, sister, and little jessie: everywhere we go, we go together.

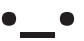




\section{"A hidden tuning fork in the great cold sends out its tone.}

I stand under the starry sky and feel the world creep in and out of my coat, as in an ant hill."

Thomas Transtromer 


\section{ABSTRACT}

This thesis represents both a material investigation and an architectural vision. This investigation sought to explore and document practical methods available for creating starch bioplastic building components. Using readily available raw materials and simple tools, potential recipes for and applications of starch-based bioplastic were explored and recorded. Design solutions were explored through the architectural detail, seeking to imagine how biodegradability can become a generating idea for architectural expression. As changing climatic and environmental pressures continue to create unique challenges for architects and engineers, the unprecedented ability to design building materials from a fundamental level offers new opportunities for reducing our impact on this planet. 


\section{CONTENTS}

Chapter 1

Chapter 2

Chapter 3

Chapter 4

Chapter 5

Chapter 6

Chapter 7

Chapter 8

\section{ABSTRACT 4}

METHODOLOGY 6

RESEARCH 9

DESIGNING MATERIALS 17

MAKING 28

ANALYSIS 42

MATERIAL IMAGINATION 54

CONCLUSION 82

POST SCRIPT 84

BIBLIOGRAPHY 85 
Over the course of this thesis, I sought to explore, discover, and document practical methods available for creating starch bioplastic building components. Using readily available raw materials and simple tools, potential recipes for and applications of starch-based bioplastic were explored and recorded. From these initial recipes, I explored design solutions for bioplastic starch building components through models, materials research, architectural details, and a thorough review of the relevant literature. In order to provide specific direction for this exploration, the research was guided by the questions and objectives described below.

\subsection{Questions to answer:}

1. What does the material "want to be"?

2. How might this material be produced? Who can produce and use it?

3. How might it be assembled and disposed of?

4. What are the benefits / drawbacks of bioplastic in the built environment?

5. What are the physical limitations of bioplastic components? How do they withstand stress and strain when in compression or tension? How would they behave in emergency situations, such as a fire? 


\subsection{Research Objectives:}

One of the main objectives of this research was to create a set of recipes and processes for making bioplastic starch which are relevant for specific architectural applications. These recipes and process have been fully documented in the following chapters, so that they could be reproduced and replicated by anyone with a minimal investment of energy, materials, and / or tools. As such, a large component of the work involved documenting and providing details of assemblies, components, and tools required to produce imagined building components.

\subsection{Study Phases:}

The study was broken up into five distinct phases in order to obtain a thorough understanding of the use of bioplastic starch as building material, and apply this knowledge through practical material production and testing. From these cursory tests of its mechanical properties, possible applications of bioplastic starches and assemblies were theorized.

1. Research - The first phase, Research, involved gathering data and relevant literature to better understand the context of the issue and the extent of research, particularly as it pertains to architecture and development. I undertook a thorough review of the pertinent literature to better understand the history and current research on starch bioplastic in the built environment.

2. Material Design - The second phase, Material Design, involved testing ways in which starch bioplastic material could be applied to address specific design 
needs and functions. Material testing was performed in order to determine an appropriate recipe and process for producing starch-based bioplastic components. These recipes were evaluated on their capacity to produce optimal qualities for constructing architectural components.

3. Making - In the third phase, Making, a large range of bioplastic test samples and 1:1 scale components were crafted using the processes and designs established in previous phases. The samples produced were meant to discover the innate physical characteristics of this new material which would prove interesting or useful in architectural applications.

4. Analysis - The fourth phase, Analysis, involved the thorough testing of the material and components to determine structural limits and performance in environmental conditions similar to those experienced in the built environment. Social, economic, and disposal considerations were examined in detail.

5. Material Imagination - The final phase, Material Imagination, involved the speculative design and application of the new material; ranging from imagined construction details to single dwellings and hypothetical urban frameworks. This theoretical demonstration of the potential for bioplastic starch in the built environment was informed by the novel characteristics of starch bioplastic discovered in previous explorations, and imagines a new mode of dwelling within these new materials and constructions. 


\section{RESEARCH}

\subsection{What is starch?}

Starch is a naturally occurring polysaccharide (carbohydrate) that functions as the energy storage system within plants. ${ }^{1}$ It is comprised of two main components, amylose and amylopectin, both of which are also naturally occurring polymers composed of differing arrangements of glucose. ${ }^{2}$ Plants store their energy in the form of starch through the process of photosynthesis. ${ }^{3}$ During this process, energy from the sun is utilized to biochemically convert carbon dioxide and water into glucose and oxygen. The carbohydrate glucose is required for the continued functioning of the plant, just as our human bodies require carbohydrates to perform bodily functions. Following the creation of glucose in the green leaves of the plant, it is transferred to a storage organ, (such as tubers, roots, or nuts) where it is converted into starch. ${ }^{4}$ These storage organs serve to physically store captured bio-chemical energy in the form of

\footnotetext{
1 Scott, Gerald. Polymers and the environment. Royal Society of Chemistry, 1999. P.4

2 Maria Teresa Pedrosa Silva Clerici, and Adel El-Sonbati. "Physical and/or Chemical Modifications of Starch by Thermoplastic Extrusion." Thermoplastic Elastomers. Rijeka: InTech, 2012. P.39.

3 Maria Teresa Pedrosa Silva Clerici, and Adel El-Sonbati. "Physical and/or Chemical Modifications of Starch by Thermoplastic Extrusion." Thermoplastic Elastomers. Rijeka: InTech, 2012. P.39.

$4 \quad$ Avérous, Luc, and Eric Pollet. "2." Environmental silicate nano-biocomposites. London: Springer, 2012. P.17. Print.
} 
starch granules for when it may be needed later. ${ }^{5}$

Under the right conditions, solid starch granules can become a versatile bioplastic which has many functional uses and benefits. ${ }^{6}$ In order to produce bioplastic from starch, water and heat energy must be applied. When mixed with an aqueous plasticizer (such as water) and sufficient heat energy, starch undergoes "gelatinization". In this process, the normally insoluble starch granules experience a "loss of molecular organization", and absorb some of the surrounding water, while simultaneously releasing amylose from the starch granules. ${ }^{7}$ With the removal of heat, the gel cools (or retrogrades) into a rigid solid. During retrogradation, the structure of the starch granules is re-organized into a more ordered structure within a matrix of amylose, resulting in a rigid solid ${ }^{8}$. This bioplastic is rigid, durable, flexible, and is adept at making thin films.

\subsection{Using Starch}

Starch biopolymers have been used for thousands of years as a stiffening or binding agent. Throughout antiquity starches were widely used in the production of food products, but have also been utilized in a large range of industrial applications. From binding papyrus in 4000 BCE Egypt to resisting

\footnotetext{
5 Avérous, Luc, and Eric Pollet. "2." Environmental silicate nano-biocomposites. London: Springer, 2012. P.17. Print.

6 Avérous, Luc, and Eric Pollet. "2." Environmental silicate nano-biocomposites. London: Springer, 2012. P.18. Print.

7 Bertolini, Andréa C.. Starches: characterization, properties, and applications. Boca Raton: Taylor \& Francis, 2010. Print. P.3

8 Bertolini, Andréa C.. Starches: characterization, properties, and applications. Boca Raton: Taylor \& Francis, 2010. Print. P.3
} 
ink penetration in 300 CE Chinese paper, starches have advanced industrial technology outside of the food industry for thousands of years. ${ }^{9}$ Aside from their utility as a laminate for paper products, starches have found industrial and commercial applications throughout history as the powder for powdered wigs in 18th century Europe, a critical component of the gum industry in Germany and Britain during the Industrial Revolution, and as an invaluable resource for the textile industry since the Middle Ages. ${ }^{10}$

Starches today have an exceptionally wide range of uses that continues to grow, making them an appealing choice for both food and industrial applications. From the recent successes of starch based bioplastic products, including paper, cardboard, and packaging films, the opportunity for starch bioplastic in non-food industries (such as construction) is becoming increasingly apparent. ${ }^{11}$ Architects and designers are now recognizing and exploring these new materials, as their economic advantages, environmental implications, and manufacturing processes become better understood. As a result of their high value as a binding agent, modified potato, cassava, and corn starches are being introduced into common construction elements through commercially available building products, such as mortar, plaster, particleboard, concrete, and insulation. At this point in time, we are witnessing the first real-world materializations of bioplastic building components suitable for the built environment as plausible additions to our palette of materials.

9 BeMiller, James N., and Roy Lester Whistler. Starch chemistry and technology. 3rd ed. London: Academic, 2009. Print. P.2

10 BeMiller, James N., and Roy Lester Whistler. Starch chemistry and technology. 3rd ed. London: Academic, 2009. Print. P.3

11 Maria Teresa Pedrosa Silva Clerici, and Adel El-Sonbati. "Physical and/or Chemical Modifications of Starch by Thermoplastic Extrusion." Thermoplastic Elastomers. Rijeka: InTech, 2012. P.48. 


\subsection{Bioplastic in the built environment}

On the forefront of innovation, the Institute of Built Structures and Structural Design (ITKE) at Stuttgart University in Stuttgart, Germany, recently produced one of the most notable and exciting examples illustrating the emergence of bioplastics into the built environment. In October of 2013, this team of architects, materials scientists, and environmental experts published a process for fabricating a bioplastic exterior panelling system using a material referred to as "ArboSkin". This unique blend of renewable materials is comprised of lignin, starch, cellulose, organic additives, natural resins or waxes and natural reinforcing fibers. ${ }^{12}$ It is comprised of over $90 \%$ renewable materials, is completely thermoformable, can be machined by computer numeric control (CNC) routers or traditional hand tools, and is fully compostable. ${ }^{13}$ According to the design team, this project represents the first application of bioplastic sheets that are comprised primarily of renewable resources, specifically designed for construction, and suitable for exterior applications. ${ }^{14}$

Another project, led by Dr. Andrew Abbott at the University of Leicester, has recently demonstrated a practical and pragmatic application of starch bioplastic within the domestic sphere. Dr. Abbott and his team have produced a medium-density fibreboard (MDF) that is comprised of recycled wood flour and thermoplastic starch resin; they were awarded the Royal Society Brian Mercer Award for Innovation in 2013 for their efforts. Medium density fibreboard

\footnotetext{
12 Köhler, C.. "Biobased plastics for exterior facades." BioPlastics Magazine 1 Apr. 2014: 12-14.

13 Knippers, Jan. "ArboSkin: Durable and Recyclable Bioplastics Facade Mock-Up ." Press Release. ITKE University of Stuttgart . University of Stuttgart, Stuttgart. 10 Feb. 2013. lease. ITKE University of Stuttgart. University of Stuttgart, Stuttgart. 10 Feb. 2013.
} 
is typically made from a combination of wood flour and urea-formaldehyde resin. As a result of the use of urea-formaldehyde, these wood products are not recyclable and are often linked to a wide variety of health concerns. The replacement of petroleum based resin with a stable biodegradable biopolymer not only allows for the unprecedented recycling of these fibreboards, it has resulted in a product which is absolutely comparable in strength and application to its petroleum derived counterpart while mitigating the adverse health effects associated with urea-formaldehyde..$^{15}$

From this literary research analysis of starch bioplastic, it is clear that we are working with a material with a myriad of beneficial properties. Bioplastic starch is rigid, easily mouldable, and deteriorates organically in the natural environment. On the other hand, it tends to be brittle, has a limited useful life when chemically unmodified, and experiences structural issues when exposed to water. As architects and designers continue to acknowledge bioplastics as a feasible building material, it is becoming increasingly important to address its individual scale capacity for construction. These unique challenges presented by bioplastics in the built environment can always be overcome with ingenuity in design; we are, as always, limited by the bounds of our collective imagination and creativity.

15 Abbott, Andrew P., Jesus Palazuela Conde, Stefan J. Davis, and William R. Wise. "Starch as a replacement for urea-formaldehyde in medium density fibreboard." Green Chemistry 14.11 (2012): 3067. Print. 
Figure 1 - Biochemical storage of solar energy as starch

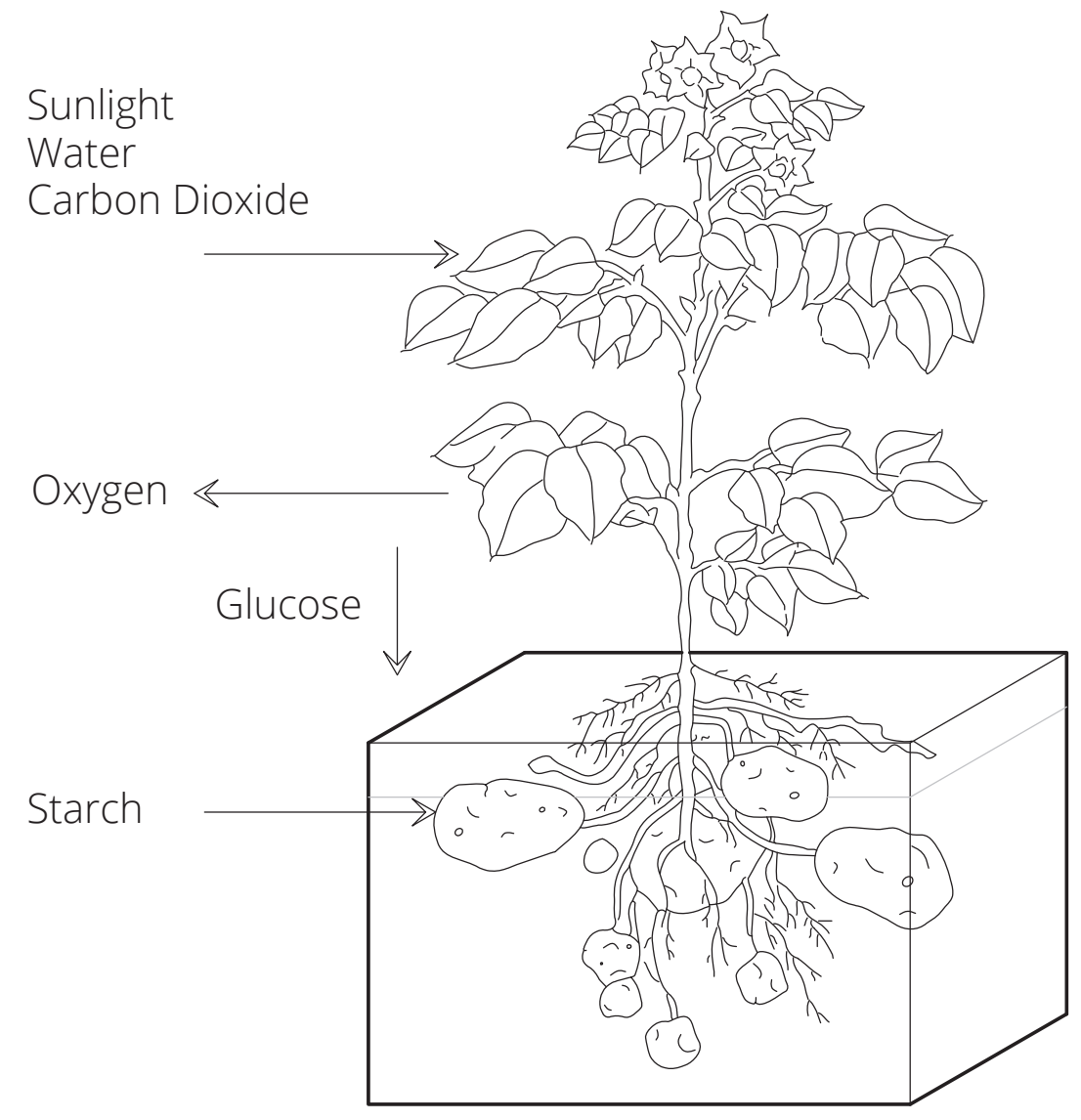

Figure 2 - Chemical composition of a starch granule

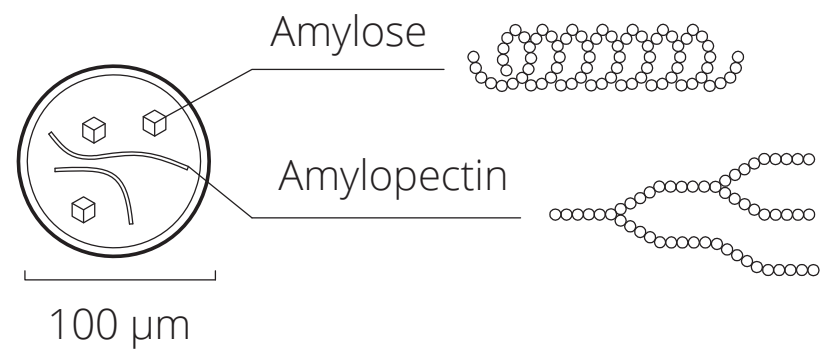


Figure 3 - Gelatinization of a starch granule

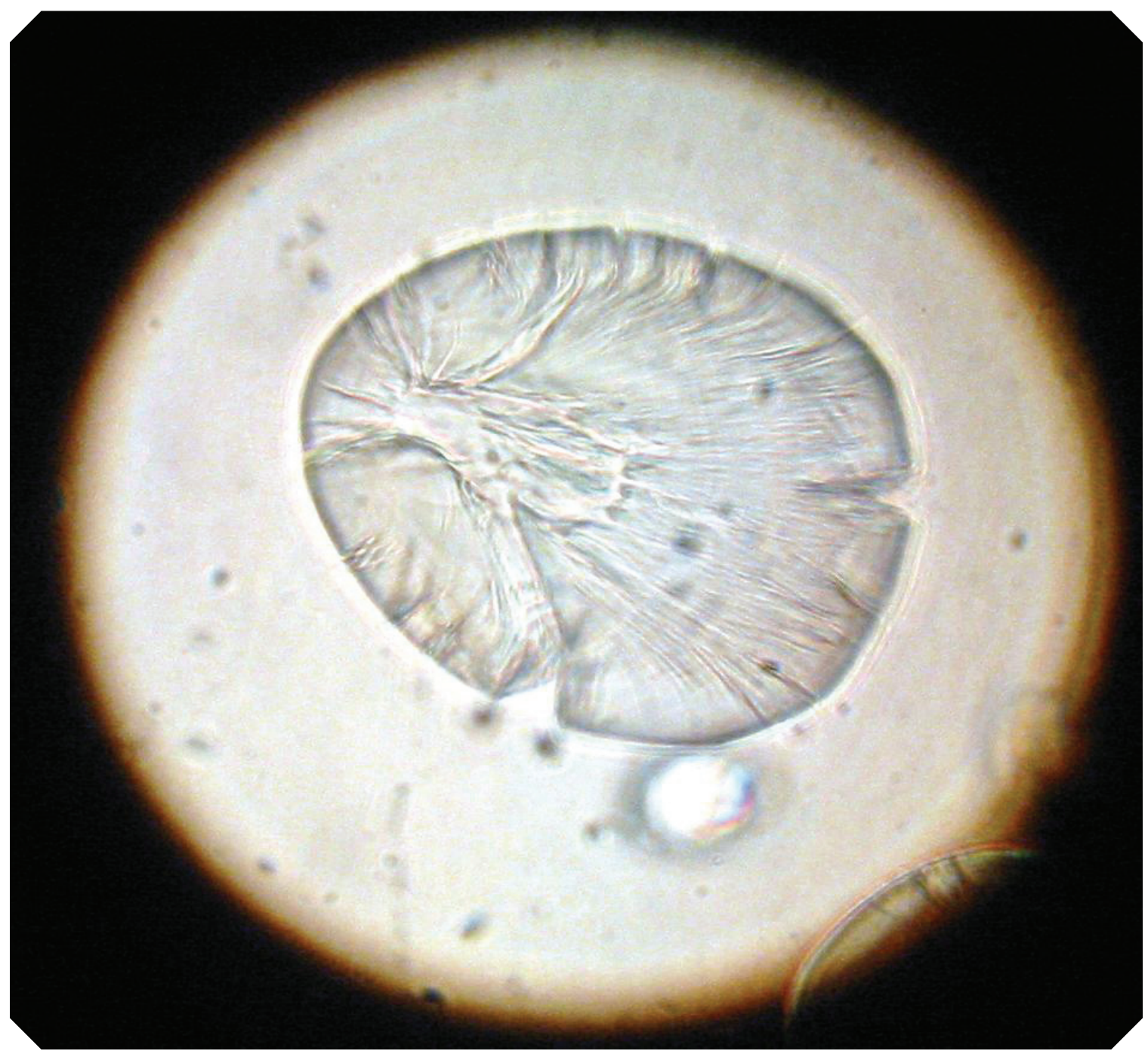

Source: Cyber Colloids - http://www.cybercolloids.net/information/technical-articles/starch-damaged-potato-starch

Figure 4 - Gelatinization of a starch granule

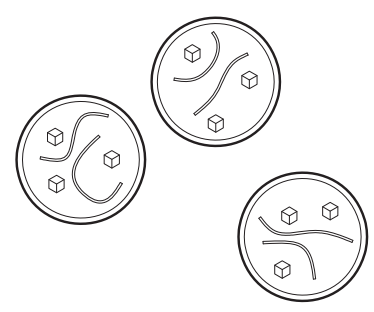

Dry

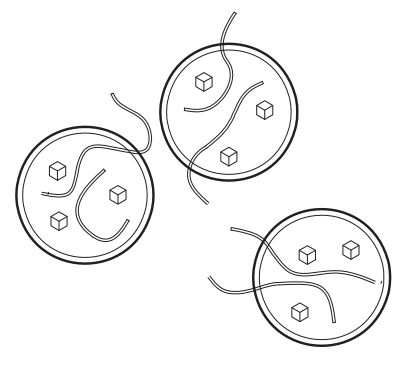

Gelatinization

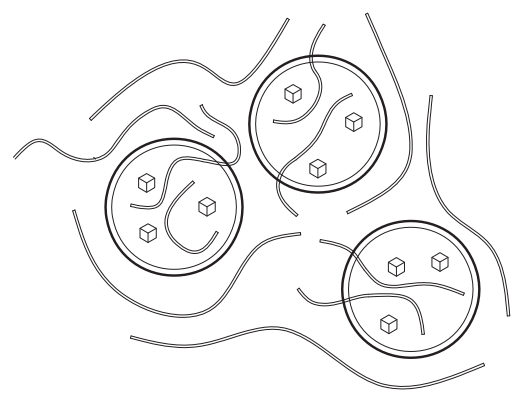

Retrogradation 
Figure 5 - ArboSkin Pavilion facade

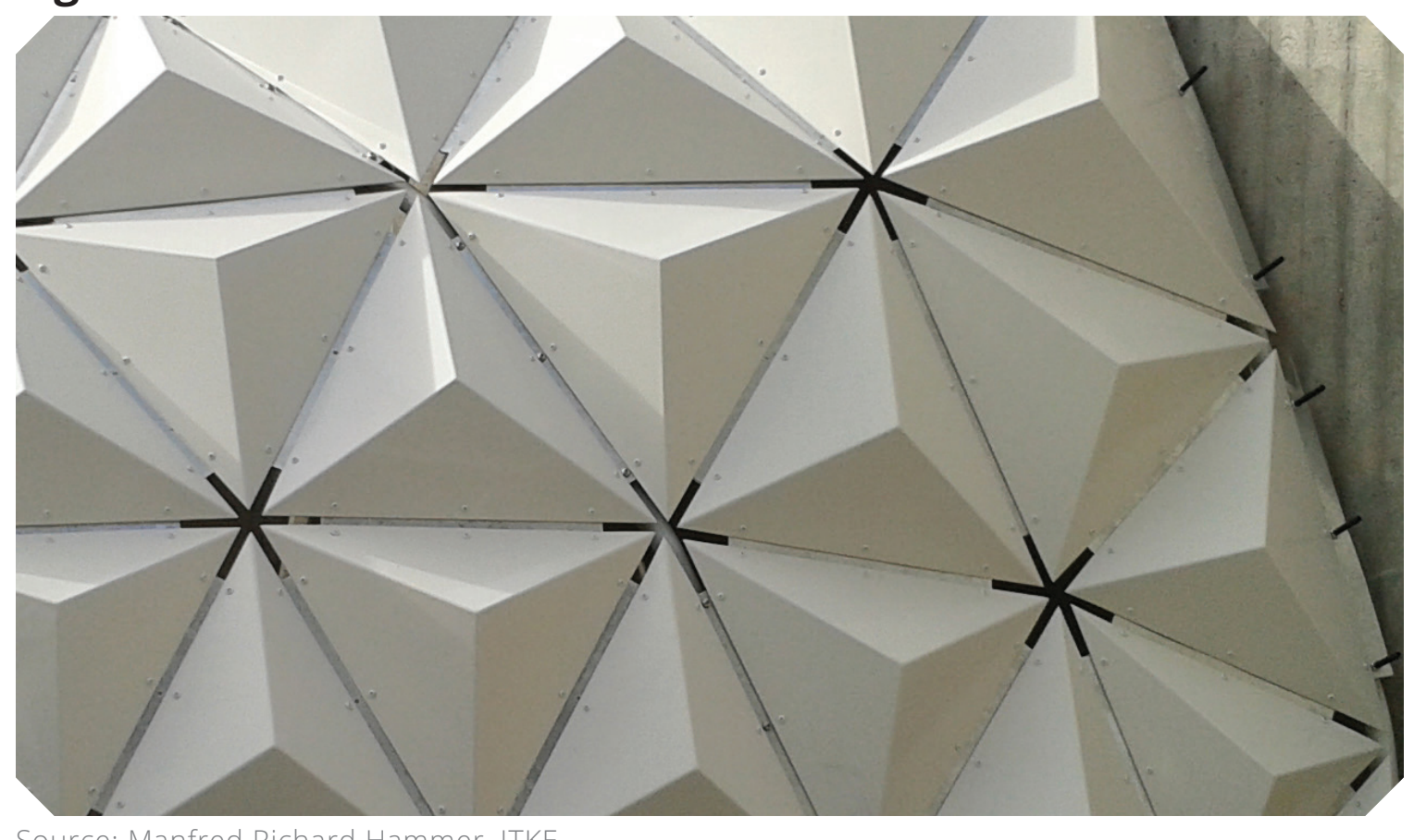

Source: Manfred Richard Hammer, ITKE

Figure 6 - ArboSkin Pavilion completed assembly

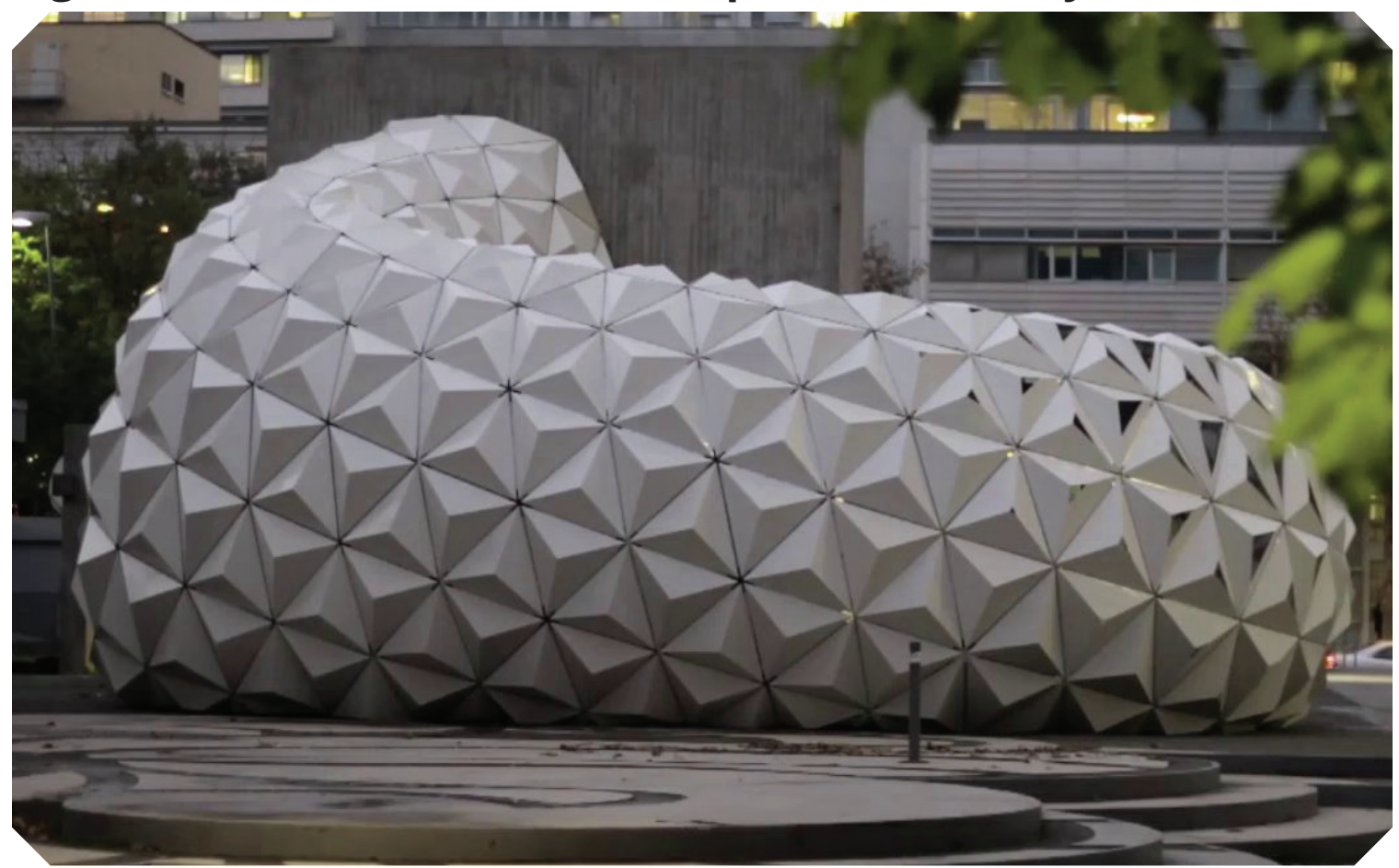

Source: Manfred Richard Hammer, ITKE 


\section{DESIGNING MATERIALS}

"If you think of Brick, you say to Brick, 'What do you want, Brick?' And Brick says to you, 'I like an Arch.' And if you say to Brick, 'Look, arches are expensive, and I can use a concrete lintel over you. What do you think of that, Brick?' Brick says, 'I like an Arch.' And it's important, you see, that you honor the material that you use. You can only do it if you honor the brick and glorify the brick instead of shortchanging it." - Louis Kahn

\subsection{The Architecture of Materials}

The cultural and formal overlap between cuisine and architecture has become a long-standing analogy within these two disciplines over many decades of discourse. From the surgical preparation of food and the architectonic processes of designing meals to the experience of dining and its formal manifestation(s), the linkage between cuisine and the production of space is concretely established within the architectural imagination. ${ }^{1}$ As a result of this ideological intersection, the emergence of and critical praise for the discipline of 
molecular gastronomy over the past three decades suggests a departure from traditional design thinking and making within cookery which holds significant implications for architecture and our perception of raw materials. The notion of molecular gastronomy typically refers to a shift from traditional methods and raw materials to the in-depth exploration of the physical and chemical phenomena that occur within food while cooking. ${ }^{2}$ The primary purpose of molecular gastronomy is to actively design new tastes, textures, and experiences for diners that are not available through traditionally available raw materials or techniques by manipulating the physical and chemical characteristics and processes of the ingredients and their assemblage.

Addressing the physical and psychological phenomena of culinary art through the lens of scientific observation is a novel approach to hautecuisine that offers interesting parallels to the field of architecture. Whereas the discipline of molecular gastronomy has clearly demonstrated the potential to influence the physical manifestation and subtle idiosyncrasies of cuisine, we can speculate that there exists a similar opportunity to influence the physical and similarly idiosyncratic attributes of the built environment from within the discipline of architecture. There is an emerging body of research in healthcare architecture, often referred to as "evidence-based design", that primarily seeks to understand the substantial impact that building materials hold for the subconscious and psychologically nuanced facets of human inhabitation, such 


\section{Figure 7 - Molecular gastronomy cuisine}

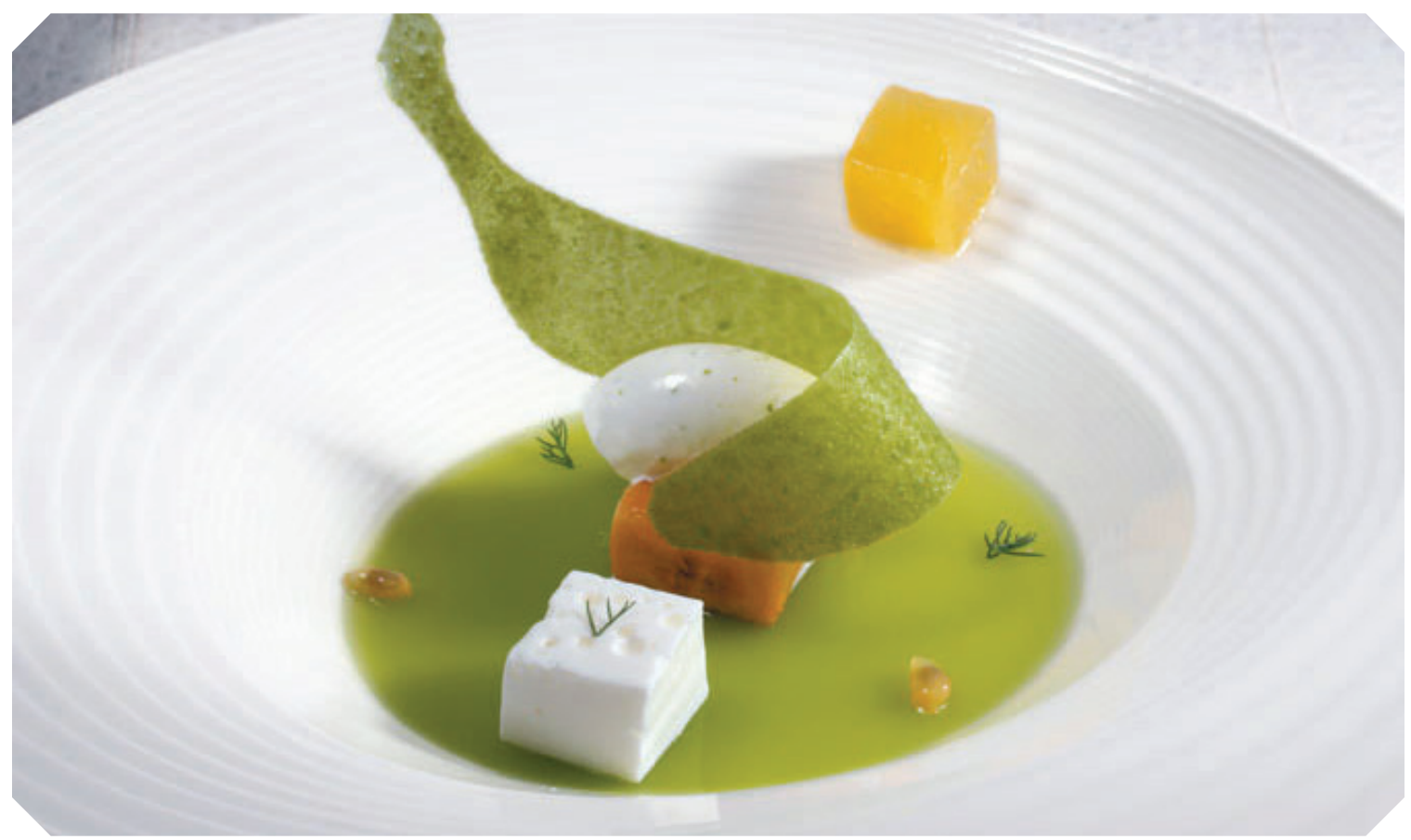

Source: El Bulli, taken from: http://mavillard.blogs.cultureplex.ca/

\section{Figure 8 - Transparent concrete}

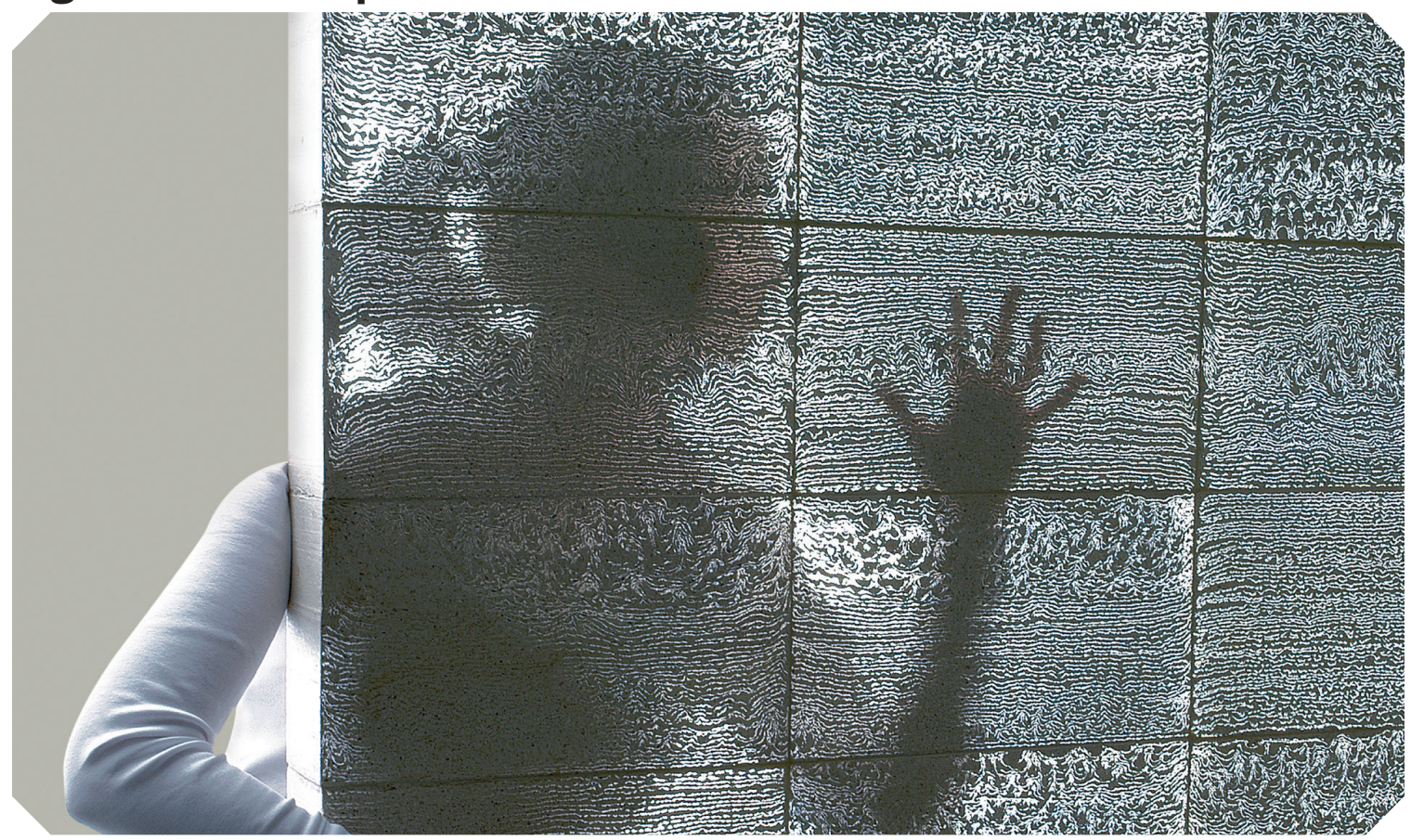

Source: Litracon Light Transmitting Concrete 
as symbolic or emotional meaning, or emotive response. ${ }^{3}$ Since the materials with which we choose to build define the physical boundaries and composition of our lived environments (what they look and feel like), they play a significant role in directly shaping our lifestyles and influencing our behaviours and moods. Just as molecular gastronomy has illustrated that extremely subjective and highly personal qualities of cuisine such as texture, flavour, smell, or aesthetic value can be negotiated on a quantitative and molecular scale using scientific observation and manipulation, the notion of evidence-based design fundamentally embraces the idea that the materials with which we surround ourselves on a daily basis have a significant impact on our mental and physical health which can be objectively understood and manipulated for psychological benefit.

Architects have always selected their material palette with purpose and to achieve specific objectives. Selecting materials based on architectural advantages and limitations is much different than designing what those advantages or limitations are, however. Learning from the wealth of rigour on molecular gastronomy, scientific observation and quantitative analysis focussed on interrupting and reinterpreting the process of making could hold significant implications for the formal and cultural manifestations of our built environments in the future. As the pressure from environmental concerns becomes increasingly important over upcoming decades, the opportunity to consciously design materials with specific pre-determined life-cycle objectives could drastically reshape the ways in which we percieve of building. Projects such as

3 McCullough, Cynthia S.. "Chapter 3: Healing Environments." Evidence-based design for healthcare facilities. Indianapolis, IN: Sigma Theta Tau International, 2010. 45. Print. 
the ArboSkin Pavilion and Abbott's biodegradable fibreboard are testament to this analogous shift in design thinking. In both of these examples, the design process embedded the designed advantages of raw materials within completed assemblies to achieve substantially different outcomes than conventional materials allowed.

Our material palette expands daily with innovative new materials, and the ways in which they are applied and to what end are ultimately at the discretion of architects and designers. We now have the unprecedented ability to control the limitations and abilities of our materials through technological advancement and scientific observation. This reconceptualization of building materials signals a shift from "materials in architecture" to the "architecture of materials", where design processes consider the physical characteristics and implications of the material on the molecular scale. Within her article "Material Innovations: Transparent, Lightweight, Malleable, and Responsive", Professor Filiz Klassen at Ryerson University summarizes this notion quite succinctly:

"Being a designer or an architect does not only imply giving form to materials chosen from a catalogue but now also requires the sensitivity and knowledge of a chemist and a biologist to alter materials' molecular structure. Scientific research has produced materials that last longer, reduce waste, change form, and adjust to environmental conditions in different contexts. Architects and designers should have the knowledge, ethics, and creativity to transfer these technological innovations developed by other industries into the built environment. Achieving or expressing absolute truth of design through autonomous artistic organization and material embellishments no longer seem to provide a convincing goal for many innovative architects. In contrast, many architects are becoming involved in 'alchemy' of construction, translating advanced material innovations into a more responsive and responsible built environment." 
In this sense, Professor Klassen insinuates that the notion of honouring the material may have drifted or evolved from what Louis Kahn stated in 1971. When Louis Kahn asked the brick what it wanted to be, he was considering the brick as the fundamental material of assembly. As we consider the architecture of our materials themselves, we have the opportunity to push this line of questioning much deeper; to go beyond the brick, and delve into the elementary components of the material itself.

\subsection{Exploring starch bioplastic: Recipes and processes}

As per the methodology prescribed by this investigation, this phase of the process involved testing ways in which starch bioplastic recipes could be crafted to address specific design needs and functions. A suitable recipe and process for creating starch based bioplastic was identified based on physical experimentation and research of methods and techniques from reputable sources. Several recipes were tried and tested before a stable and desirable outcome could be reliably produced.

The field-testing of the bioplastic recipes took place in a common kitchen, where practical ways of applying the preferred recipe of potato starch material were explored. Readily-available tools (such as pots, pans, and wooden spoons) and appliances (oven and range) were utilized in order to develop bioplastic components that might be suitable for specific construction applications. From these material investigations, a preferred recipe and method of application were identified, which was used to inform the design phase of the research project. 
Different combinations of raw ingredients were investigated until an "optimal recipe" was identified, which would be suitable for use in upcoming phases of the thesis. These raw ingredients varied between recipes, but typically included: potato, corn, or tapioca (cassava) starch, water, vinegar, gelatin, and glycerin. The base recipes, proportion of ingredients, and methods of making starch bioplastic were informed by the bioplastic community forums on Green Plastics and Appropedia, as well as Marilu Valente's research on bioplastic morphologies at Westminster University. ${ }^{57}$ The ingredients were mixed in a graduated measuring cup and transferred to a large cooking pot where heat was applied. Some samples were microwaved in order to apply heat to the mixture, with interesting and encouraging results. The addition of heat and water to the base starch mixture allowed it to gelatinize over a period of approximately 5 minutes. After five minutes, the majority of the water had been absorbed by the swelling starch granules, and a semi-viscous gelatinous paste had formulated in the cooking pot. This paste was ladled into a muffin tin, where it could cool, or retrograde. During cooling, the soft gelatinous plastic became a hard plastic material over the course of approximately 8 hours. Once cooled and solidified, the resultant plastic material was evaluated based on the common criteria requisite of building materials, such as rigidity, strength, and brittleness, among others.

\footnotetext{
5 "Bioplastics." - Appropedia: The sustainability wiki. Web. 23 July 2014. <http://www.appropedia.org/Bioplastics>.

$6 \quad$ Valente, Marilu. "(bio)Plastic Morphologies." WeWantToLearn.net. Web. 14 Sept. 2014. <https://wewanttolearn.wordpress.com/2013/03/01/bioplastic-morpholgies/>.

7 "The basics of making corn starch bioplastic." Green Plastics. Web. 14 Sept. 2014. <http:// green-plastics.net/posts/76/qaa-help-with-cornstarch-pla-plastic-project/>.
} 


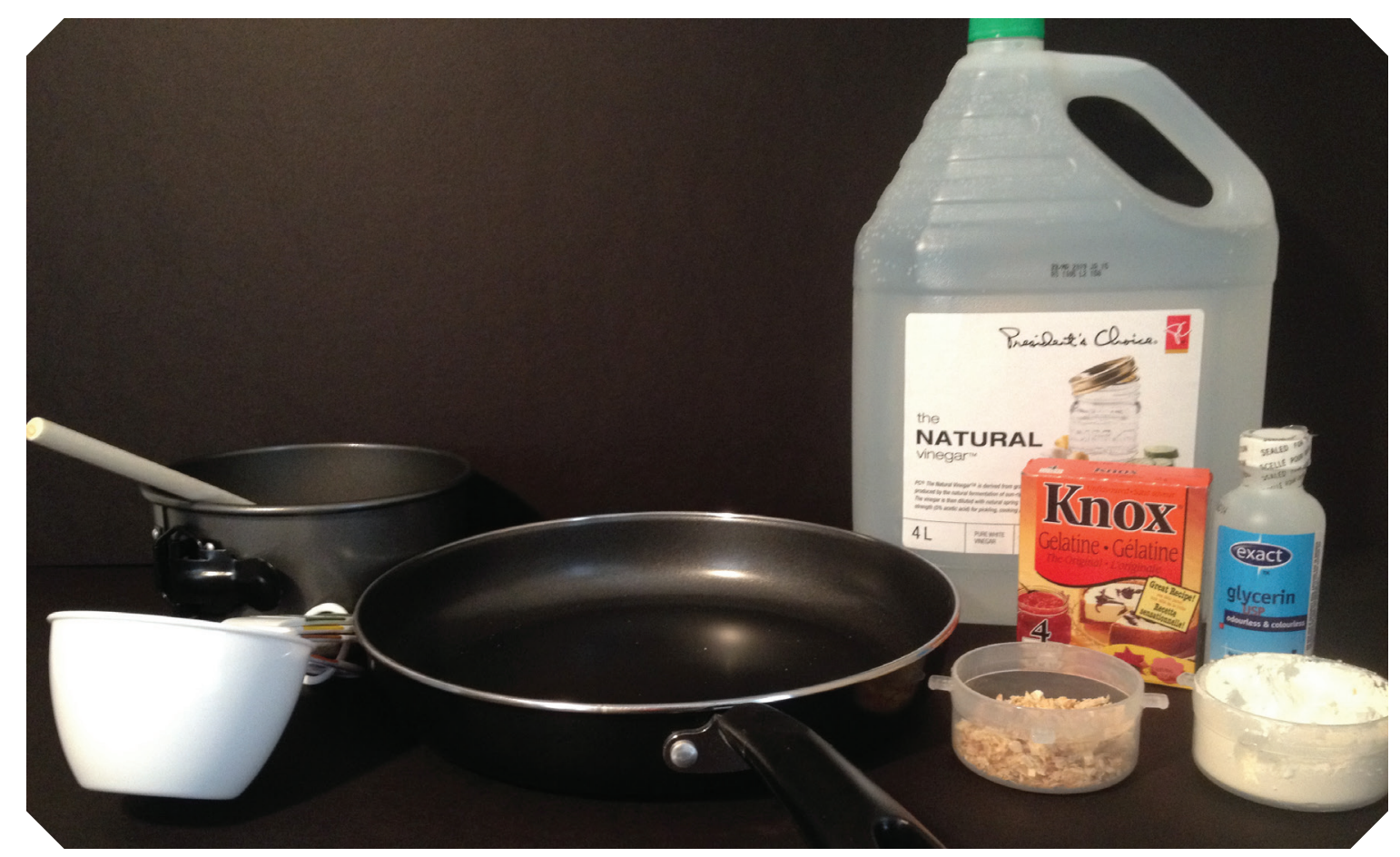

\section{Table 1 - Recipe and Directions}

\begin{tabular}{|l|l|}
\hline Optimal Recipe & Directions \\
\hline $\begin{array}{l}\text { Ingredients: } \\
700 \mathrm{ml} \text { water } \\
150 \mathrm{ml} \text { vinegar } \\
300 \mathrm{ml} \text { starch (dry, powder) } \\
50 \mathrm{ml} \text { glycerin } \\
\text { Optional: } 750 \mathrm{ml} \text { aggregate }\end{array}$ & $\begin{array}{l}\text { 1. Mix all the ingredients in a cooking } \\
\text { pot, and heat at } 120^{\circ} \mathrm{C} \text { until the mixture } \\
\text { gelatinizes. Once the starch has gelatinized, } \\
\text { aggregates can be added. } \\
\text { 2. Once gelatinized and aggregate has been } \\
\text { added, pour the mixture into the mould. } \\
\text { 3. Set the mould aside to dry for at least } \\
\text { 2 hours. After 2 hours, the brick can be } \\
\text { removed from the mould and should be } \\
\text { allowed to air dry for at least 24 hours. }\end{array}$ \\
\hline
\end{tabular}

\subsection{Data Tables}

The following are the results of the experimentation which took place in March and April of 2014. 

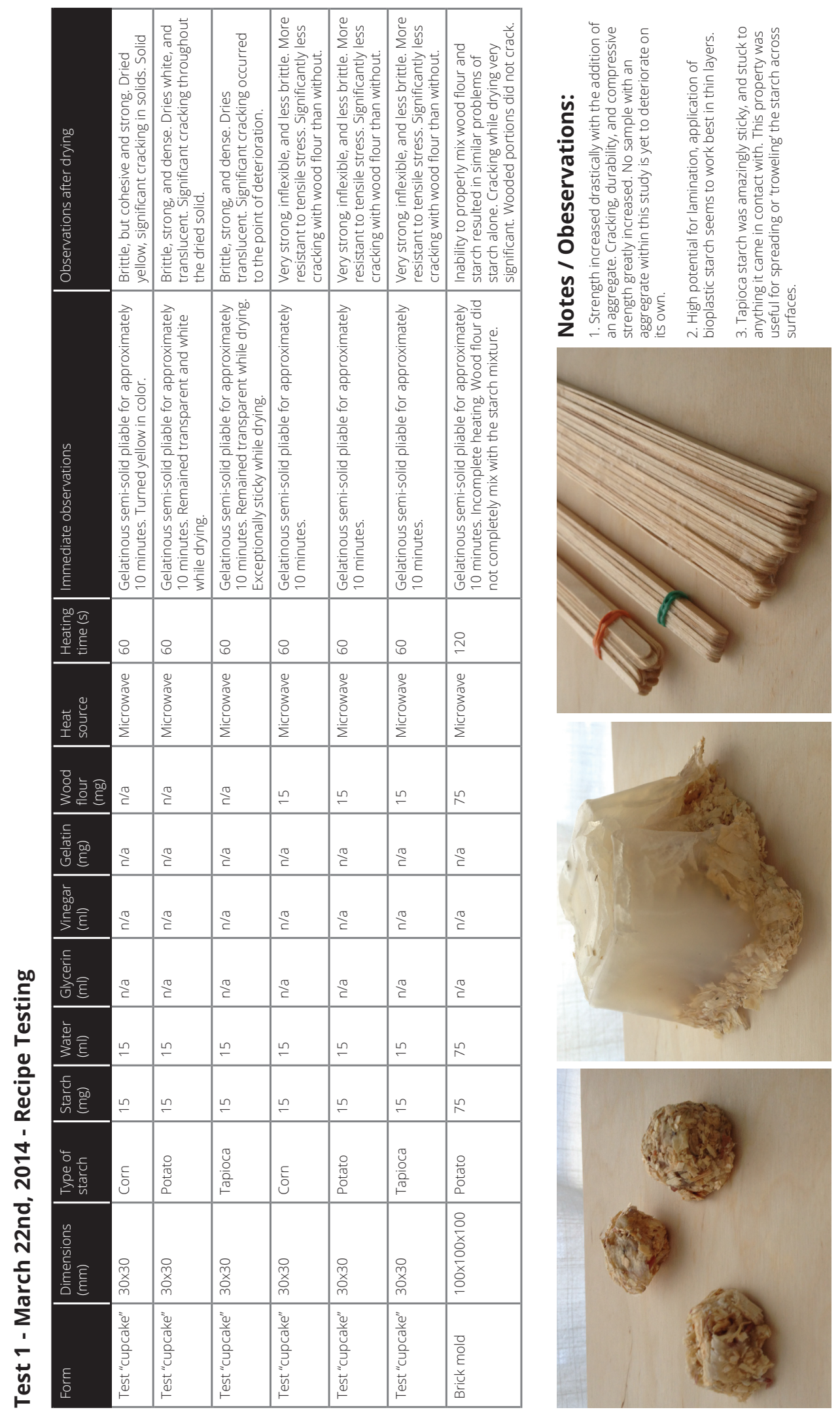


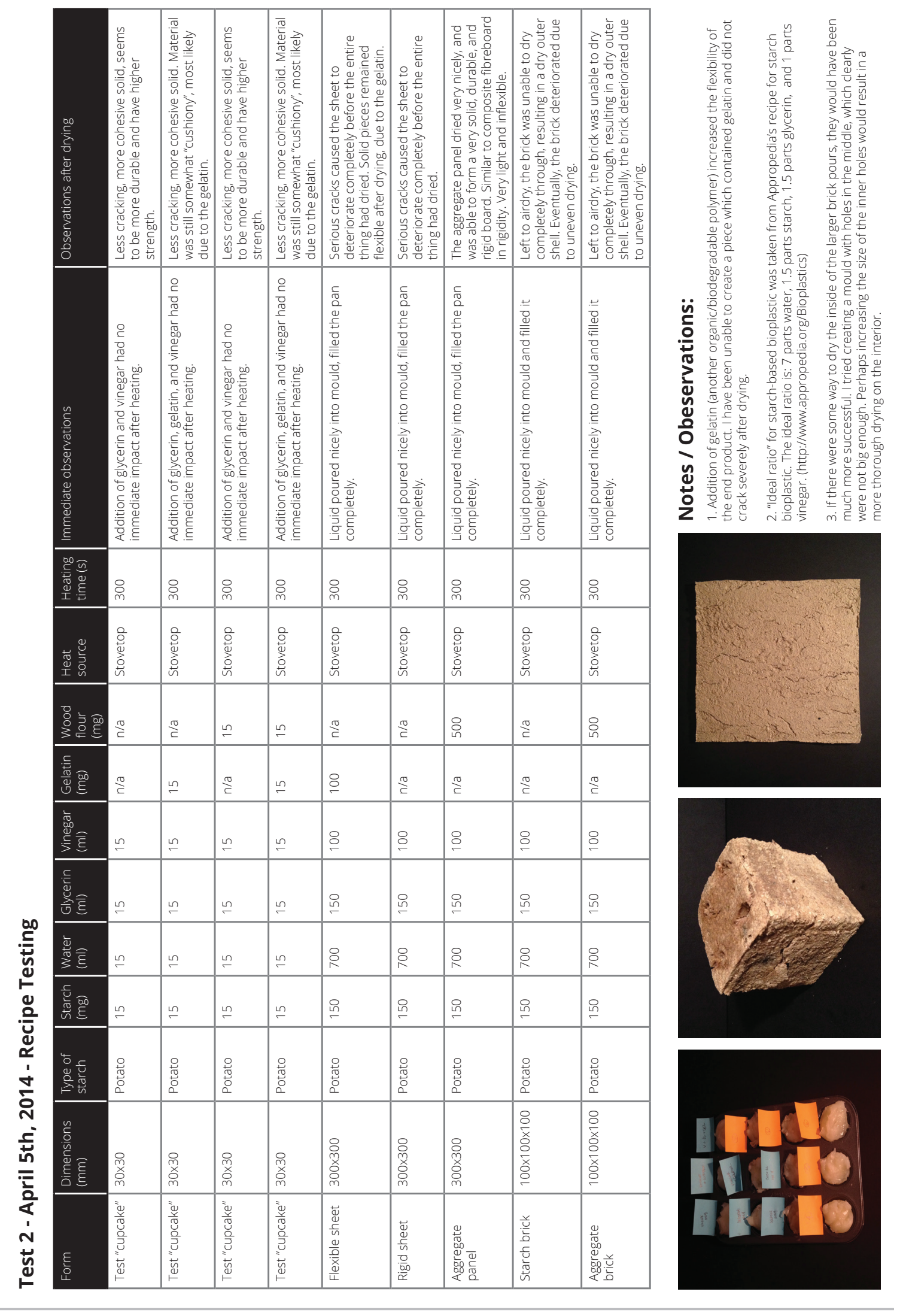

Page 26 


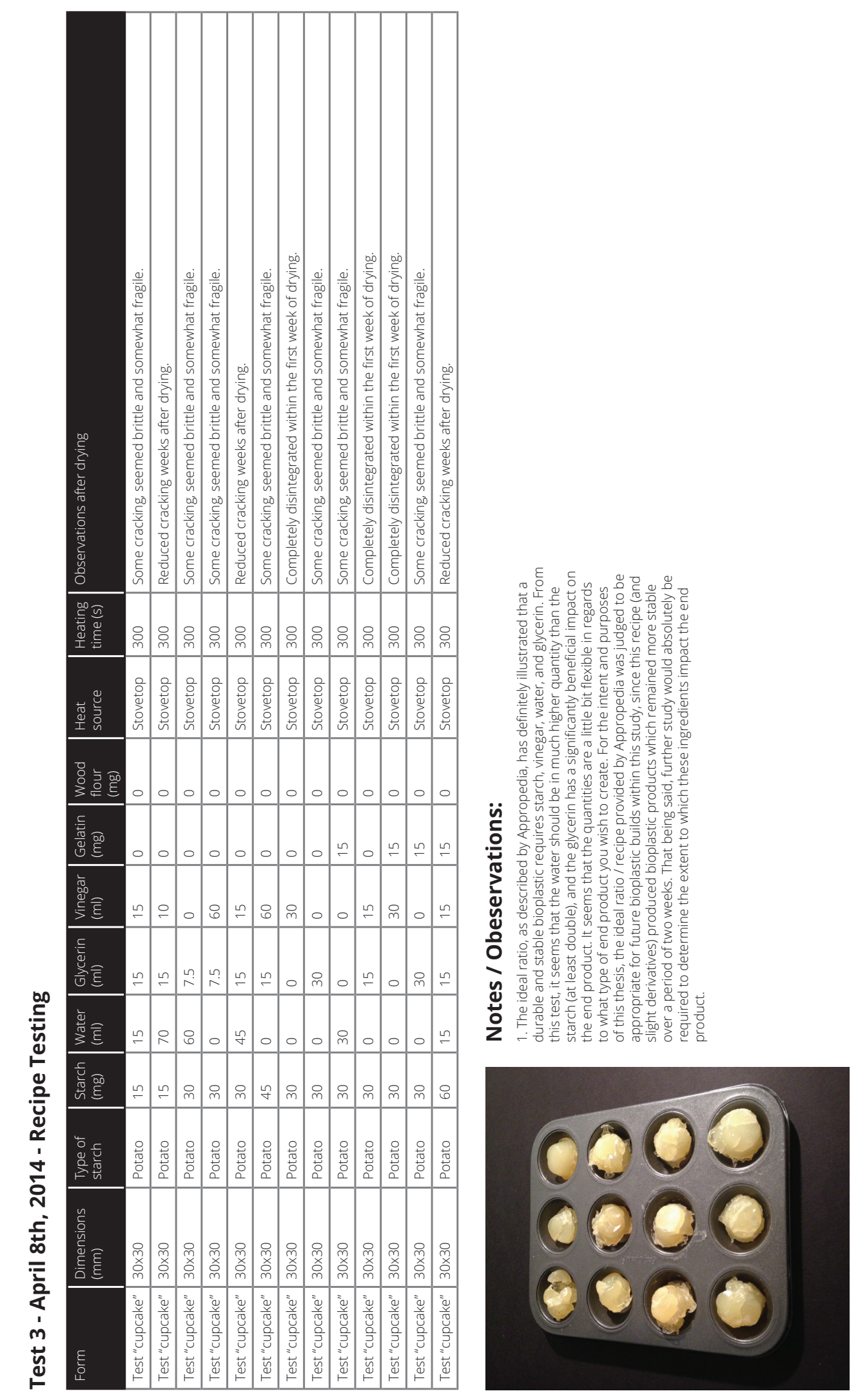




\section{MAKING}

\section{"The factory of the future will be everywhere and the designer will be everyone." - Nick lerodiaconou}

\subsection{Embodied Design}

Modes of consumption and production are changing at a rate never before experienced in human history. New technologies and methods of production such as 3D printers, stereolithography, and digital fabrication tools are beginning to enter the domestic sphere; signalling an inevitable shift in the location of production from the industrial and mass produced to the domestic and custom-made. At this time, we are undoubtedly experiencing an explosion of technological innovation which ranks among the greatest in human history. As the power to create with a high degree of precision is becoming available to individual consumers at an unprecedented rate, we are witnessing the role reversal of consumers and producers.

In his paper entitled "The Future of Architecture Education and Research"11, Javier Sanchez Merina asks us to consider the following in light of 
this imminent shift of production modes in the future: "What is the role of the designer when the production and consumption needs are met in every home?" In response to Dr. Merina's intriguing inquiry, it seems logical that the challenge of architects and designers in the future will be exploring ways to embed their highly skilled and valuable design knowledge within the designs they create for download. Similar to the concept of "embodied energy", we might entertain the metaphor of "embodied design" within digitally downloaded design artifacts of the near future. Informed by their expertise, intuition, and creative imagination, designers have the ability to diffuse their extremely valuable design knowledge within digital objects themselves. As Javier suggests, designers in the future will be asked to create "templates", as opposed to being responsible for the production of design objects themselves. In this regard, the role of architects and designers is realigned, shifting towards creating the fundamental building blocks of design objects; but consumers will ultimately determine how they are arranged or used.

One incredibly innovative project which clearly illustrates the emergent phenomenon of the reversal of consumer as producer in architecture is the WikiHouse. This intriguing project is the brainchild of Alastair Parvin and Nick lerodiaconou from the London-based design firm "OO", and has been gaining attention since being unveiled at the Gwangju Design Biennale (South Korea) in 2011. The mission statement of the project is simple:

"WikiHouse is an open source construction set. The aim is to allow anyone to design, download, and 'print' CNC-milled houses and components, which can be assembled with minimal formal skill or training." ${ }^{2}$ - WikiHouse Mission Statement 
In this regard, the WikiHouse project exists as a method by which individual consumers can download architectural "templates" from the design team, manipulate them as suits their needs, and assemble the designed components to create a functional dwelling suitable for inhabitation. Within this process, the architectural knowledge of the designers is inherently transferred to consumers through their digital (open-source) downloads. The onus lies on those who assemble the components to capitalize on the architectural considerations embedded within these "templates".

In a recent interview, Nick lerodiaconou expressed that "the factory of the future will be everywhere and the designer will be everyone."3 While this certainly reinforces the vision of future building as depicted by the WikiHouse project, it is important to consider that the notion of the "template" or building block need not necessarily be restricted to the high-tech world of digital fabrication and production. Similarly, embodied design knowledge can be transferred from architects and designers to consumers through low-technology making. Just as design knowledge is digitally embedded in a template for download and production on a 3D printer, architects can pass along research, expertise, and knowledge through the design of raw materials, processes, or tools. To use this thesis investigation as an example, architects currently have the ability to design materials, processes for assembly, or templates for building components that consumers can reproduce on their own. While the architect may not have direct control over the ways in which these fundamental building units are assembled, they still have the ability to transfer valuable design knowledge to the consumer 
Figure 9 - WikiHouse download, construction, and assembly
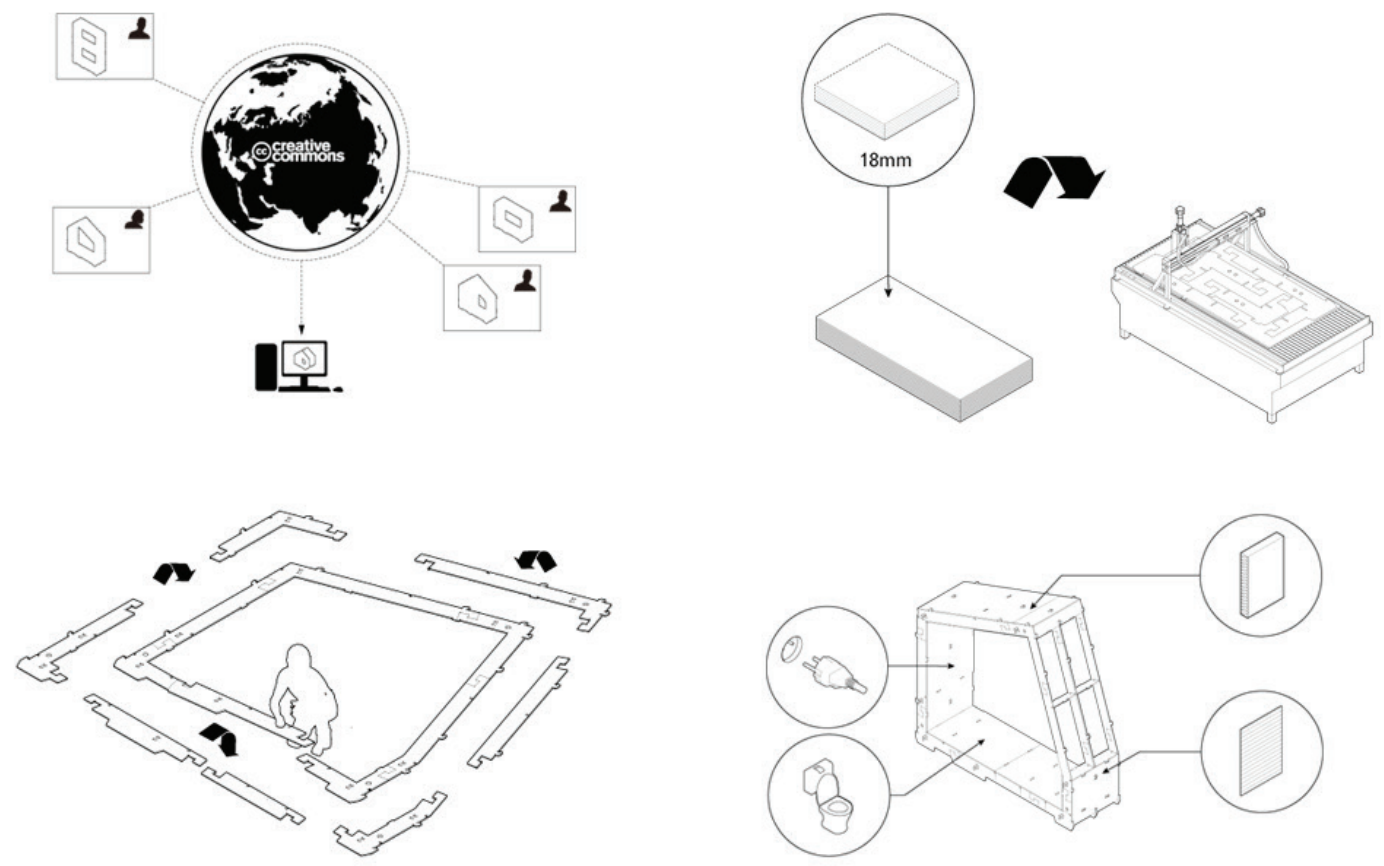

Figure 10 - WikiHouse physical assembly

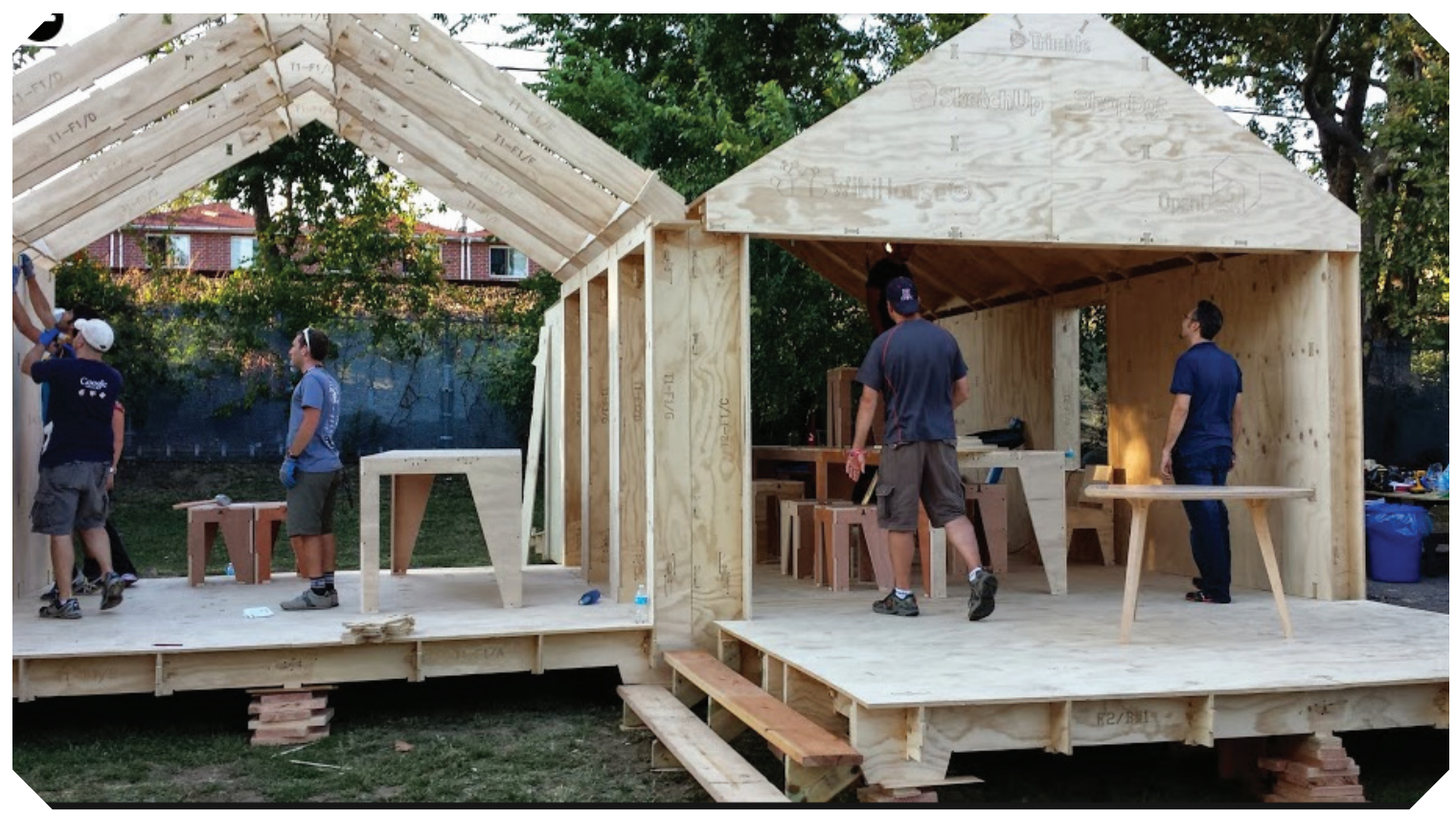


since the material and process has been the subject of their research and design. In this regard, the architecture of the project becomes less about the physical manifestation of the design, and more about the designed experiences and outcomes that their templates can achieve within the multiplicity of their arrangement.

\subsection{Making with bioplastic starch}

Once an ideal recipe was identified, methods of producing useful or interesting building components were explored that were informed by the physical and chemical limitations and advantages of the bioplastic starch itself.

This exploration of the application of the bioplastic found formal expression in a wide variety of different solids and applications, each with very specific characteristics and intriguing properties. From this wide range of unique components produced, the intent was to inspire the architectural imagination as to the design possibilities of working with this emergent material. 


\section{Table 2 - Building Components}

\begin{tabular}{|c|c|c|c|}
\hline No. & Component & Materials & Dimensions \\
\hline 1 & Laminated popsicle sticks & $\begin{array}{l}\text { Cassava starch bioplastic } \\
\text { Popsicle sticks }\end{array}$ & $150 \mathrm{~mm} \times 10 \mathrm{~mm}$ \\
\hline 2 & Composite bricks & $\begin{array}{l}\text { Potato starch bioplastic } \\
>2 \mathrm{~mm} \text { sand }\end{array}$ & $\begin{array}{l}260 \mathrm{~mm} \times 110 \mathrm{~mm} \times \\
60 \mathrm{~mm}\end{array}$ \\
\hline 3 & Plastic film & Corn starch bioplastic & $\begin{array}{l}300 \mathrm{~mm} \times 150 \mathrm{~mm} \times \\
1 \mathrm{~mm}\end{array}$ \\
\hline 4 & Balloon Casts & $\begin{array}{l}\text { Cassava starch bioplastic } \\
\text { Balloons }\end{array}$ & $100 \mathrm{~mm} \times 80 \mathrm{~mm} \times 60 \mathrm{~mm}$ \\
\hline 5 & Casting mould & Medium density fibreboard & $\begin{array}{l}150 \mathrm{~mm} \times 150 \mathrm{~mm} \times \\
150 \mathrm{~mm}\end{array}$ \\
\hline 6 & Large aggregate plastic sheet & $\begin{array}{l}\text { Potato starch bioplastic } \\
>1 \mathrm{~cm} \text { pebbles }\end{array}$ & $\begin{array}{l}120 \mathrm{~mm} \times 120 \mathrm{~mm} \times \\
25 \mathrm{~mm}\end{array}$ \\
\hline 7 & Sawdust cylinder & $\begin{array}{l}\text { Sawdust }>5 \mathrm{~mm} \\
\text { Potato starch bioplastic }\end{array}$ & $\begin{array}{l}200 \mathrm{~mm} \text { (diameter) } x \\
100 \mathrm{~mm}\end{array}$ \\
\hline 8 & Wood flour cube & $\begin{array}{l}\text { Wood flour }>1 \mathrm{~mm} \\
\text { Potato starch bioplastic }\end{array}$ & $\begin{array}{l}150 \mathrm{~mm} \times 150 \mathrm{~mm} \times \\
150 \mathrm{~mm}\end{array}$ \\
\hline 9 & Re-melted plastic & Corn starch bioplastic & $30 \mathrm{~mm} \times 30 \mathrm{~mm}$ \\
\hline 10 & Wood flour panel & $\begin{array}{l}\text { Wood flour }>1 \mathrm{~mm} \text { Potato starch } \\
\text { bioplastic }\end{array}$ & $300 \mathrm{~mm} \times 300 \mathrm{~mm}$ \\
\hline 11 & Wood flour 'pancake' & $\begin{array}{l}\text { Wood flour }>1 \mathrm{~mm} \text { Potato starch } \\
\text { bioplastic }\end{array}$ & $\begin{array}{l}100 \mathrm{~mm} \text { (diameter) } \mathrm{x} \\
10 \mathrm{~mm}\end{array}$ \\
\hline 12 & Sawdust cast & $\begin{array}{l}\text { Sawdust }>5 \mathrm{~mm} \text { Cassava starch } \\
\text { bioplastic }\end{array}$ & $\begin{array}{l}100 \mathrm{~mm} \times 100 \mathrm{~mm} \times \\
120 \mathrm{~mm}\end{array}$ \\
\hline 13 & Starch-only cast & Cassava starch bioplastic & $80 \mathrm{~mm} \times 80 \mathrm{~mm} \times 60 \mathrm{~mm}$ \\
\hline 14 & 'Built-up' panel & $\begin{array}{l}\text { Grid pattern metal frame } \\
\text { Potato starch } \\
\text { bioplastic }\end{array}$ & $\begin{array}{l}400 \mathrm{~mm} \times 200 \mathrm{~mm} \times \\
20 \mathrm{~mm}\end{array}$ \\
\hline 15 & Colour test & $\begin{array}{l}\text { 'Ice Blue' Kool-aid } \\
\text { Potato starch bioplastic }\end{array}$ & $40 \mathrm{~mm} \times 20 \mathrm{~mm} \times 10 \mathrm{~mm}$ \\
\hline 16 & Planter brick & $\begin{array}{l}\text { Potato starch bioplastic } \\
>2 \mathrm{~mm} \text { sand } \\
\text { Bamboo plant } \\
\text { Loose soil \& fill }\end{array}$ & $\begin{array}{l}260 \mathrm{~mm} \times 110 \mathrm{~mm} \times \\
60 \mathrm{~mm}\end{array}$ \\
\hline 17 & Aggregate tile & $\begin{array}{l}\text { Potato starch bioplastic } \\
>1 \mathrm{~mm} \text { fine sand }\end{array}$ & $\begin{array}{l}120 \mathrm{~mm} \times 120 \mathrm{~mm} \times \\
30 \mathrm{~mm}\end{array}$ \\
\hline 18 & Starch-only panel & Potato starch bioplastic & $\begin{array}{l}300 \mathrm{~mm} \times 150 \mathrm{~mm} \times \\
10 \mathrm{~mm}\end{array}$ \\
\hline 19 & Laminated elastic bands & $\begin{array}{l}\text { Potato starch bioplastic } \\
\text { Elastic bands }\end{array}$ & $\begin{array}{l}30 \mathrm{~mm} \times 30 \mathrm{~mm} \times \\
30 \mathrm{~mm}\end{array}$ \\
\hline 20 & Sawdust cast & $\begin{array}{l}\text { Sawdust }>5 \mathrm{~mm} \\
\text { Potato starch bioplastic }\end{array}$ & $\begin{array}{l}200 \mathrm{~mm} \text { (diameter) } x \\
100 \mathrm{~mm}\end{array}$ \\
\hline
\end{tabular}



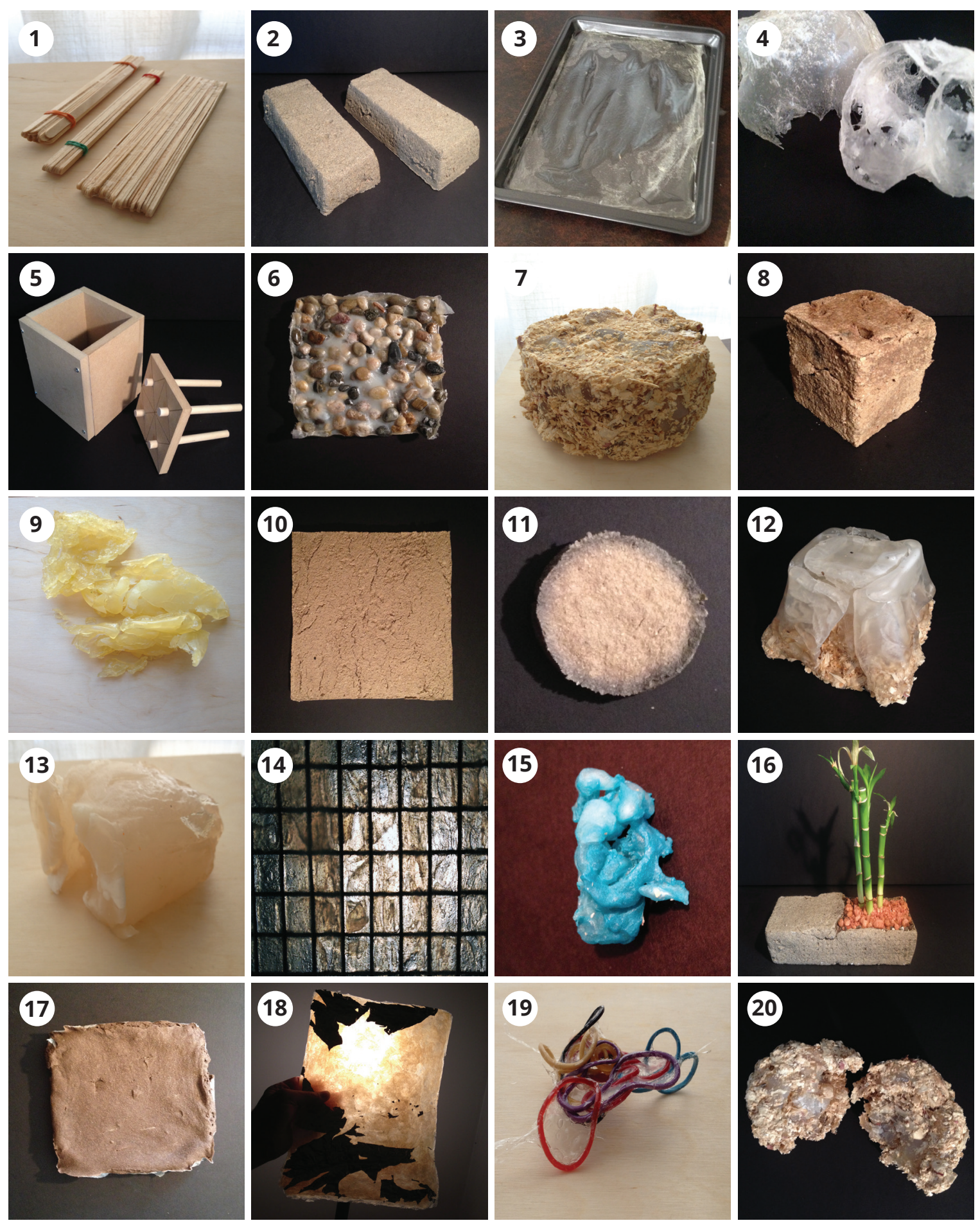
Through the process of producing and working with these imagined building components, several notable properties of bioplastic starch were discovered which would be of interest to architects and the architectural imagination.

\section{Table 3 - Noted Properties}

\begin{tabular}{|l|l|}
\hline Property & Description \\
\hline Translucency & $\begin{array}{l}\text { Starch bioplastic is translucent, and allows the passage of } \\
\text { light through the plastic solid. It can be dyed using food } \\
\text { colouring, with no effect on translucency. }\end{array}$ \\
\hline Laminate & $\begin{array}{l}\text { Since the starch bioplastic is molecularly configured to } \\
\text { make film-like sheets, it's potential as a laminate is very } \\
\text { high. It works well as a binding agent, laminating several } \\
\text { discrete entities together as a uniform solid. }\end{array}$ \\
\hline Composites & $\begin{array}{l}\text { Different composites were added to the starch bioplastic } \\
\text { mixture with varying results. Sawdust (5mm) or wood } \\
\text { dust (<1 mm) showed significant promise for creating } \\
\text { building materials, with many of the results appearing } \\
\text { similar to MDF or particleboard. }\end{array}$ \\
\hline Solidifying Liquid & $\begin{array}{l}\text { The process of creating starch bioplastic mimics the } \\
\text { notion of pouring cement; a viscous liquid is produced } \\
\text { which hardens into a rigid solid within a matter of hours. }\end{array}$ \\
\hline Thermoplastic & $\begin{array}{l}\text { Bioplastic starch is thermoformable, even after it has } \\
\text { dried once; It can be reheated and reshaped (at least } \\
\text { once) if needed. It is not known how many times this } \\
\text { process could be undertaken at this time. }\end{array}$ \\
\hline
\end{tabular}

Issues which seemed somewhat unique to working with starch were documented, identified, and actively addressed through modifications to the recipe, application, or process. Some of the issues encountered and the apparent solutions are listed below. 


\section{Table 4 - Issues Identified}

\begin{tabular}{|l|l|}
\hline Issue & Description \\
\hline Cracking & $\begin{array}{l}\text { When the starch was cooling, it would sometimes result } \\
\text { in very large cracks throughout the plastic structure. } \\
\text { This could have been caused by overly rapid cooling } \\
\text { or too much starch. It was found that when too much } \\
\text { of the solid plastic was laid down at once, the solid } \\
\text { wouldn't completely dry. }\end{array}$ \\
\hline Bowing & $\begin{array}{l}\text { Often, the plastic would warp its shape as it cooled. } \\
\text { Possibly due to differing rates of cooling, the problem } \\
\text { was addressed by increasing the amount of cooling } \\
\text { time. }\end{array}$ \\
\hline Hydrophilic & $\begin{array}{l}\text { Starch is extremely hydrophilic, which means it actively } \\
\text { absorbs water when it is available. }\end{array}$ \\
\hline Non-uniform drying & $\begin{array}{l}\text { Bioplastic starch does not "cure" chemically, it dries with } \\
\text { exposure to air. In this regard, as outer layers dry, the } \\
\text { inner areas are left unexposed and therefore do not dry } \\
\text { at the same rate (or at all). }\end{array}$ \\
\hline
\end{tabular}



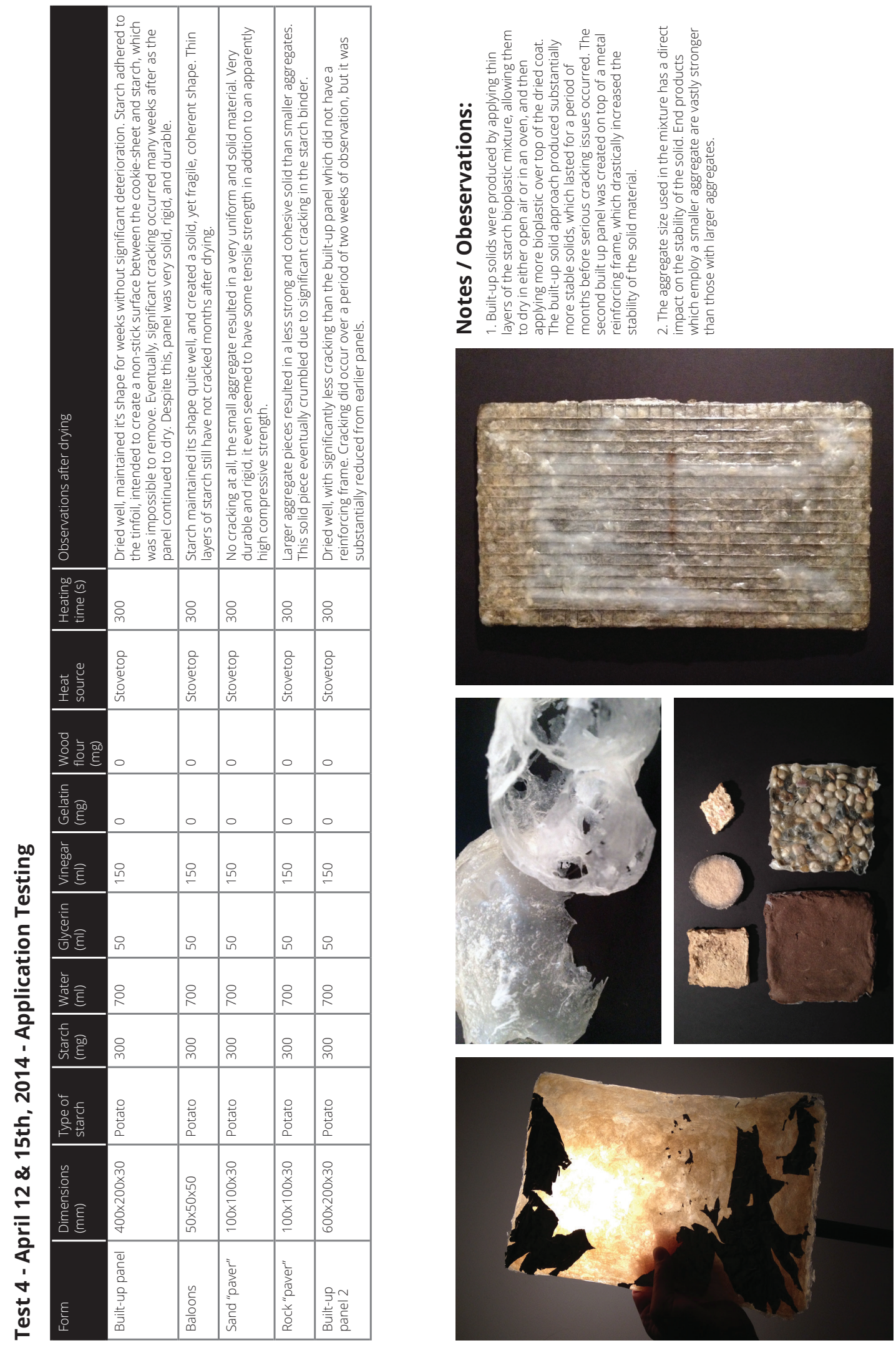

Page 37 
Figure 11 - Large (<3mm) Aggregate Panel

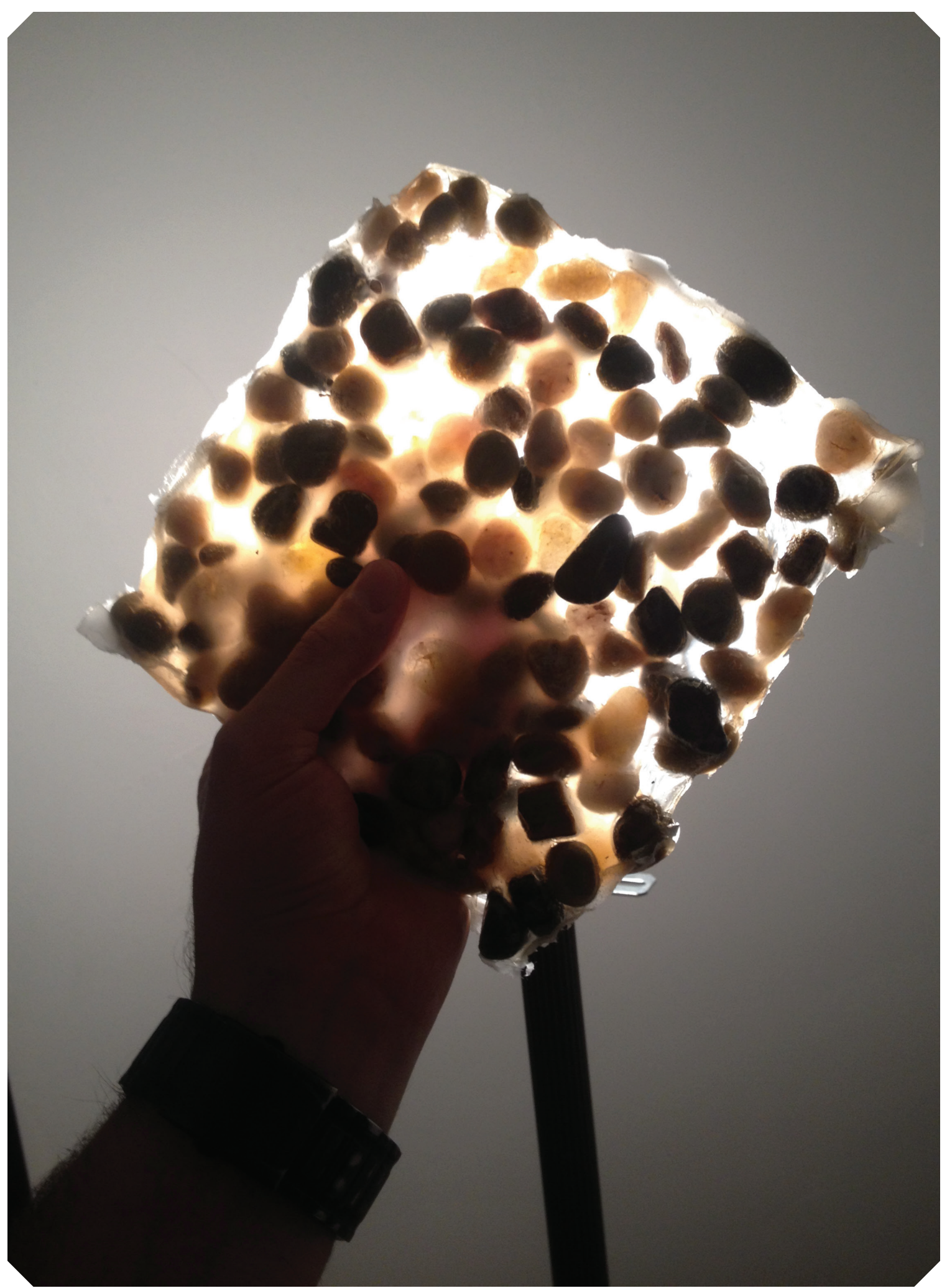


Figure 12 - "Planter Brick” - Sand, Bioplastic, and Bamboo

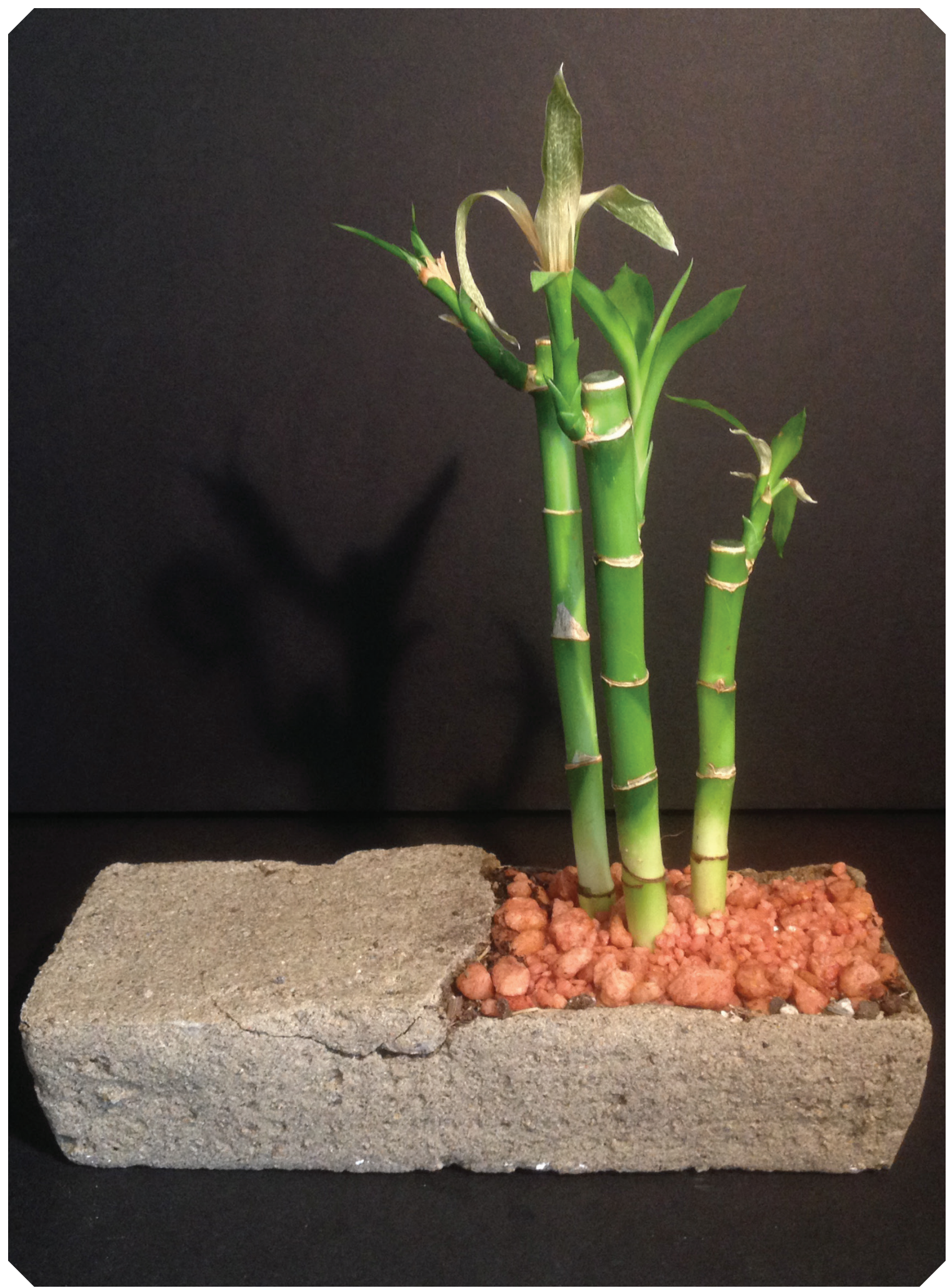


Figure 13 - Built-Up Aggregate Panel

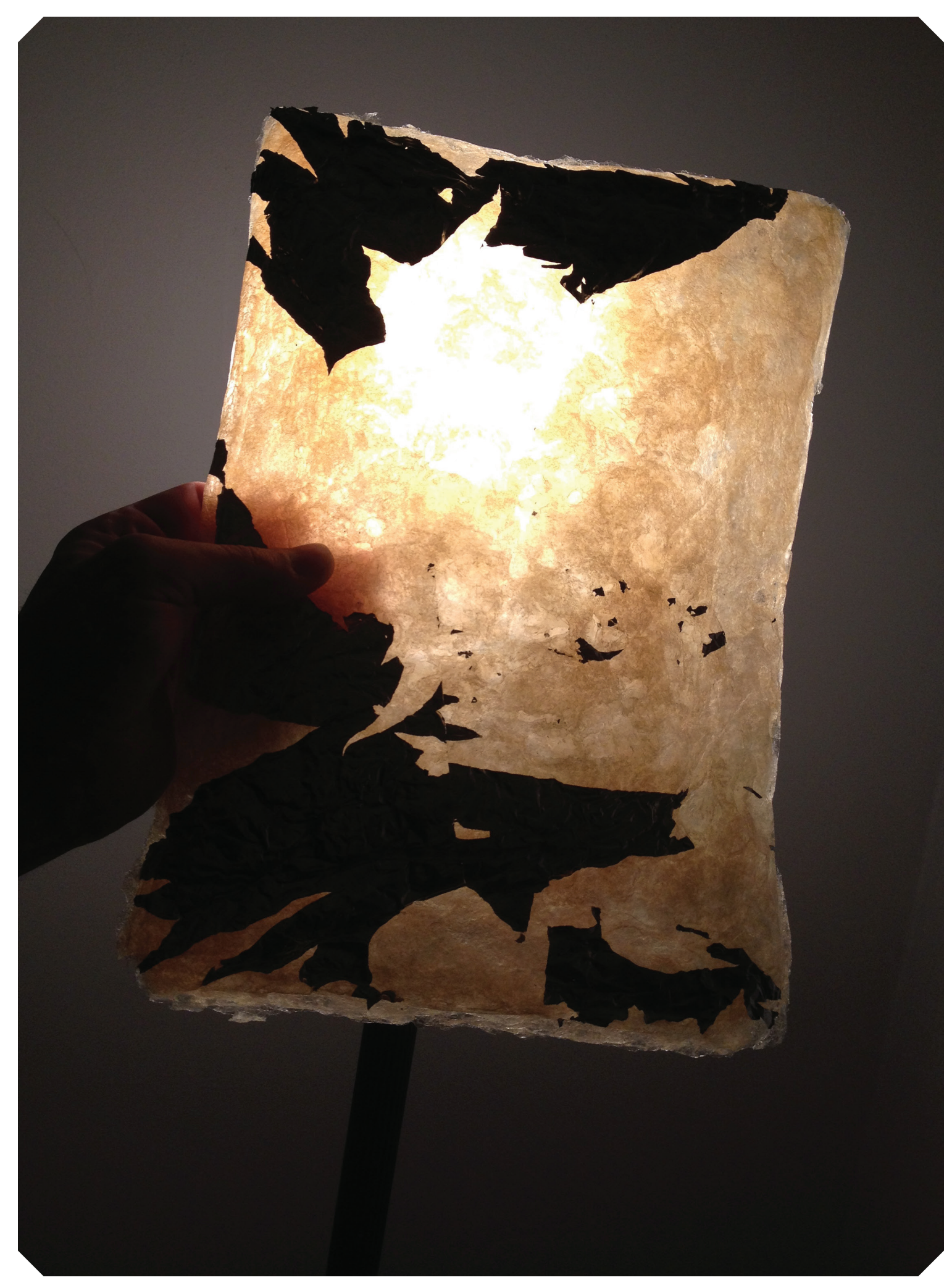


Figure 14 - Balloon Laminated “Casts"

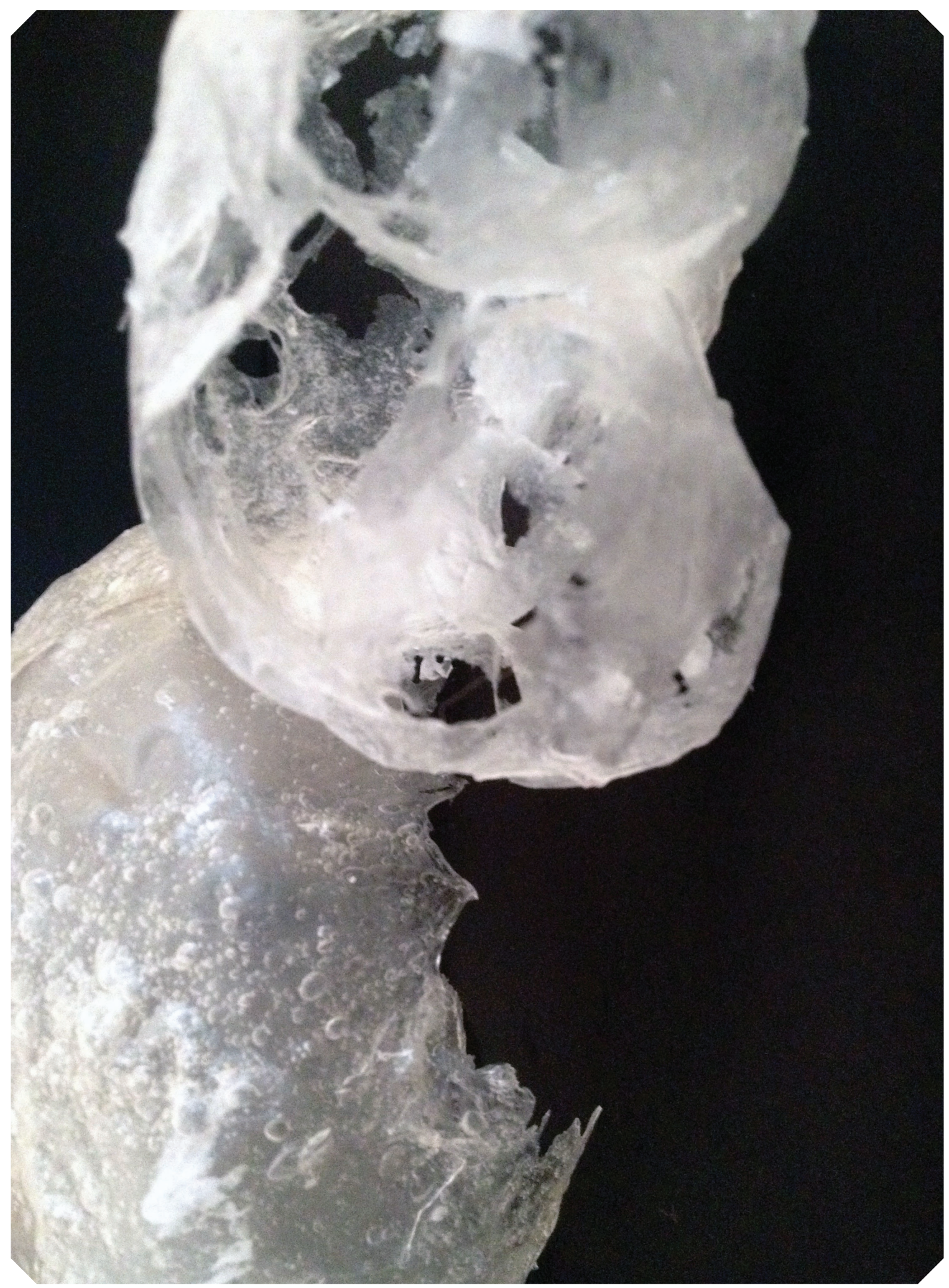




\section{ANAYYSIS}

\section{"I believe that the material doesn't need to be strong to be used as a strong structure. The strength of the structure has nothing to do with the strength of the material." - Shigeru Ban}

\subsection{Degradation vs. Deterioration}

Understanding how, when, why, and where materials will deteriorate is critical knowledge for architects and engineers to understand their functional use. We quite consistently, however, fail to recognize the value of building materials once they have undergone this process of deterioration and/or degradation. It is here where an interesting distinction between degradation and deterioration can be made. In the most literal sense, the word deterioration means "to diminish or impair in quality, character, or value"1. Degradation, on the other hand, is slightly more nuanced; referring to the breaking down of an element into fundamental components, a process that does not necessarily detract from the quality or value. In this regard, there exists a substantial difference between building materials that deteriorate uselessly into elementary 
units with little value to society, and those that degrade into distinct yet comparatively valuable fundamental constituents.

In 2013, William McDonough and Michael Braungart released a book entitled "The Upcycle: Beyond Sustainability-Designing for Abundance" that expands upon the holistic design approach they developed in the book "Cradleto-Cradle: Remaking the Way we Make Things"2. Within their new book, the authors primarily sought to illustrate that consumptive behaviour in human societies need not always be demonized as negative, when that particular behaviour results only in positive externalities. An externality, in this sense, refers to an unintended consequence born from the processes of production and consumption of economic goods. When concrete is produced, for example, a large amount of energy is expended and a substantial volume of greenhouse gasses are released into the atmosphere. While over time and in aggregate, these greenhouse gas emissions pose a direct threat to human health and nominal ecosystem functioning; however, the company that produced these gasses is not held fully accountable for the economic costs of climate change or adverse health effects suffered by society as a whole. This is a common example of a negative externality. We know the same to be true of tobacco products; the true economic costs associated with consuming cigarettes is not shouldered by the company that produced them. It is here where Braungart and McDonnough suggest the notion that production that results only in positive externalities might also be a possibility within the modern industrial paradigm: "where human industry is not just 'less bad', but how it can be more good, an extraordinary positive

2 McDonough, William, and Michael Braungart. The Upcycle: Beyond Sustainability - Designing for Abundance. New York: North Point Press, 2013. Print. 
force in this world." In this context, they are alluding to a new process of design; one where each step of the design phase has been carefully considered to create positive external consequences. Most importantly, they point to the end-of-life cycle as the starting point for this new process of design to establish traction.

From an architectural perspective, the notions presented by McDonnough and Braungart in their book beg the question, what do we do with our buildings once they have reached the end of their useful life? Within the "Upcycle" framework, all products and materials which enter our built or natural environments must be purposefully designed to infinitely recirculate through our production chains as waste becomes resource. While this may appear more as a utopian ideal than a pragmatic approach to building, several notable projects have surfaced in recent years which clearly illustrate that the "less bad, more good" approach to craft, making, and construction is in fact possible. One project in particular which exemplifies this notion perfectly is David Benjamin's "Hy-Fi", a collection of cleverly connected cylinders constructed of interlocking bricks made from mycelium and agricultural waste. Designed for MoMA's PS1 Young Architects Program, the structure exists as a temporary pavilion intended to illustrate the potential design possibilities offered by new and emergent sustainable materials. The bricks used to create the structure were crafted on site using locally sourced and recycled materials. They are individually composed of recycled agricultural waste (corn husks) which are bound together using fungal mycelium (the thread-like "roots" of mushrooms), and do not require

3 McDonough, William, and Michael Braungart. The Upcycle: Beyond Sustainability - Designing for Abundance. New York: North Point Press, 2013. Print. 
Figure 15 - MoMA “Hy-Fi” completed interior

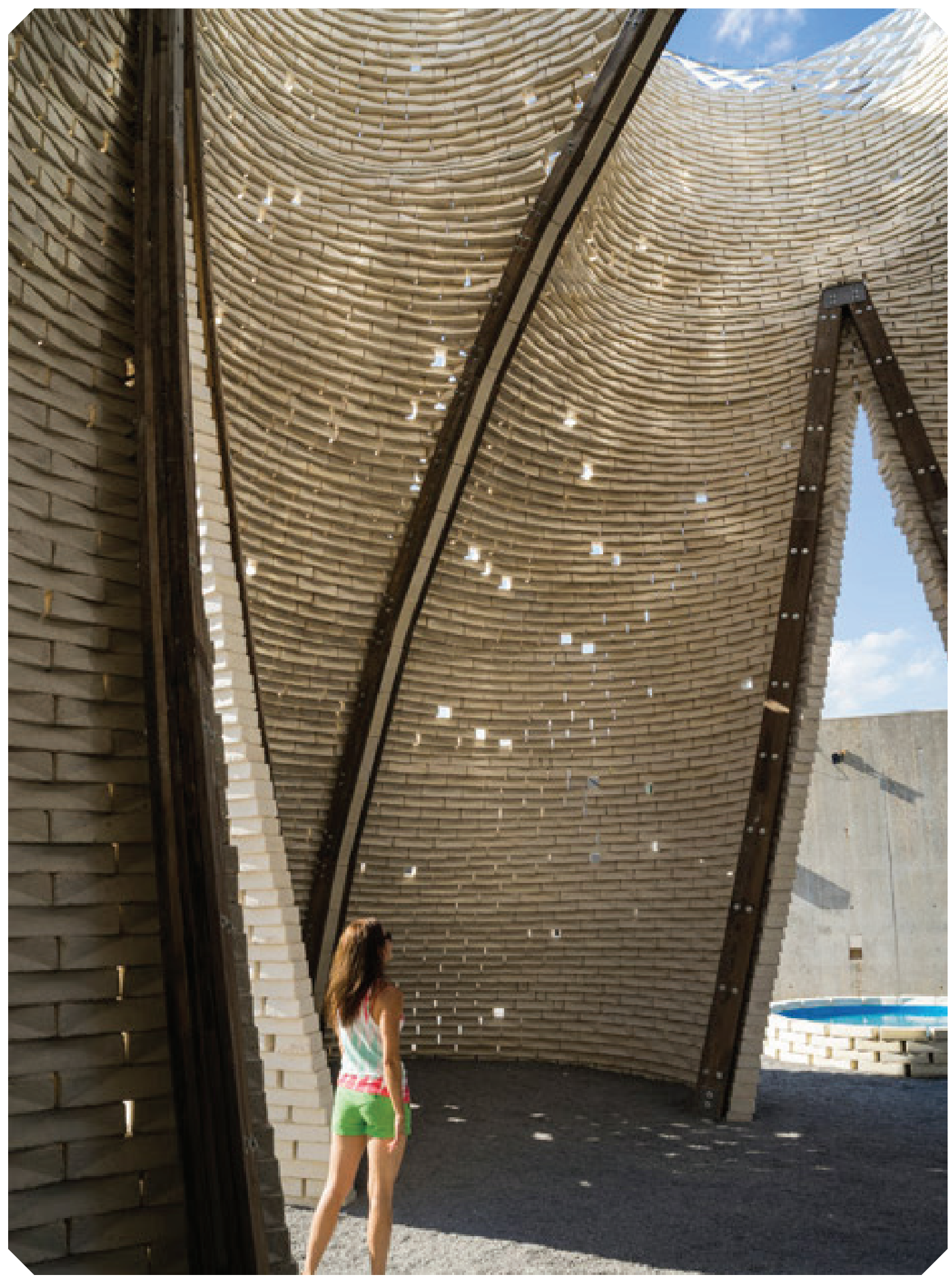

"Hy-fi" - Source: www.dezeen.com 
specialized equipment or expertise to create.

"[Hy-Fi] will use a new method of bio-design, resulting in a structure that is 100\% organic material. The structure temporarily diverts the natural carbon cycle to produce a building that grows out of nothing but earth and returns to nothing but earth - with almost no waste, no energy needs, and no carbon emissions. This approach offers a new vision for society's approach to physical objects and the built environment." (MoMA 2014 YAP Winner Announcement)

The way that we understand and conceptualize what is "waste" and what is "resource" will undoubtedly be an important consideration for architects and engineers as environmental pressures continue to escalate. This is exactly the "new vision" that David Benjamin and MoMA refer to; understanding the role that we as inhabitants of the planet play in ecological cycles is crucial to the continued functioning of those systems. According to Braungart and McDonnough, our task as the designers of future urbanity is to design buildings and materials which do not create an additional burden upon decomposition and disposal. While it is obviously not beneficial nor productive for our building materials to decay too rapidly (as durability is also a central consideration of sustainable design), contemporary development quite typically fails to acknowledge the end-of-life cycle of buildings within the built environment. This behaviour is also not beneficial nor productive; it seems there must exist a balance between the permanence and ephemerality of the materials we introduce into the built environment that is sensitive to the paradoxical need for buildings to be simultaneously durable as well as biodegradable.

$4 \quad$ "Young Architects Program International." New York / Young Architects Program. N.p., n.d. Web. 7 Aug. 2014. <http://www.moma.org/interactives/exhibitions/yap/2014ny_living.html> 


\subsection{Degradation of Starch Bioplastics}

All materials degrade in time. Even petrochemical polymers will eventually degrade in the natural environment when exposed to aerobic conditions. Modified starch bioplastics, in similar fashion to petroleum-based plastics, decompose as a result of microbial and fungal activity ${ }^{5}$, which is exacerbated by exposure to UV radiation and optimal conditions for microbial attack. Due to the hydrophilic nature of starch bioplastic, any starch biopolymer used as a building material (most likely) could not be left exposed to the natural environment without protection, as the material itself has an affinity for moisture retention. With physical protection (such as a paint or wax coating) and further modification to its chemical composition however, it reasonable to hypothesize that this building material could attain a useful lifespan spanning multiple decades.

There is unfortunately a lack of research on the degradation of starch bioplastic solids in the natural environment. Starch bioplastics are typically employed as films or binding agents at this point in time, and there is little research regarding the degradation of solid masses of bioplastic. There are, however, a myriad of commercially available products which are currently available to consumers that have embraced bioplastic starch for its environmental and economic advantages. Specifically used as an adhesive additive to gypsum plasters and dry mortars, these products are testament to the viability of bioplastic starch in the built environment. Increased research and 
scientific observation are required and encouraged to fully understand both the useful life and total lifespan of this emergent building material, as well as the consequences of its degradation over time.

\subsection{Compressive \& Tensile Strength}

A variety of starch composite bricks were produced for this study, with a wide range in size, weight, aggregate, and shape. Different manipulations of the physical attributes of the brick were modified to explore the impact on the overall strength and utility of the brick as a building material. Most notably, there was an obvious correlation between the size of the aggregate and overall strength: generally speaking, the smaller the aggregate, the stronger the brick.

Compression testing was undertaken on two of the starch bioplastic bricks produced for this study. The bricks that were tested for compressive strength measured $260 \mathrm{~mm} \times 110 \mathrm{~mm} \times 60 \mathrm{~mm}$, and were comprised entirely of potato starch bioplastic and fine-grained loose sand $(>1 \mathrm{~mm})$. The results of the compression testing indicated that the starch bioplastic bricks had an overall compressive strength of $0.27 \mathrm{MPa}$. The bricks failed around $7.5-8.0 \mathrm{kN}$ of force, most likely due to inconsistent drying of the solid bioplastic. It is likely that the structure failed at this force since the exterior and interior of these particular bricks dried at different rates, causing large voids and air bubbles.

While 0.27 MPa is not directly comparable to a clay fired brick, whose compressive strength averages $15 \mathrm{MPa}$ in domestic applications and can be 

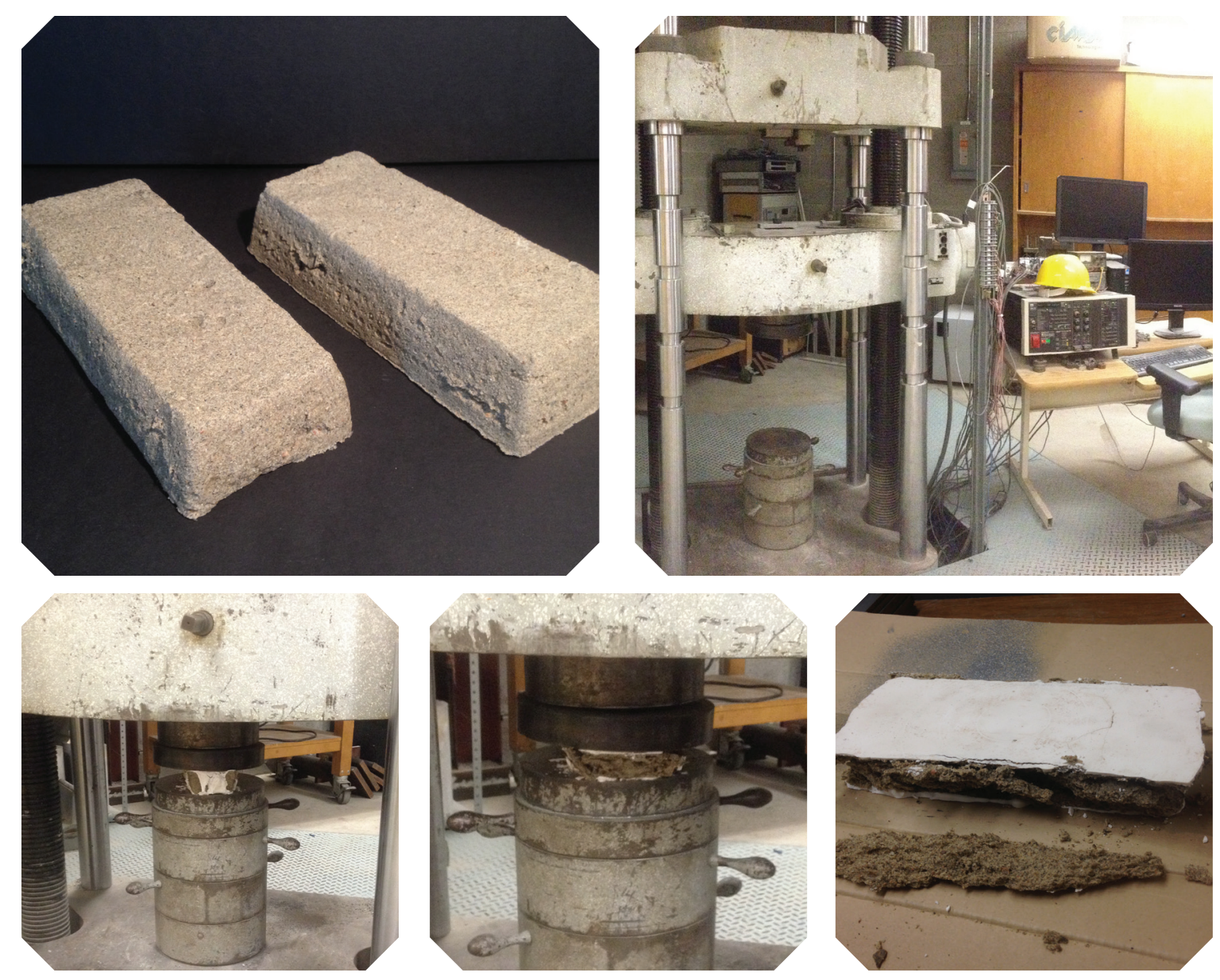

Figure 16 - Compressive Strength of Starch Bioplastic Bricks

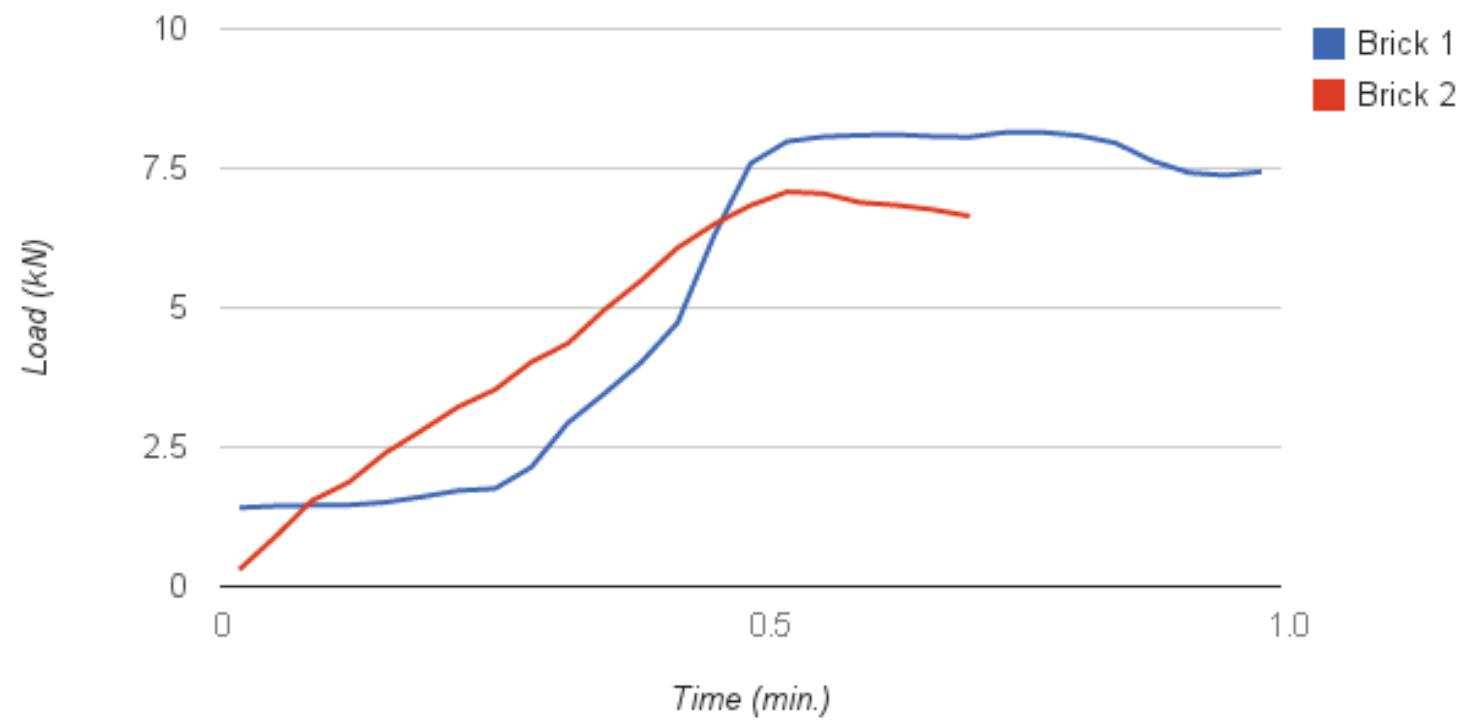


as high $100 \mathrm{MPa}$ in certain circumstances, it illustrates a potential opportunity in comparison to other similar organic masonry products such as rammed earth or mycelium bricks. With thoughtful redesign of the shape and process of sculpting starch bioplastic bricks, it seems optimistic that a reliable and structurally significant earthen masonry unit could be developed. Future study might explore the compressive strength of bioplastic starch composites in comparison to brick shape and drying process, to better understand the relationship between production processes and overall strength.

\subsection{Insulative Value}

Commercial forms of Insulation available on the consumer market today are almost entirely petroleum based, with too few organic or non-petroleum options available. We have recognized for decades the significant health and environmental issues that result from the use of petroleum-based insulations (particularly extruded polystrene), the most concerning of which are production, off-gassing, and disposal. The production of petroleum-based insulation often requires a host of dangerous, toxic, and carcinogenic chemicals, which are often released from within their foam cells as they age. Furthermore, they can not be readily recycled or reused at the end of their useful life, resulting in an increased burden of safe disposal.

As housing needs continue to expand in the developing and developed worlds alike, there is a constant and increasing need for sustainable and environmentally responsible insulation products. Starch bioplastic has significant potential to function as an insulator, either employed as a bioplastic foam or as an organic binder for other (often cellulosic) fibrous materials, such 
as hemp or straw. As part of a case study for his thesis at Brunel University's School of Engineering and Design, Michael Bonin compared the insulative properties of polyethylene and starch based foam insulations, and concluded that the starch insulation consistently outperformed its petroleum counterpart in regards to thermal resistance and insulative value. ${ }^{6}$ It was noted that starch insulation has several significant drawbacks which are unique to this particular material. The hydrophilic nature of starch means that water will actively be absorbed by the material, making it unsuitable for outdoor application without a hydrophobic coating.

\subsection{Safety: Fire \& Sound}

Within his study of the mechanical properties of starch-based foams, researcher Michael Bonin found that there were no significant acoustical advantages to starch foams over other types of insulation. Fire safety was unable to be tested within the bounds of this study, but due to the thermoformable nature of bioplastic starch, it is possible that these building components comprised of this material would be fairly susceptible to failure due to heat and fire. Specific fire protection for this material would need to be developed and tested thoroughly before safety precautions for starch bioplastic could be fully understood.

\subsection{Socio-economic Impacts}

Starch is one of the most common naturally occurring polymers on the planet. It is ubiquitous in our contemporary society, even if we are generally 
unaware of its presence; so much so, in fact, that our modern diet derives the majority of our daily caloric intake from starches. ${ }^{7}$ In 2012, the world produced more than 75 million tons of starch from various sources. ${ }^{8}$ Both domestically and industrially, starch is fairly easy to extract from biomass, such as potatoes, cassava (tapioca), corn, or other starchy crops. Its production basically entails finely chopping the raw source, and straining the mash through water to create a "starchy milk". The starch milk then needs to be de-watered in a manner that does not involve heat (as heat energy would trigger gelatinization), resulting in a fine white dry powder. This process does not require industrial equipment or dangerous chemicals to undertake. Starch could be produced anywhere in the world, from virtually any food crop or agricultural waste, substantially lowering the costs of production and transportation in comparison to other building materials. Powdered starch for building components could be mixed on-site, in similar fashion to concrete today.

Bioplastic starch offers several distinct benefits to building on the local scale since it is locally produced, manufactured on-site, and is highly inclusive. The benefits of locally produced building materials are becoming increasingly recognized as the cumulative global impact of our consumptive building practices continues to compound. Local building materials inherently have a lower embodied energy in comparison to imported materials due to the offset costs of transportation and production. They are typically cheaper and

\footnotetext{
$7 \quad$ Maria Teresa Pedrosa Silva Clerici, and Adel El-Sonbati. "Physical and/or Chemical Modifications of Starch by Thermoplastic Extrusion." Thermoplastic Elastomers. Rijeka: InTech, 2012. P.39. Print. 
much more readily available than their imported counterparts, and are often recognized as a critical component for building in developing nations, areas of poverty, or following crisis. Since the technology and raw ingredients for producing starch are exceptionally rudimentary and widely available, bioplastic starch can be produced on-site, without specialized equipment or health / safety concerns.

It is also important to note that starch does not necessarily need to be derived from food crops. In fact, if we have learned anything from the experience of growing crops for ethanol production, it is that food crops must be used as food. There are many high-starch non-food crops suitable for producing industrial starch which could be cultivated in order to avoid detracting from global food production. Similarly, waste agricultural products could potentially represent an emerging market fuelled by an increased demand of starch products. Recycling of agricultural waste for starch could not only reduce the amount of organic waste sent to landfills, but increase the revenue of local farmers and associated industries through a new demand for waste products. 


\section{MATERIAL IMAGINATION}

\section{"Glance at the sun. See the moon and the stars. Gaze at the beauty of earth's greenings. Now, think." - Hildegard von Bingen}

\subsection{Towards an Environmental Phenomenology}

At the intersection of art and science, the nature of knowledge is in question. Since antiquity, we have devised complex systems of logic and reasoning to describe, analyze, and understand our surroundings and our place within them. At their fundamental core, the primary consideration of these systems of comprehension has been the production of knowledge and answering the fundamental question: "How do we know what we know?" The epistemological framework that we adopt to understand complicated problems is what allows us to further our understanding a subject; however, we must also acknowledge that it is probably impossible for one singular epistemology to facilitate a complete understanding or description of a subject. This was the conundrum faced by the French scientist-turned-philosopher Gaston Bachelard in the mid-twentieth century as he reconsidered the spirit and scope of scientific objectivity. Recognizing that the scientific method possessed limited potential 
to fully explain phenomena in this world, he turned to phenomenology as a means of expanding his comprehension beyond the limits of rational scientific inquiry. He described this departure as the epistemological obstacle: "For a scientific mind, all knowledge is an answer to a question. If there has been no question, there cannot be any scientific knowledge"11. In this regard, he suggests that through the juxtaposition of rationality and imagination, we can more thoroughly investigate and accurately describe phenomena both objectively and subjectively. Roch Smith provides an excellent comprehension of this duality In his book "Gaston Bachelard", where he clearly illustrates the limitation of scientific inquiry at the basis of Bachelard's explorations.

"... unlike the quantifiable, neutral space of geometry, a lived-in space acquires qualities for the imagination. Rational spatial measurements do not apply to imagined space where size may be inverted and the minuscule may loom large, and where geometrically neutral oppositions between interior and exterior may lose their symmetrical reciprocity as one is preferred over the other. When reverie replaces reason as an integrating principle, Bachelard observes, a corner has the makings of a house and a house can become a universe." 2

This expansive realm beyond the "quantifiable, neutral space of geometry" is the cognitive territory of what Bachelard refers to as the material imagination. In this mode of understanding, we refer to the ways in which matter is imagined; not only by engineers and scientists, but by poets, artists, and musicians. ${ }^{3}$ The material imagination is recognizable through the evocation of the image, our conscious understanding of matter which extends beyond

$1 \quad$ Smith, Roch. Gaston Bachelard. Boston: Twayne Publishers, 1982. Print. P.36

2 Smith, Roch. Gaston Bachelard. Boston: Twayne Publishers, 1982. Print. P.120

3 Connor, Steven. "Isobel Armstrong's Material Imagination." Radical Aesthetics: The Work of Isobel Armstrong. Institute for English Studies. University of London, London. 21 June 2002. Lecture. 
the physical. These images are more than "direct images of form"4, representing instead "direct images of matter". David Pye uses the idea of a stone and its inherent "stoniness" to illustrate this concept. In this regard, it is through reverie, as opposed to description or representation, that these images can be evoked in our imagination.

"The properties of materials are objective and measurable. They are out there. The qualities on the other hand are subjective: they are in here: in our heads. They are ideas of ours. They are part of that private view of the world which artists each have within them. We each have our own view of what stoniness is."

As discussed within this thesis, we know that the materials with which we choose to build become loaded with emotional and symbolic meaning over time. This meaning is also highly subjective, interpersonal, and dynamic; In this context, if we are able to interpret the past through materials, we must accept the notion that these materials are representative of the culture that produced them. In architecture and anthropology, the questions of "who" builds and "why", are often more evocative and intriguing than comprehending "what" was built. For example, throughout his influential career, Shigeru Ban has repeatedly convinced the architectural and engineering community that it is possible to create lasting structures fit for human inhabitation from paper tubes; a waste material we typically regard as having little or no relevance to architecture or construction. In this context, it is far more interesting (and important) to question why an architect might choose to utilize a specific nonconventional material as opposed to the multitude of other readily available

\footnotetext{
$4 \quad$ Smith, Roch. Gaston Bachelard. Boston: Twayne Publishers, 1982. Print. P.84

5 Pye, D. Taken from Ingold, Tim. Being alive: essays on movement, knowledge and description. London: Routledge, 2011. Print. P.30
} 
conventional alternatives. Perhaps, in this regard, innovators such as Shigeru Ban or David Benjamin have chosen to embrace alternative and sustainable building materials not for economic or structural reasons, but because they signal a societal shift in value, intention, or re-connection to the planet. In this regard, the "bringing forth" of other inherent and subconscious components of physical materials, such as environmental consciousness or social awareness, offers new possibilities of inhabitation within the material imagination. Where stones can evoke the image of "stoniness" within our imaginations, it is my contention that materials also have the potential to evoke images of the essential substance of sustainability and connection to the planet. Exploring beyond the objective analysis of materials offers an important line of inquiry for architects and designers to fully comprehend the impact of the materials they introduce into the built environment; surpassing the direct implications of the material world. In this regard, it is interesting and useful to consider an "alchemy of construction" as suggested by Professor Klassen earlier; where materials are considered for how they behave as opposed to what they are. 


\section{Figure 17 - The Material Imagination}

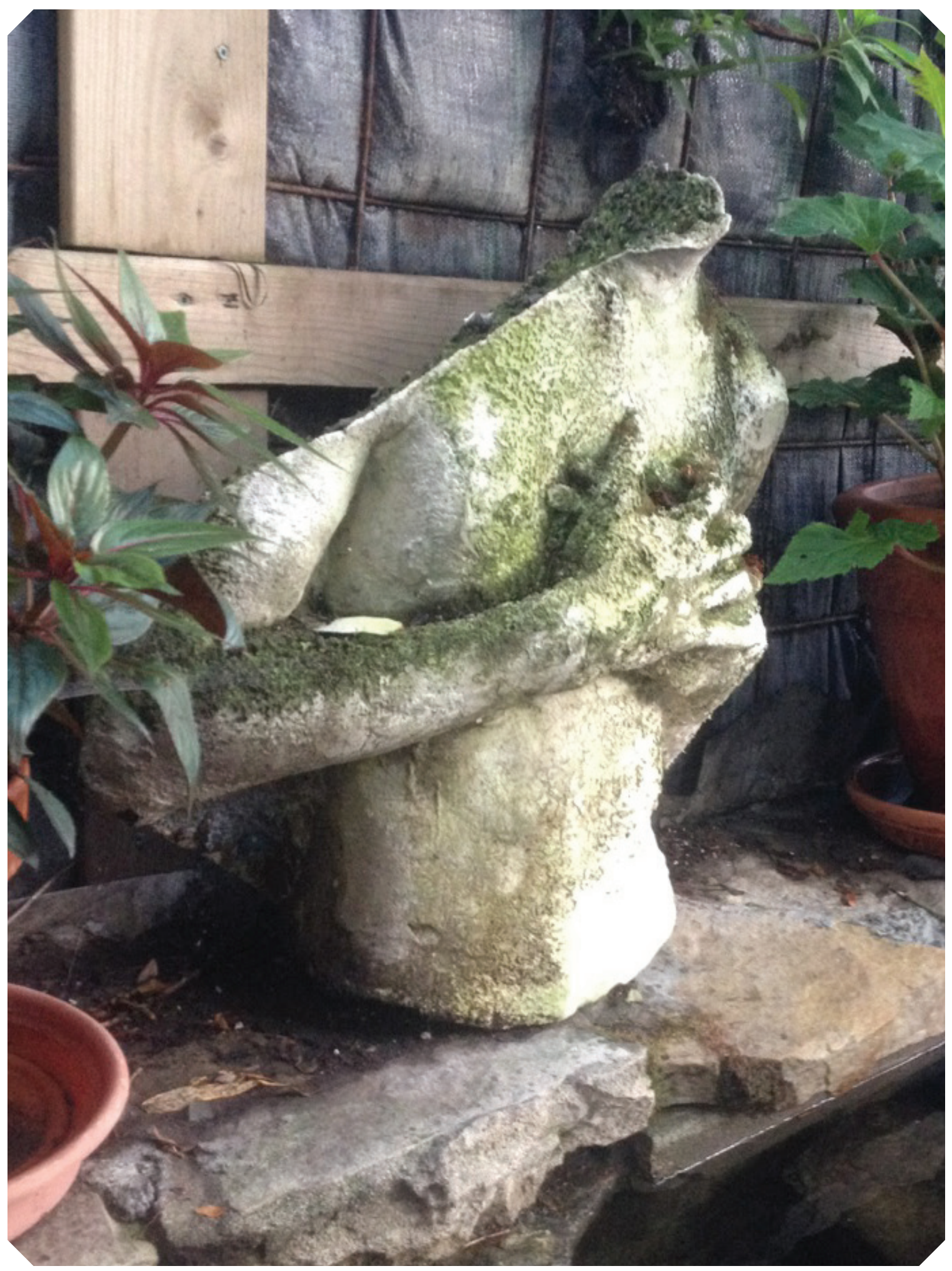

Source: Mike Knauer - Santropol, Montreal 


\subsection{The Seminal Detail: The Brick}

Now that the physical properties and limitations of bioplastic starch have been explored, it is possible to engage the material imagination to explore appropriate forms of architectural expression. Ideal typologies of bioplastic-starch-making must be imagined that are a direct result of the physical properties and limitations of the material itself. It is through these ideal typologies or formal manifestations that the architectural imagination is formally and spatially explored within this study.

One of these ideal typologies for bioplastic starch is the brick, a ubiquitous and essential building component of architecture. This discrete entity represents a fundamental unit of building; one of the essential components of architecture. From these primary building blocks, the tangible and intangible qualities of architecture become manifest. Within this investigation, the nature of bioplastic starch itself was the determining factor that informed the design of this seminal detail, the elementary brick unit. Multiple iterations of brick designs undertaken within this study resulted in the final draft that is clearly reminiscent of the long and narrow bricks produced for building by early Romans. From the compression tests undertaken on previous brick designs, it was ascertained that bioplastic starch bricks should be thinner than their conventional counterparts in order to facilitate thorough drying and optimal compressive strength. From this primary physical requirement dictated by the nature of starch bioplastic itself, the manner in which these bricks could be assembled or realistically utilized can be imagined. 
Figure 18 - Roman Brick Dimensions

BRICK

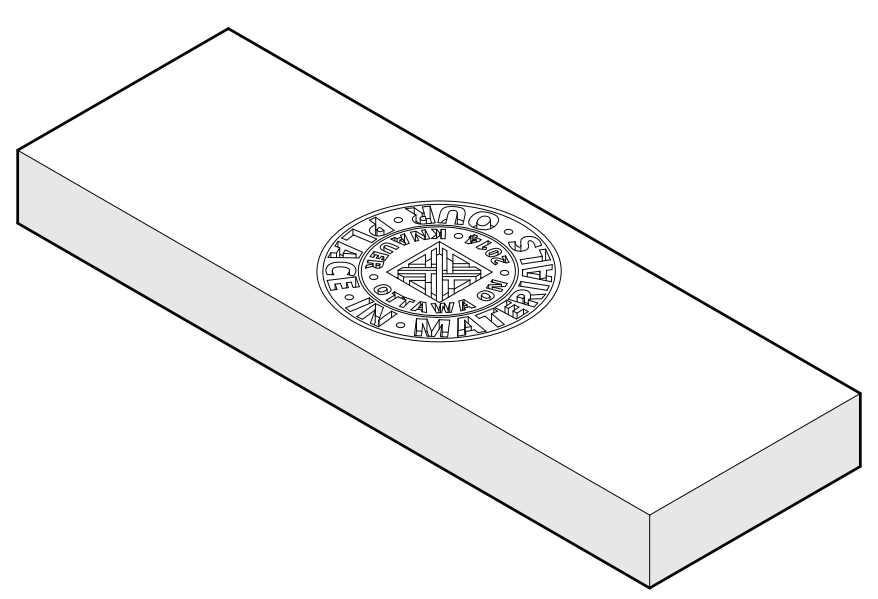

PLAN

SECTION
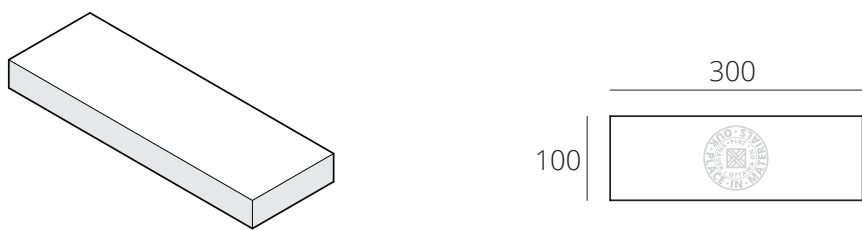

$3 0 \longdiv { 1 0 0 }$

$+$

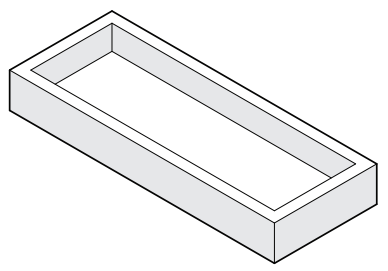

326

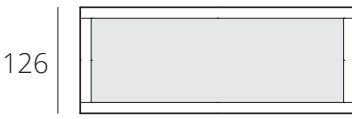

$4 3 \longdiv { 1 2 6 }$ 


\section{Figure 19 - Brick Making}

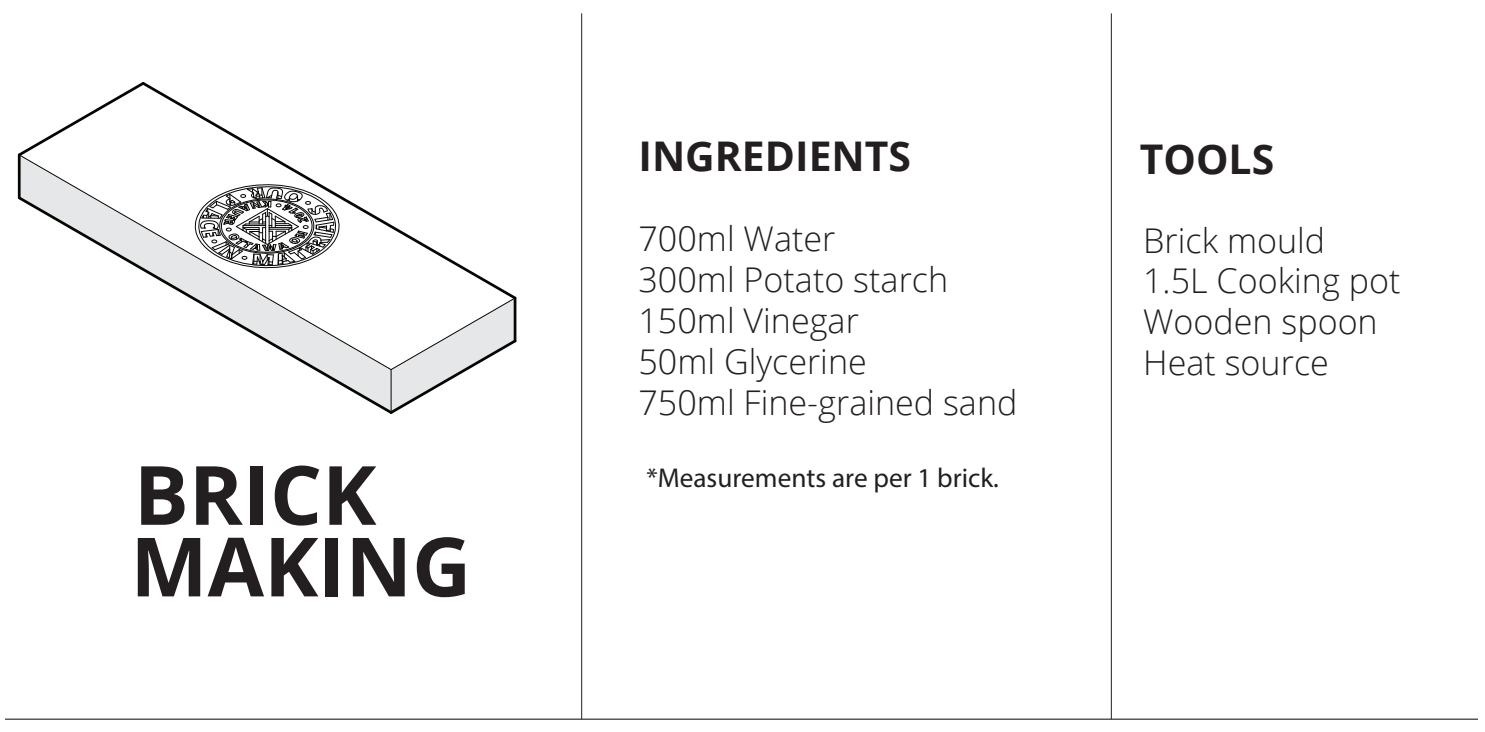

\section{STEPS}

Mix all the ingredients in a cooking pot, and heat at $120 \mathrm{C}$ until mixture gelatinizes.

Once gelatinzed, pour the mixture into the brick mould.

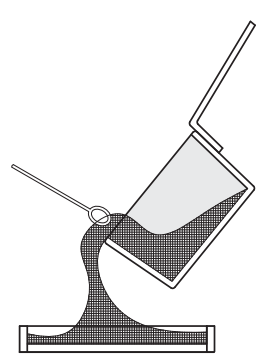

Set the mould aside to dry for at least 2 hours.

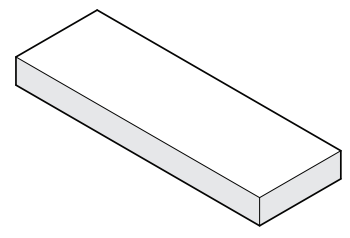




\subsection{A Family of Details}

There are detailing consequences for the properties of materials. This section represents an architectural vision of the possibilities afforded by the adoption of starch bioplastic building components as a mode of building. In totality, these design solutions represent a family of architectural details that might be arranged in a multiplicity of ways to facilitate altogether new modes of dwelling, or advance the capabilities of our existing development. Drawn from the investigations illustrated by the previous chapters of this thesis, the design principles which guided the design of this family of details are: that materials can and should be designed for specific purpose in architecture; local production and templated assembly provides universal access to valuable design knowledge; details and designs must recognize the specific physical attributes of the material; the built environment must embrace biodegradation and participation in ecosystem cycles as a fundamental ethos of construction The following design project has been separated into two distinct visions:

substitutions and newisms. Substitutions, in this sense, are components which have been designed to either replace familiar and existing building components, or are capable of integrating with contemporary and wellestablished methods of construction. Newisms, on the other hand, represent new forms and novel methods of construction and making which may be traditionally unconventional, but are faithful to the nature of starch bioplastic and it's idyllic modes of craft. Whether considered seperately or as a family, the following details all share the same ideological roots and spirit of building. As this exploration moves from one detail to the next, it is interesting to consider the possibilities for new assemblages novel modes of construction which have been made possible by this emergent material. 


\section{Figure 20 - Exterior Facade Detail}

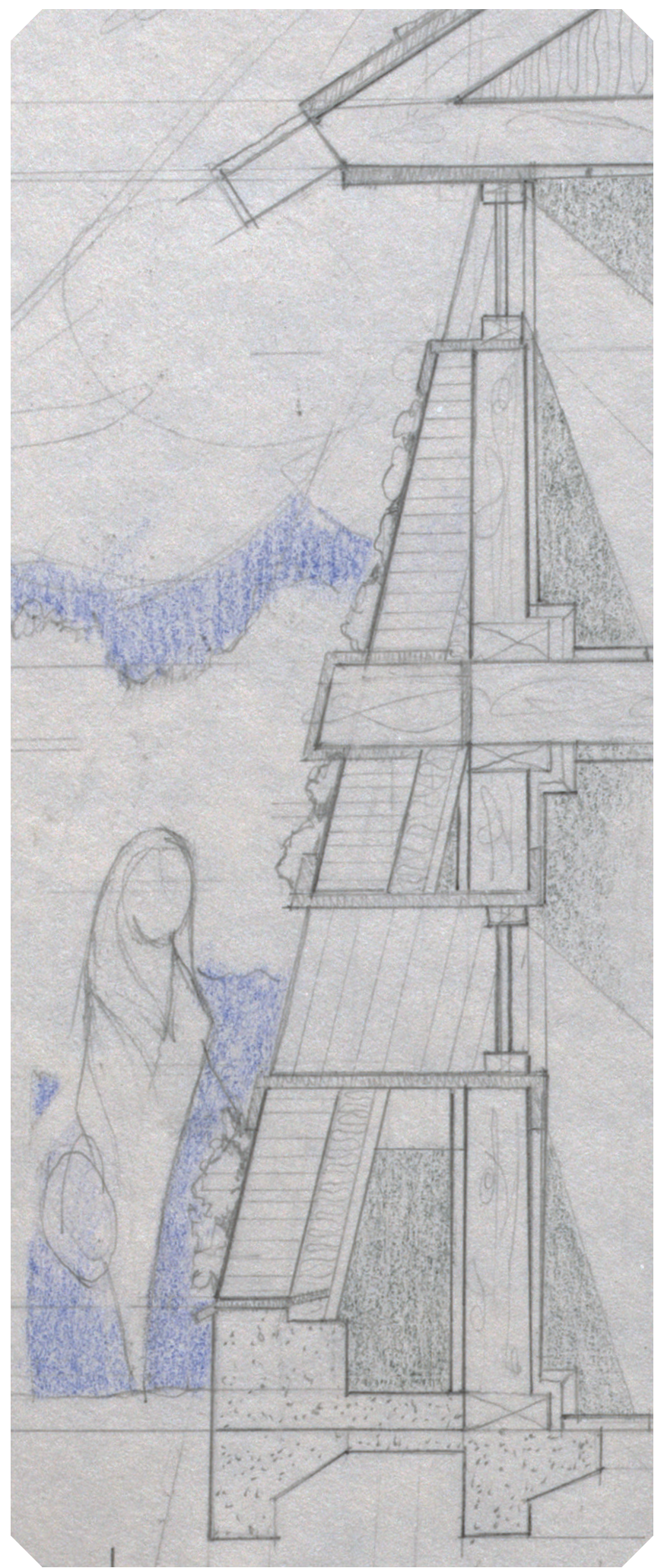

\subsection{Substitutions}

\section{1. "More Good, Less Bad"}

We can make substitutions

to the conventional pallette of materials to begin a shift towards more sustainable building practices. To this end, bioplastic bricks have the potential to replace traditional clay-fired bricks in conventional assemblies, with minimal changes necessary to the underlying structure. While more research would undoubtedly be necessary on this new material before it could be used as a functional compressive member, they would be particularly useful as a non-conventional rain screen - in similar fashion to the way we currently use clay-fired bricks. The assembly depicted in Figure 20 illustrates how a bioplastic facade might be attached to a conventional wood frame dwelling. 
As drawn within Figure 20, the new bioplastic facade addition is drawn at a slight angle to the rest of the building. This detailing consideration embraces the idea that these bricks will certainly degrade much faster than their clay-fired counterparts; however, this degradation will most likely result in an organic, nutrient rich runoff which would be beneficial for plant life. In this regard, an angular facade facilitates the cultivatation of plants within the facade itself, as well as the collection of the runoff for agricultural use later. As these bricks degrade, inhabitants would be able to produce their own replacements cheaply, as needed, without specialized tools, and using raw materials from their own garden.
Figure 21 - Planter Brick Section

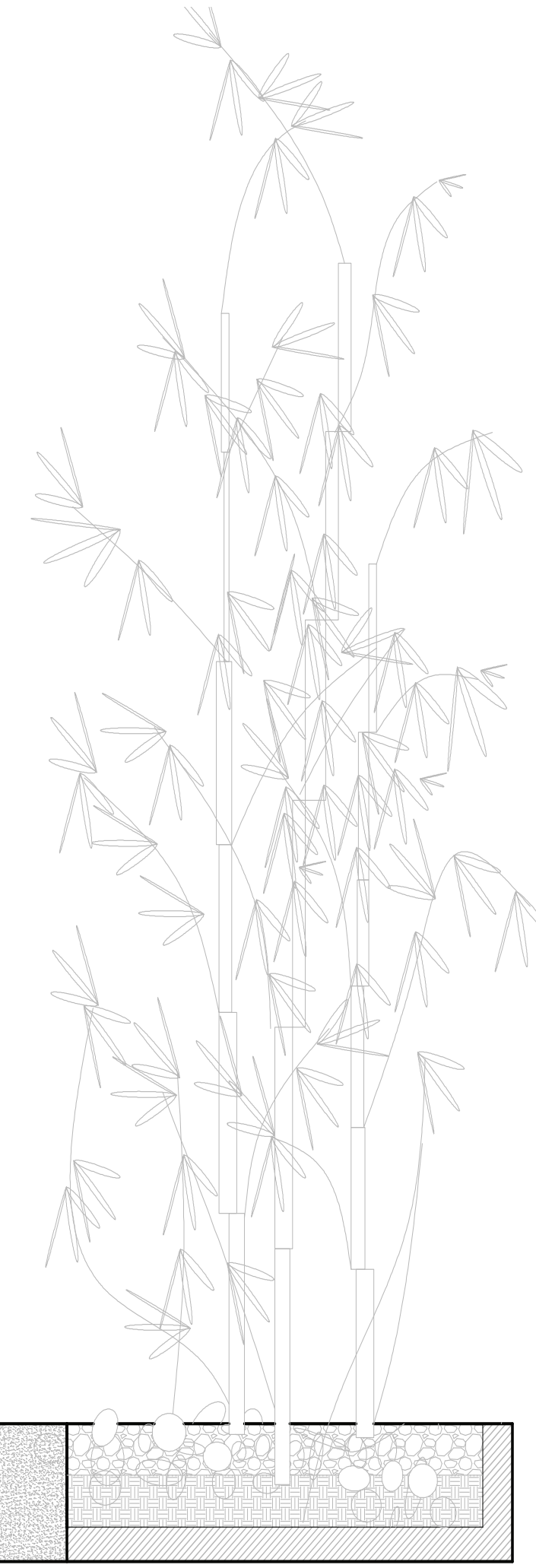




\section{Conventional Assemblies}

The thermoformable nature of starch bioplastic materials means that they are virtually unlimited in the physical form they can assume. Similar to concrete or plaster, bioplastic starch takes the shape of the mould in which it is cast. In this regard, the form is limited by the ability of the starch to thoroughly dry; a material issue which could most likely be solved by increased research and exploration. As a result of the versatility of the formal expression of starch bioplastic, it could easily mimic the form of standardized conventional building materials to replace traditional units of building. As starches continue to gain momentum within commericial applications as plastic additions to grout, plasters, and lamintates, it is an intriguing excersize to imagine the multiplicity of forms this new material might offer conventional assemblies.
Figure 22 - Brick Assemblies
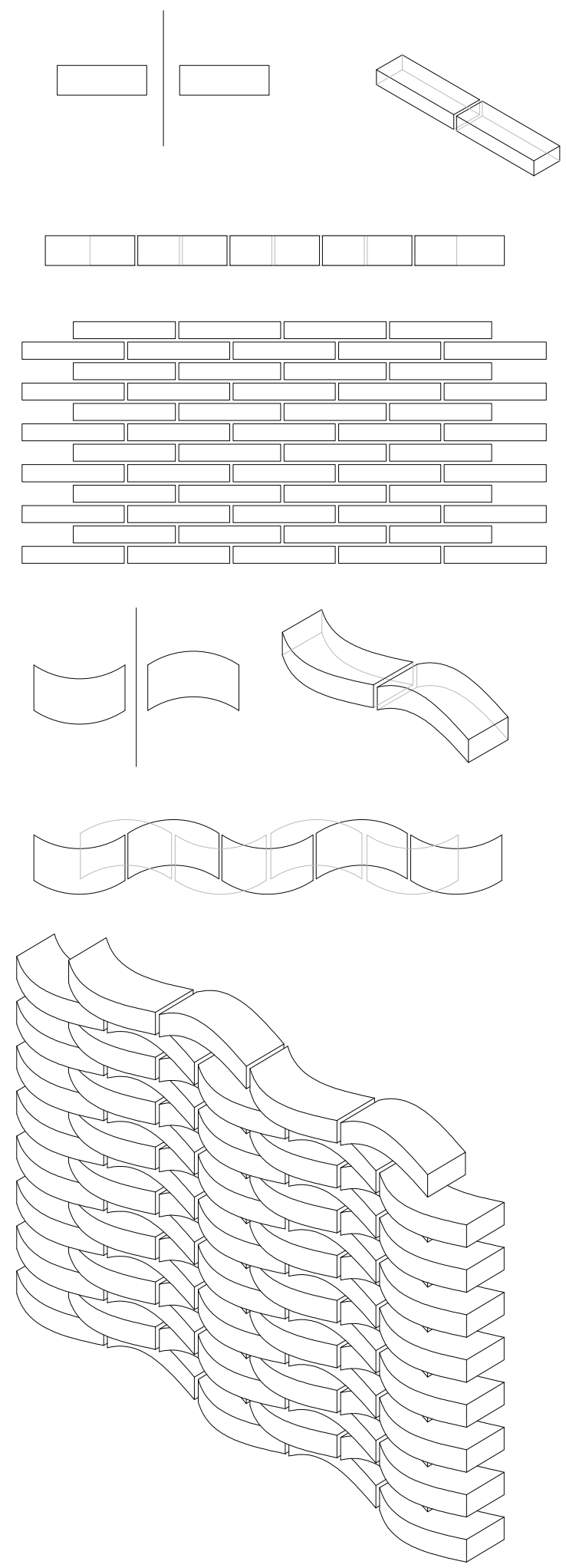


\section{Figure 23 - Possible Brick Shapes}

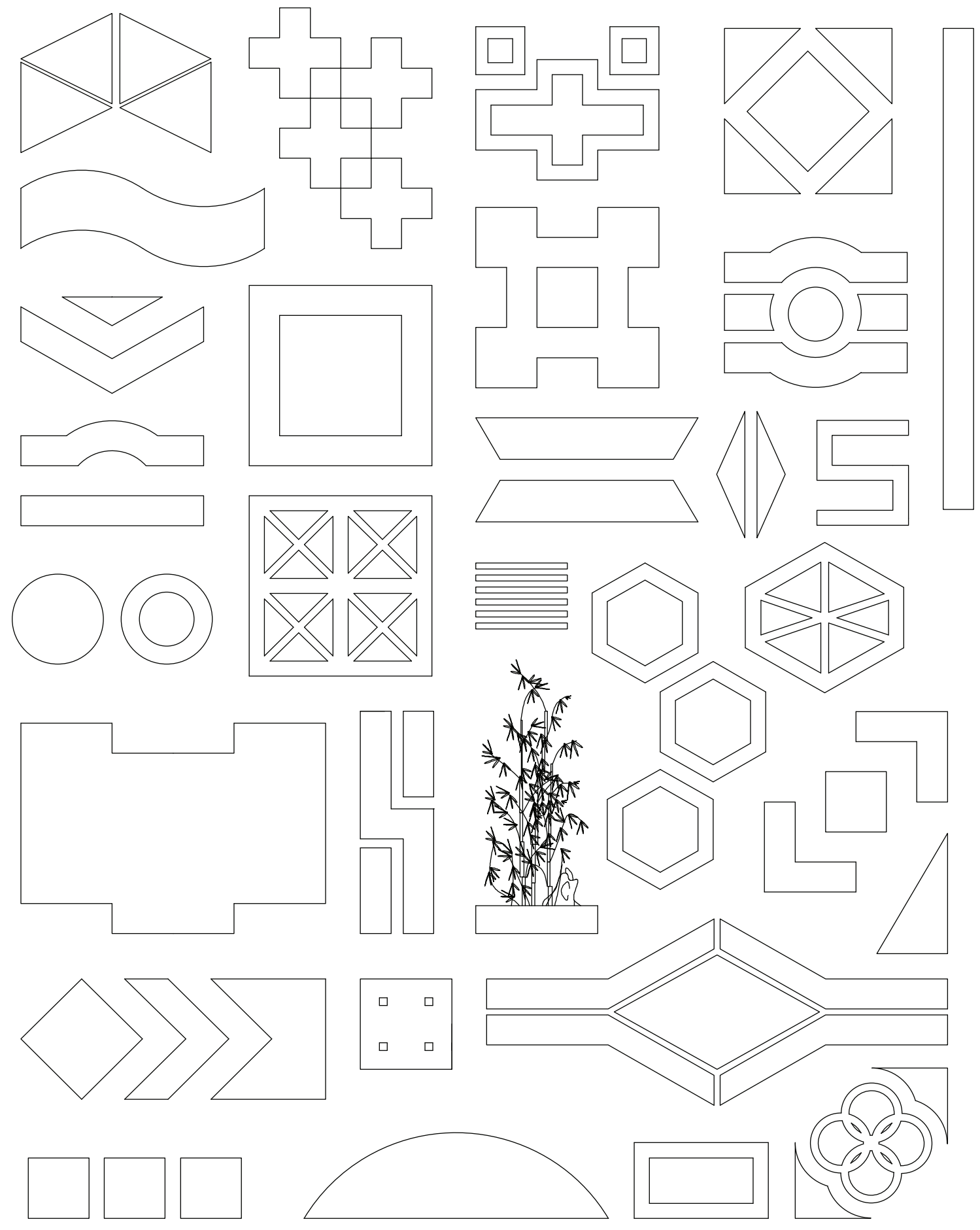




\section{Figure 24 - Facade Panel Systems}

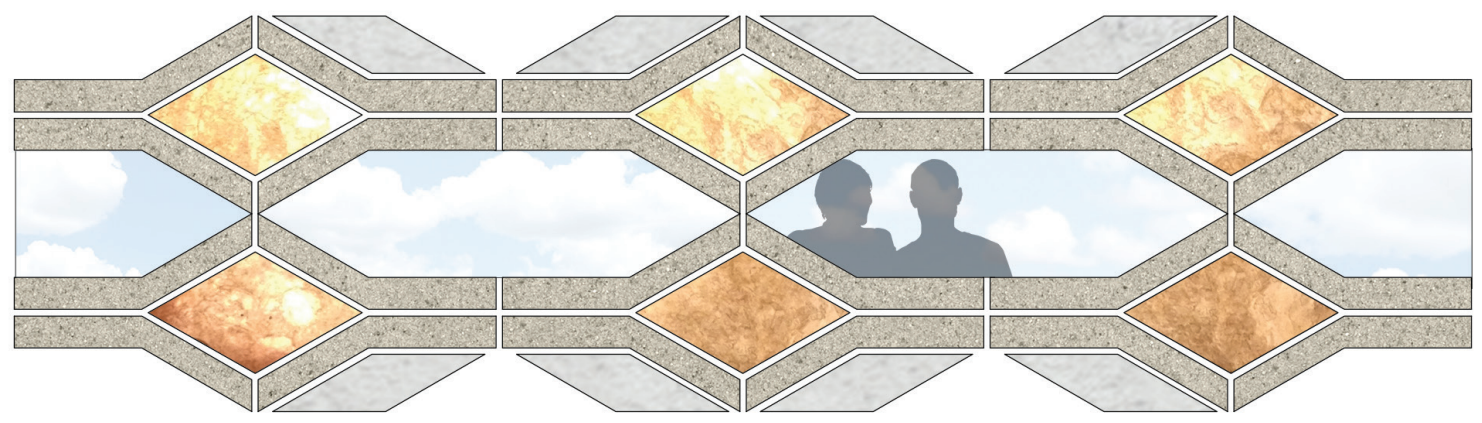

\section{Unconventional Properties in Conventional Assemblies}

Conventional assemblies could also take advantages of the unconventional properties of this new material. As illustrated in chapter five, there are several beneficial properties of bioplastic starch which would be beneficial or intriguing. Translucent facades, with degrees of transparency which varied at the descretion of the design, could facilitate an entirely new interaction with buildings and their surroundings as we have learned from the introduction of transparent concrete into our material palette. Translucency in architecture typically emotes life, liveliness, and the human spirit; a form of communication which radiates from the building itself made possible solely by human activity from within.

\section{Figure 25 - Translucent Facade Panels}
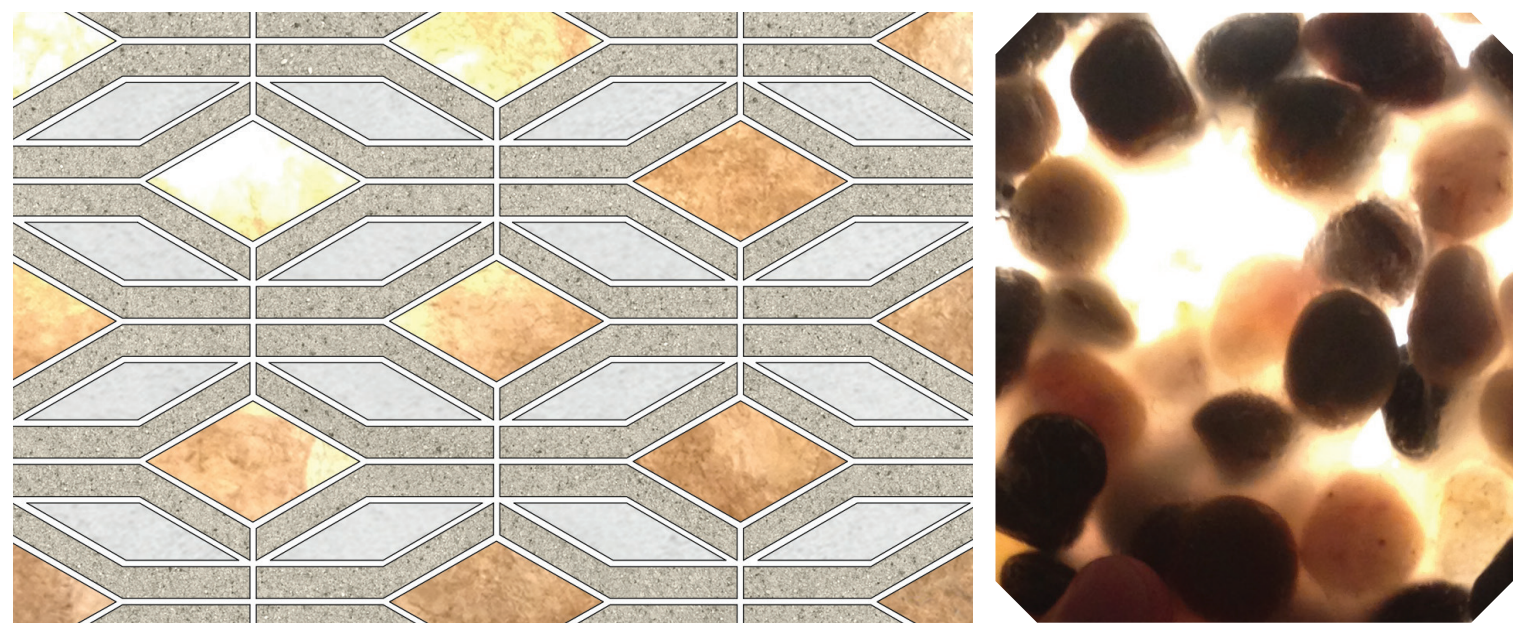


\section{Adapting to Unconventional Materials}

By embracing the biodegradable property of bioplastic starch, a standardized system of assembly and dissassebly could serve to mitigate building waste from building practice and operation. This detail illustrates a standardized panelling system which facilitates the removal and replacement of the exterior components is illustrated. Since the degradation of materials is a universal reality faced by all materials with which we choose to build, it is logical to establish a system of assembly and disassembly which caters to this unyielding fate. This detail allows inhabitants the flexibility to change or alter their facade components as they choose - and important consideration towards increasing the flexibility of the built environment and being receptive to the ever-changing technologies of building.

\section{Figure 26 - Removable Facades

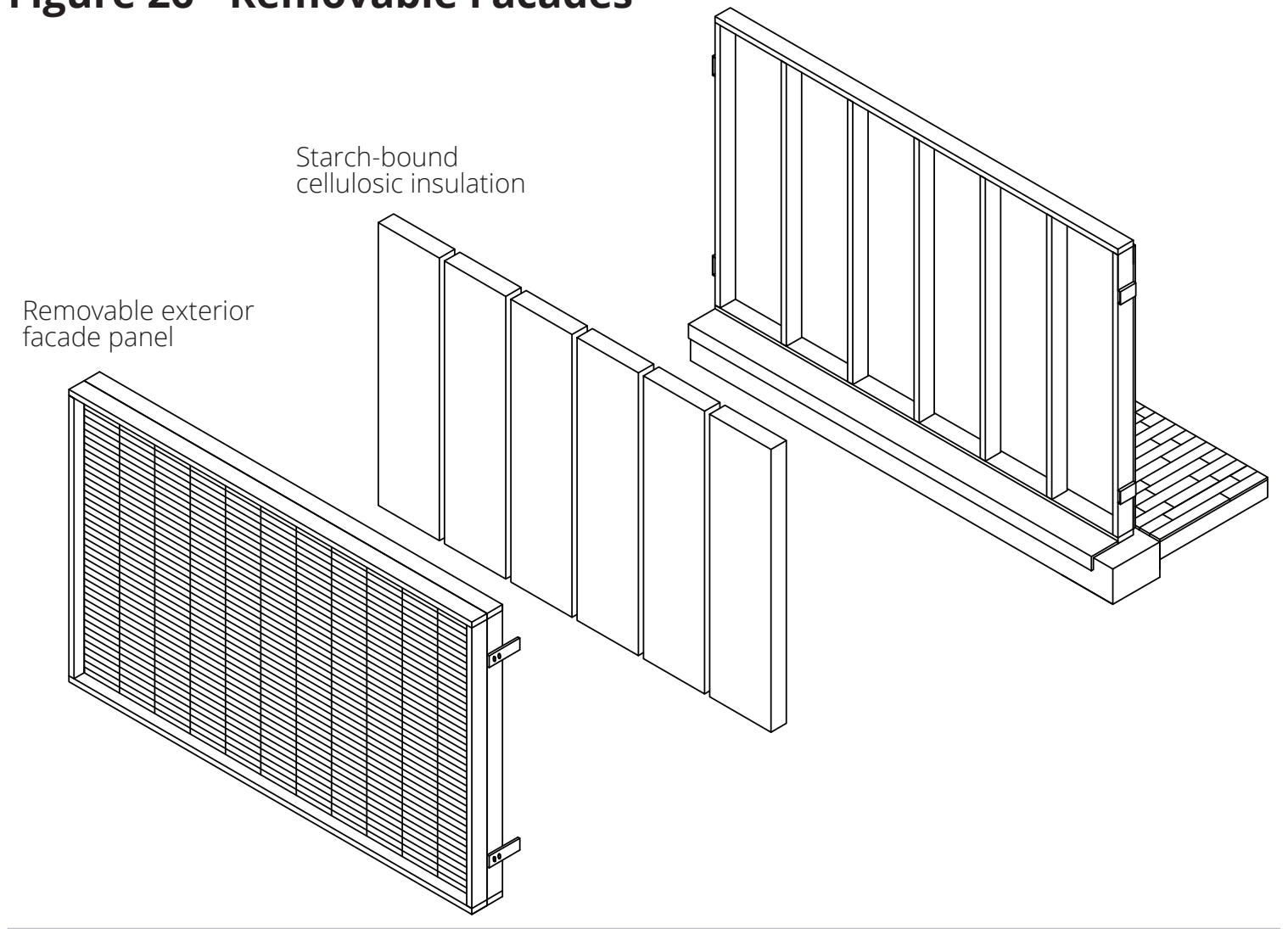




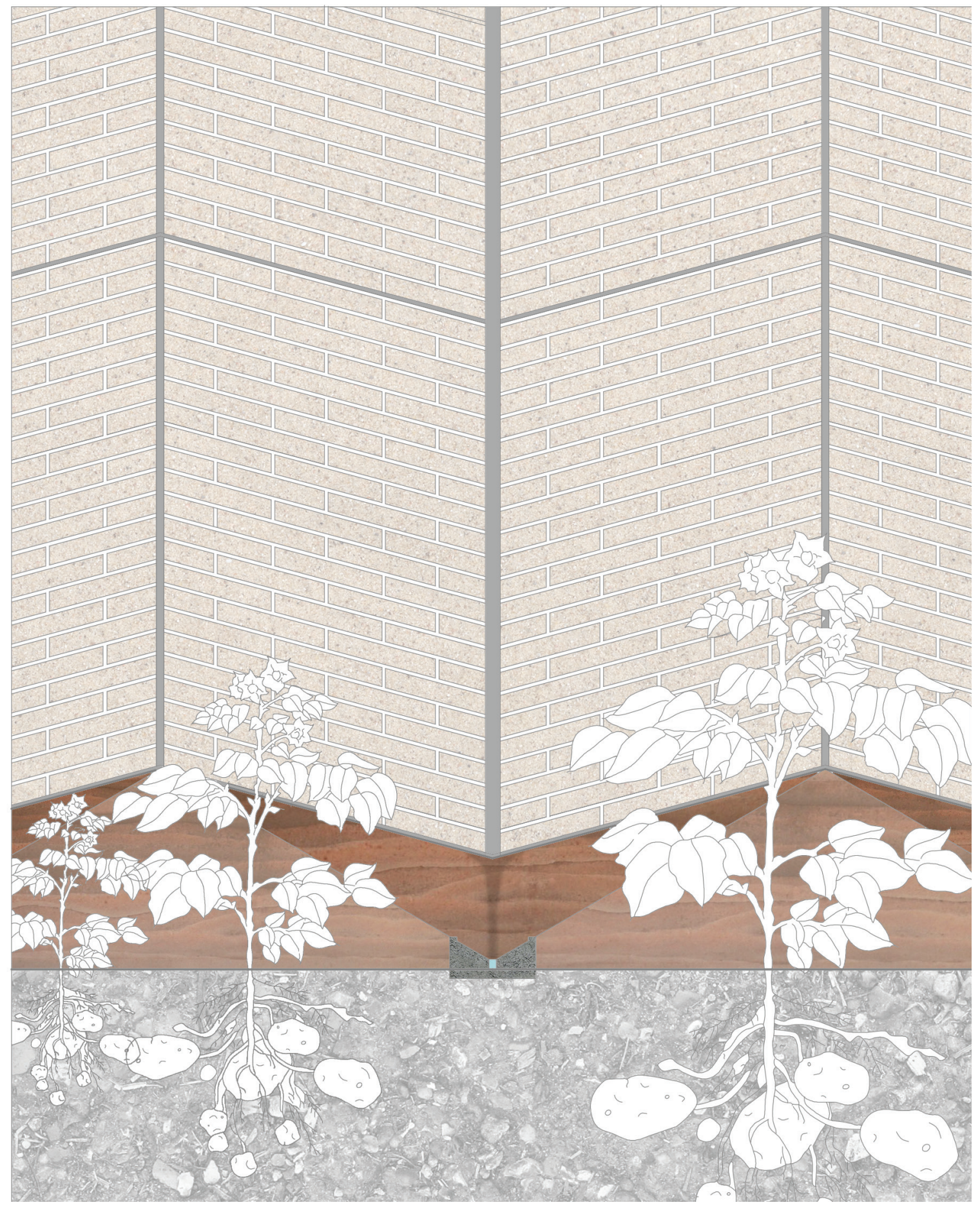

\section{Figure 27 - Channeling Degradable Facades}

Standardized paneling designed to degrade into nutrient rich runoff could allow buildings to actively participate in their surroundings, establishing a much more meaningful and utseful relationship with the boundary between the natural and built environments. 


\section{Figure 28 - Starch Curtain Wall Detail}

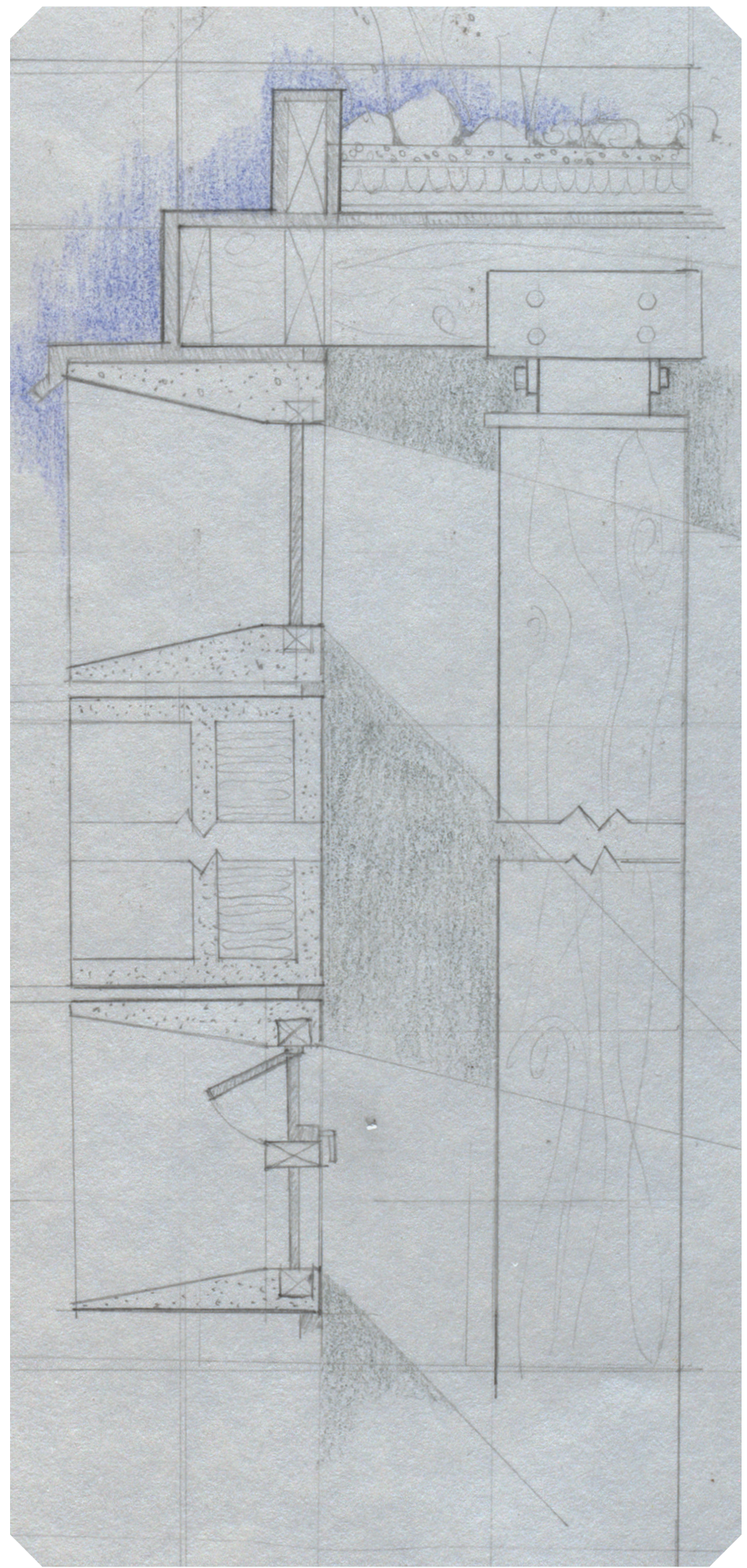

\section{Beyond Bricks}

Bioplastic starch making would be not restricted to bricks. In fact, the nature of starch bioplastic makes it particularly adept at forming films and panels. Using a technique of building up layers of bioplastic as opposed to casting homogenous solids, panels could easily be crafted which subvert specific drawbacks of this new material, such as cracking or non-uniform drying. In this detail, a facade panel assembly using starch bioplastic panels is illustrated which has been designed to integrate with a wooden post and beam frame. In order to be useful as an exterior facade material, 
Figure 29 - Starch Panels

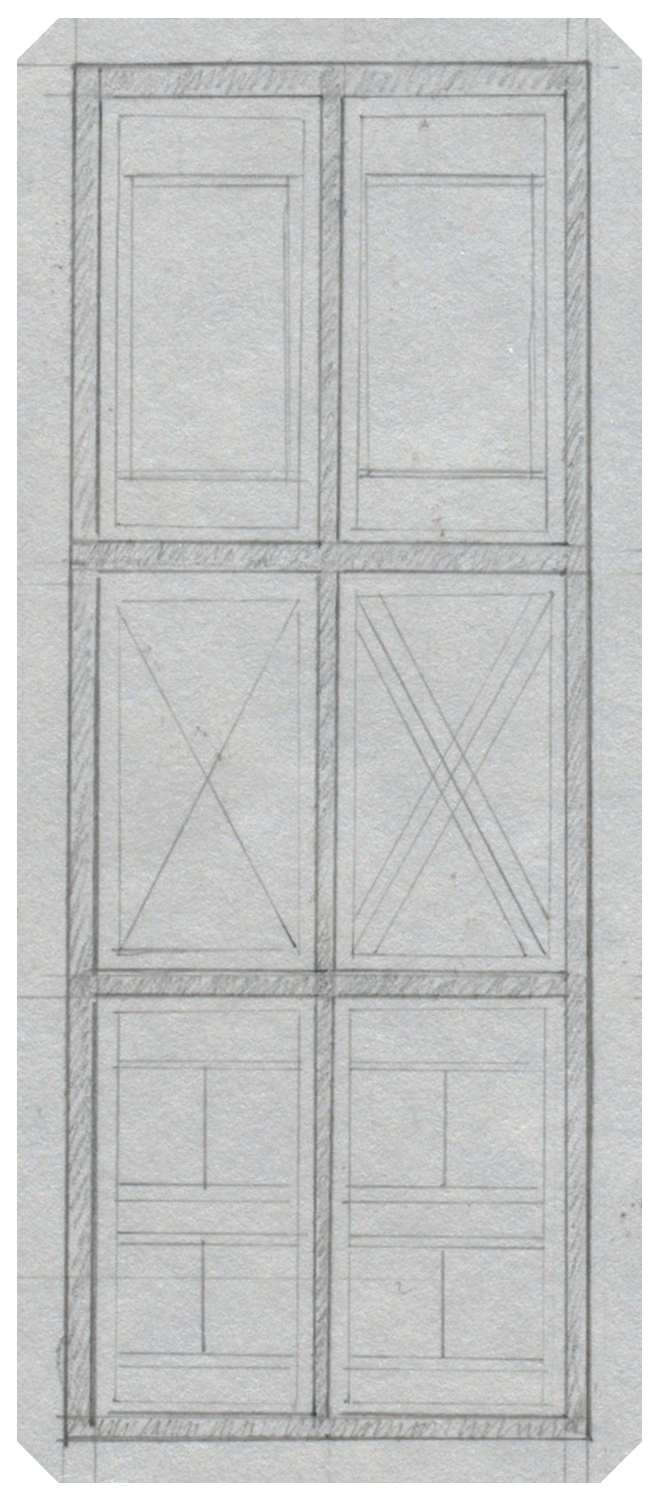

the bioplastic material would certainly need some form of weather protection, similar to the ways in which we protect exposed wood in building construction. Using starch panels for curtain wall systems would be an interesting departure from the typical glass, plastic, or metal panel constructions we currently employ. One of the more intriguing properties of starch which is particularly relevant to this design scenario is its ability to act as a protective and adhesive laminate. This property of starch bioplastic would allow for the aggregation and lamination of seperate and distinct entities as uniform solids - facilitating the creation of solid woven panels, interesting aggregates, and new methods of production which promise interesting results.

\section{Figure 30 - Starch Panels for Curtain Walls}

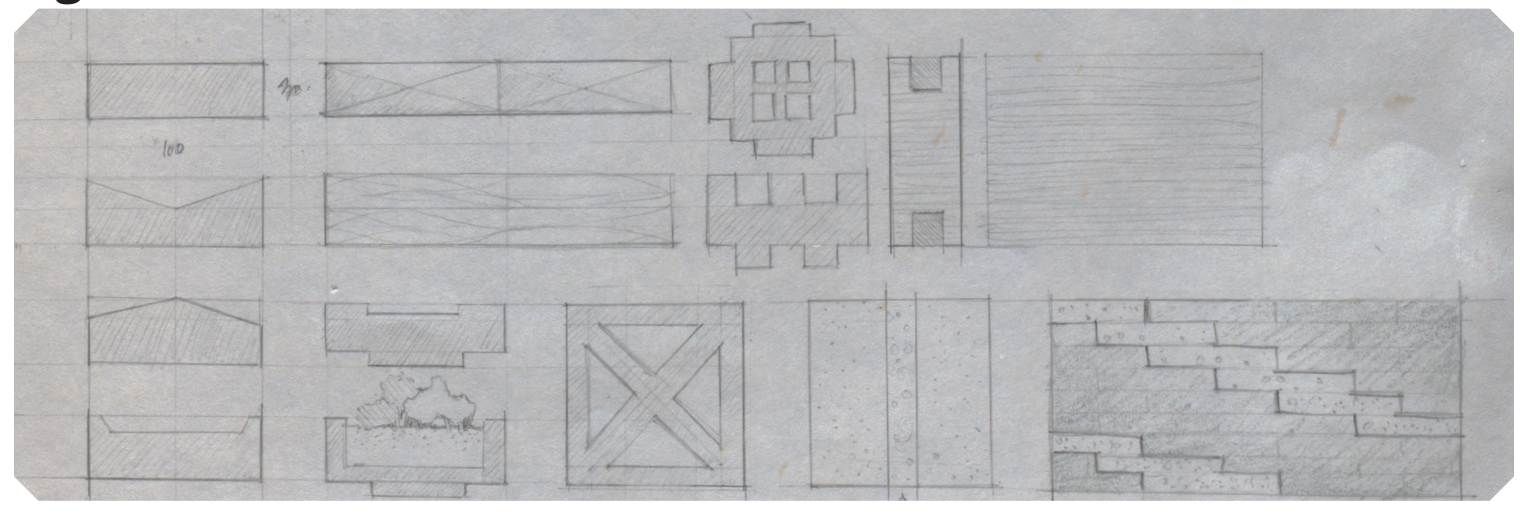




\section{Structural Members}

Structural members could also

be designed and produced from

bioplastic starch. Further research and

experimentation would be required

in order to produce a compressive

member from starch bioplastic

composites, however, initial tests and

investigations undertaken within this

study have been encouraging. With the

proper reinforcement and composite

combination, it is reasonable to speculate

\section{Figure 32 - Bioplastic Column}

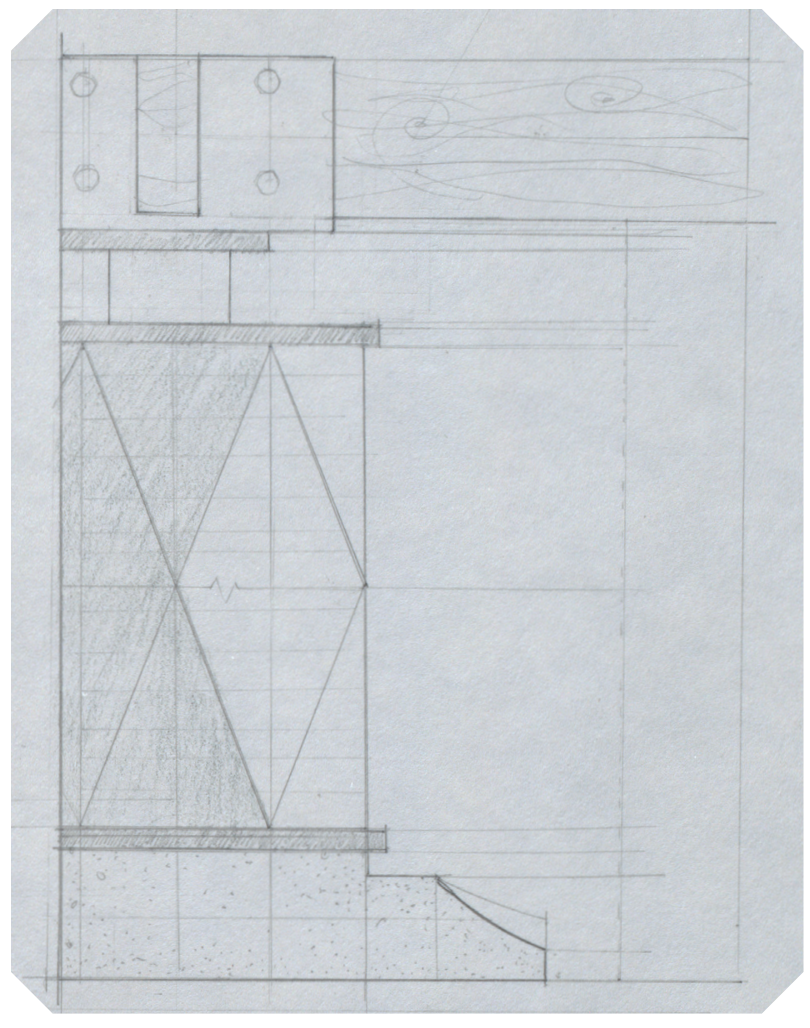

\section{Figure 31 - Brick Column}

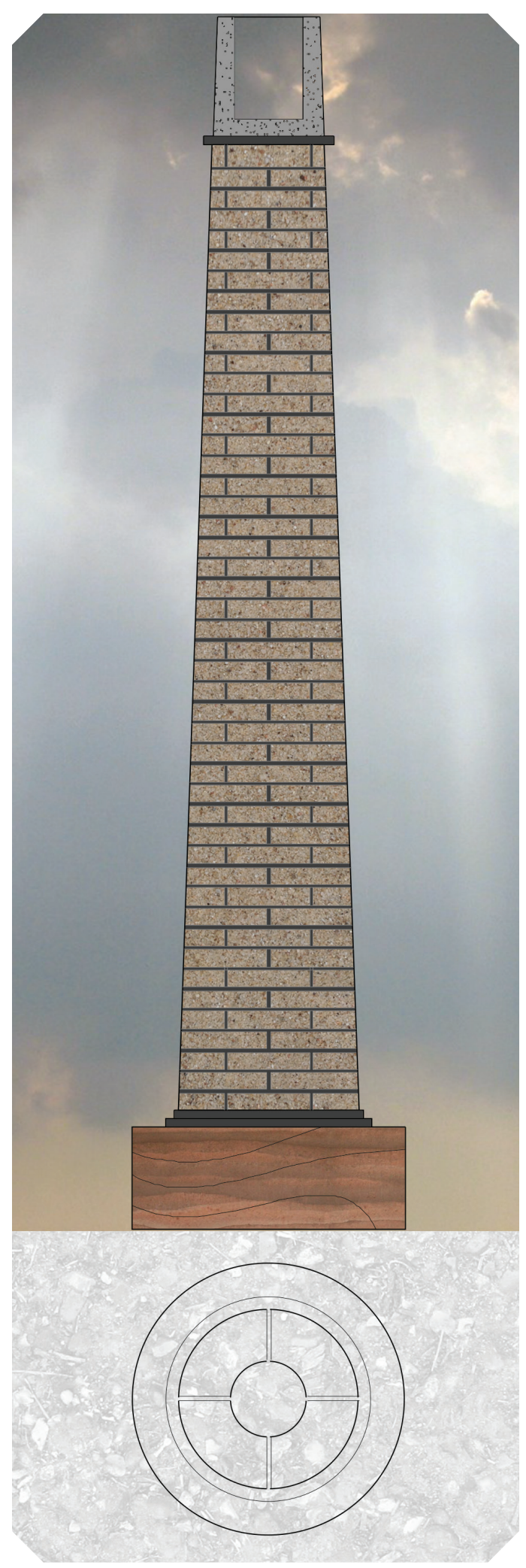


Figure 33 - Brick Arch

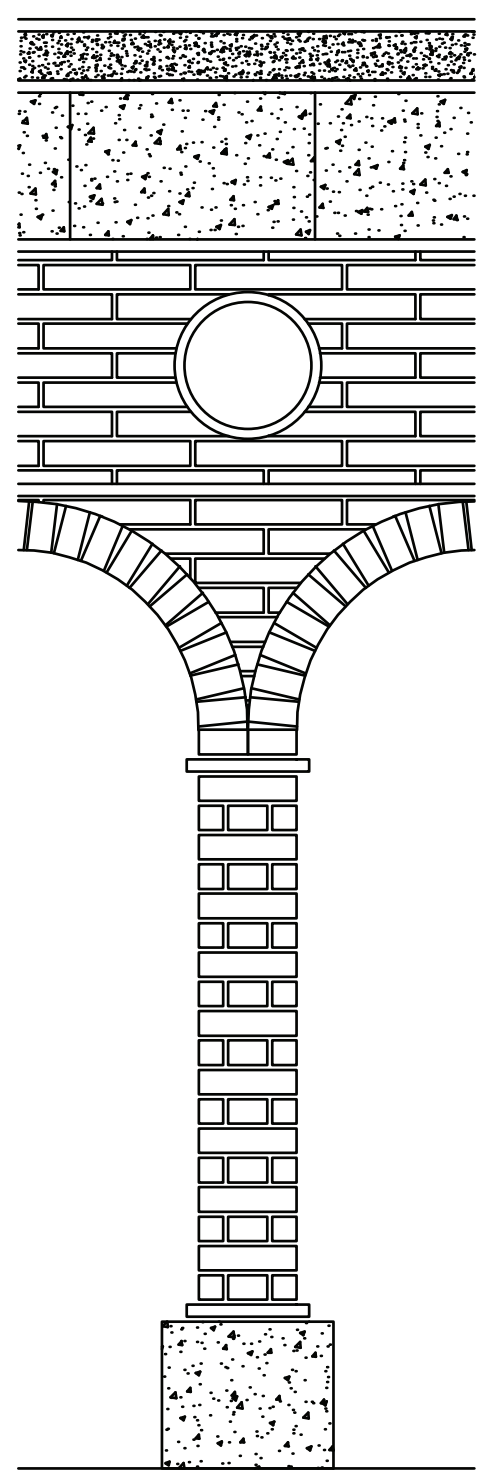

that a modified version of starch bioplastic could be suitable for producing reliable and structurally significant compressive members. This detail to the immediate left illustrates a column and arch assembly, made from starch bioplastic bricks, which could be assembled using no more tools and / or materials than required to make the bricks themselves. By returning to local methods of making and craft, new materials can draw upon the centuries of architectural knowledge and research which are bound within traditional forms. Immediately below, a colonnade of starch bioplastic columns and arches illustrates how these distinct and relatively simple to reproduce details could join together to form larger locally produced assemblages.

\section{Figure 34 - Starch Bioplastic Brick Arch Assembly}

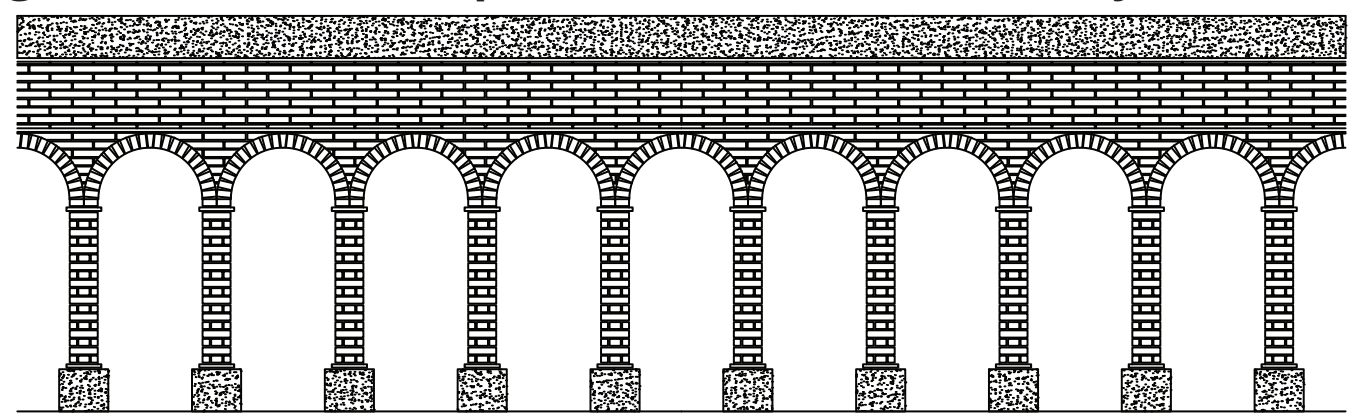




\section{Detailing Consquences for Material Properties}

There are detailing consequences which correspond to the properties of the materials we work with. As an example, the following illustration depicts an imagined assembly of bioplastic components that would be appropriate for use in both conventional building practices or more unconventional approaches. The details which are included in the assembly have been designed with the specific advantages and limitations of bioplastic starch in mind, and illustrate the ways in which these imagined components might be assembled together. The vast majority of these details rely upon wood framing for structural purposes, but as research and exploration of this new material continues, new applications and usages might allow for entire dwellings to be composed of starch bioplastics. The assemblies on the following pages imagine a small dwelling fit for human inhabitation, which has been constructed using a mix of bioplastic and traditional construction methods. Bioplastic masonry walls, curtain walls, parapets, and roof systems have all been detailed, providing insight to both the methods of assembly and disassembly. On the next page, a small interior vignette portrays a vision of life within a dwelling such as this. When employing bioplastic materials as substitutions for conventional materials, the difference in the quality of life for inhabitants would most likely be quite minimal. In this manner, this collection of substitutions has sought to illustrate that sustainable modes of urban development may be more readily available to consumers than we commonly perceive, which could be immediately compatable within established methods of contemporary building. These substitutions would not necessarily have a negative impact on our quality of life or standard of living, but would definitely have a substantial positive impact on our ecological footprint and the pressure we place on natural environments. 
Figure 35 - Imagined Substitutions Assembly

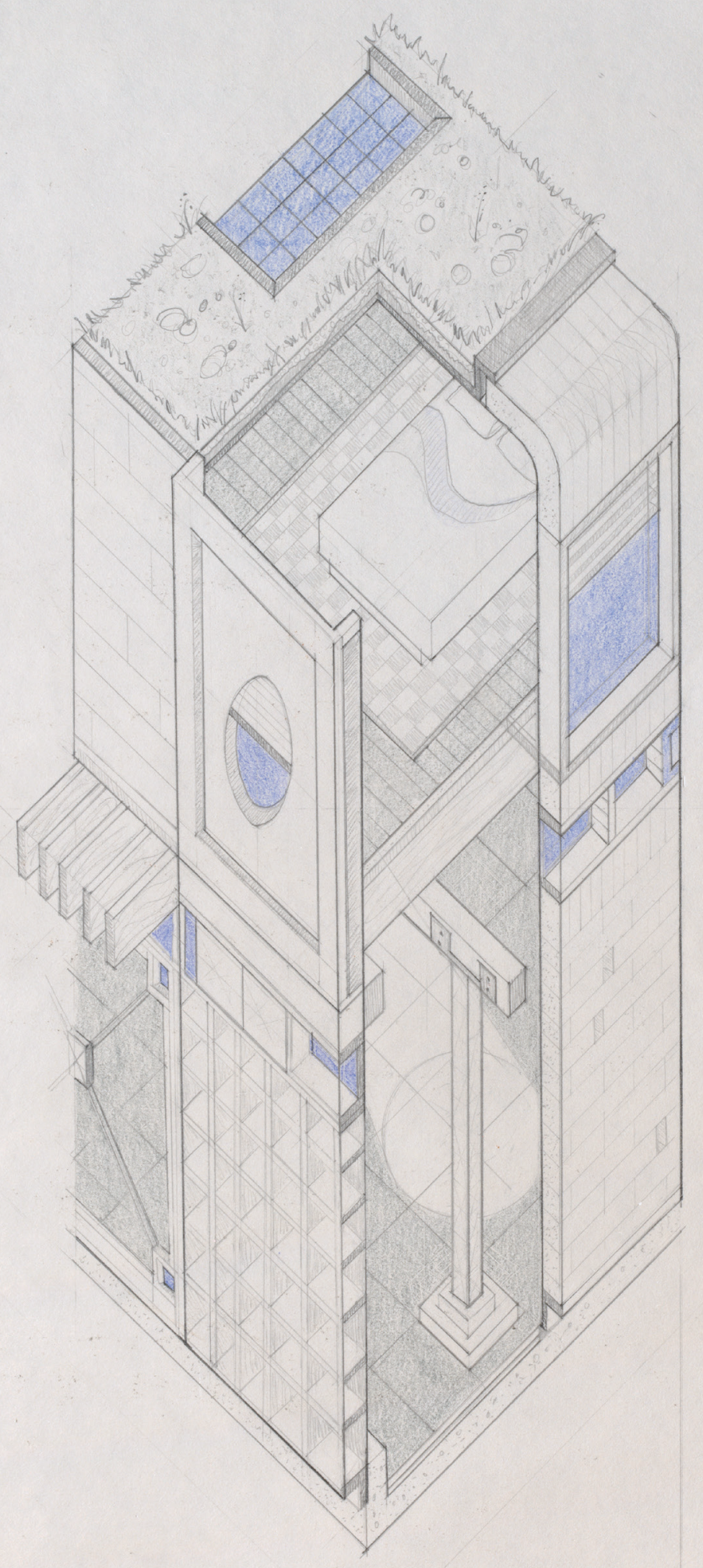



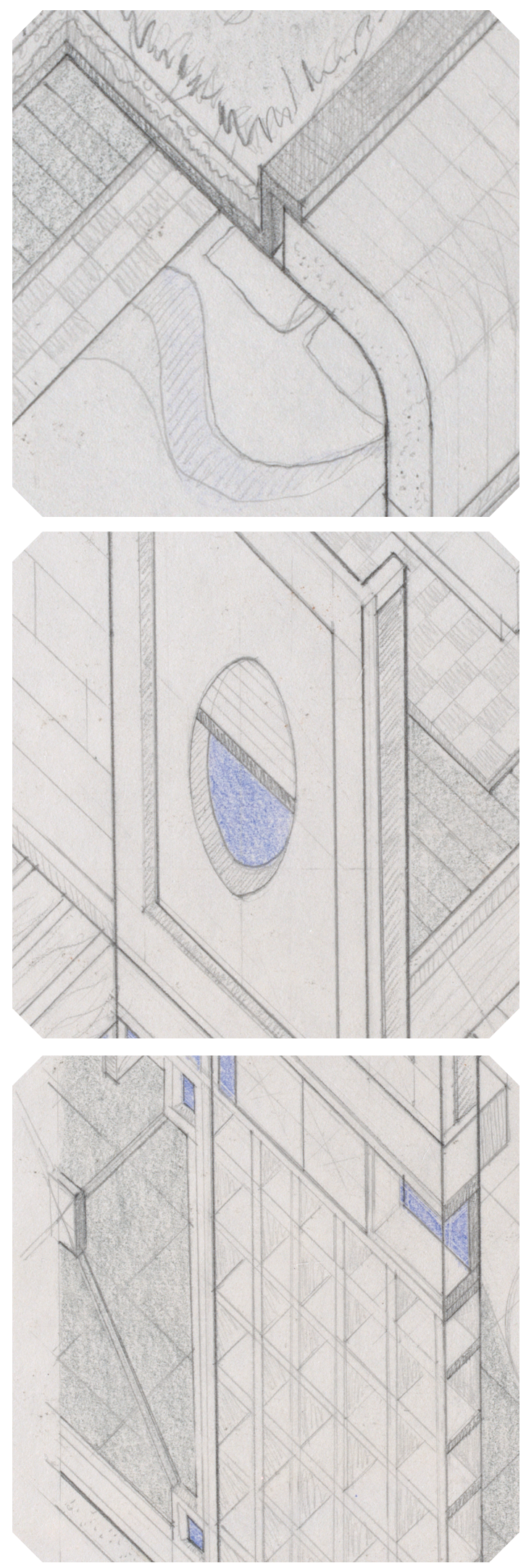

\section{Figure 36 - Curved Parapets}

Curved parapets are an example of designing for degradation. This curved shape allows for a simple parapet and roof assembly to be constructed, while simultaneously facilitating the collection and redirection of nutrients from degrading starch components.

\section{Figure 37 - Flexible Panels}

Due to the flexible nature of starch making, panels could accomodate any shape, size, or pattern that designers might imagine. Openings within panels might also take advantage of the translucent properties of starch to stasify design requirements.

\section{Figure 38 - Easy Integration}

Adapting to existing methods of building and conventional materials would be simple in practice since starch components can be locally produced and assume a nearly limitless number of formal expressions. 
Figure 39 - Curved Parapet with Interior Vignette

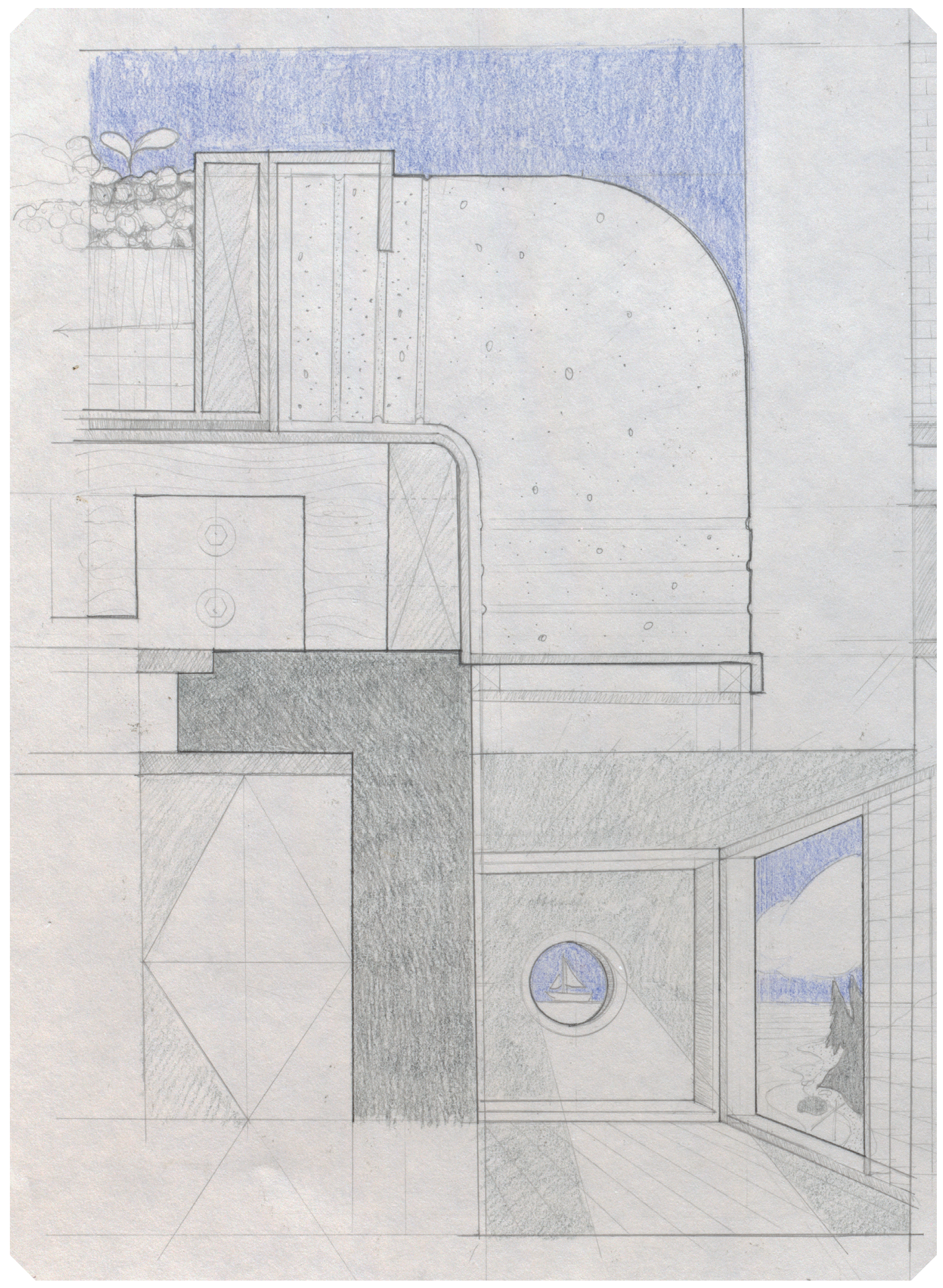




\subsection{Newisms}

New materials offer new modes of construction and new possibilites of the material imagination. In his 1908 essay "In the Cause of Architecture" written for The Architectural Record, Frank Lloyd Wright eloquently wrote: "Each material has its own message, and to the creative artists, its own song... Every new material means a new form; a new use, if used according to its nature."1 In this sense, he makes the argument that each material deserves its own specific constructive approach and distinct poetic consideration. No two materials are the same, and each has different consequences in the built environment in both application and poetic significance. In this section, newisms, bioplastic starch construction has been reconsidered in ways that might be more appropriate to its material nature; the conceptualization of construction has been extended beyond traditional methods of assembly to embrace the fantastical or imaginative. Exploring the notion of sustainability at the essence of the material is the primary motivation of this exercise, and the drawings which follow seek to illustrate the ways in which this imaginative property might find its way to fruition. This exploration is hopefully a reflection of a changing societal mindset, willing to entertain the idea of new modes of dwelling and inhabitation representative of a shift of values and beliefs towards environmental conservatism and preservation. As our collective values continue to shift, the meaning and significance with which we imbue materials also changes. In this regard, the details which follow attempt to illustrate an alternative future building scenario, where the desire for sustainability is inherently communicated as a consequence of building with bioplastic starch. 


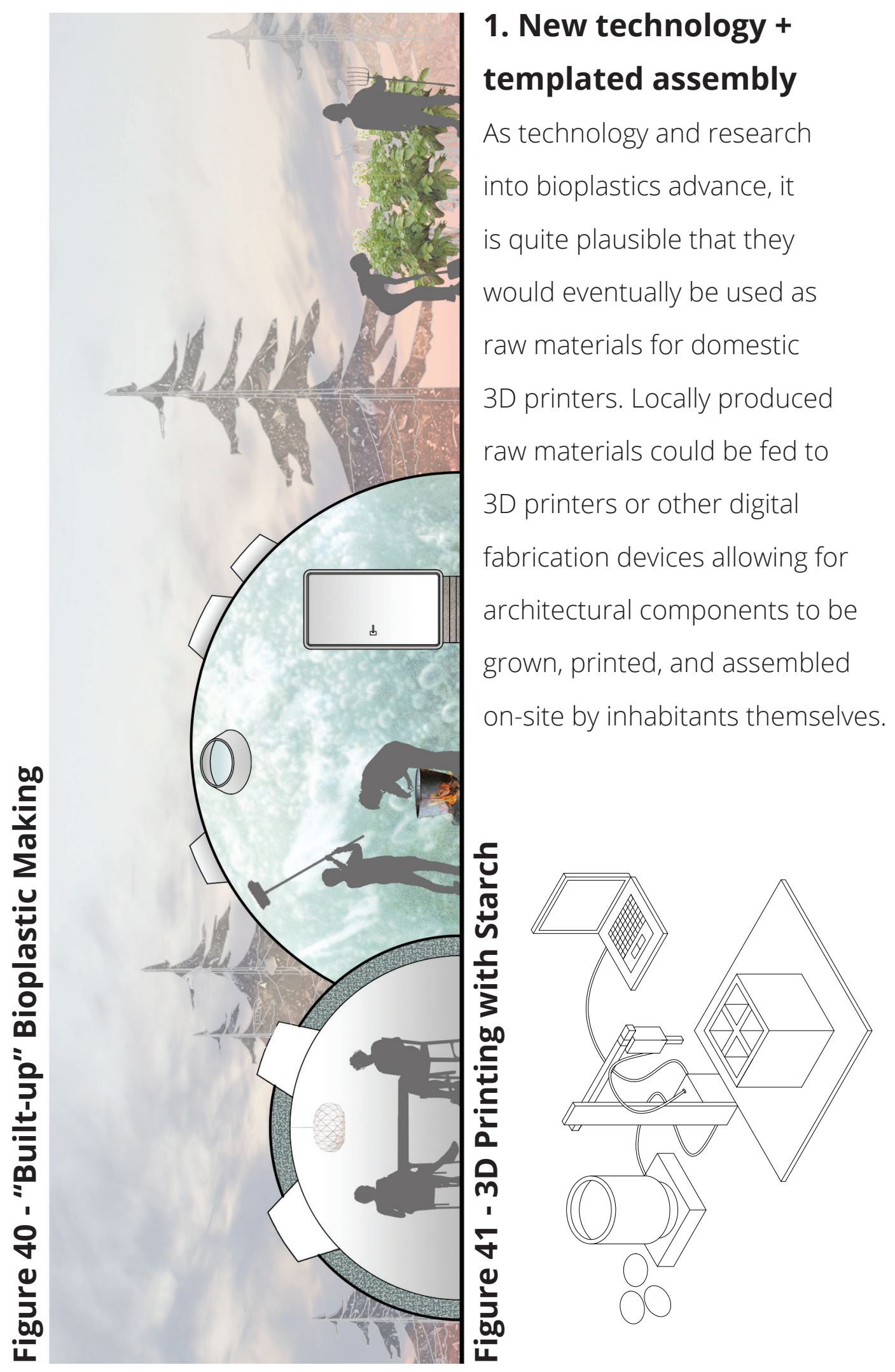




\section{Figure 42 - Imagined Application of Bioplastic Starch}

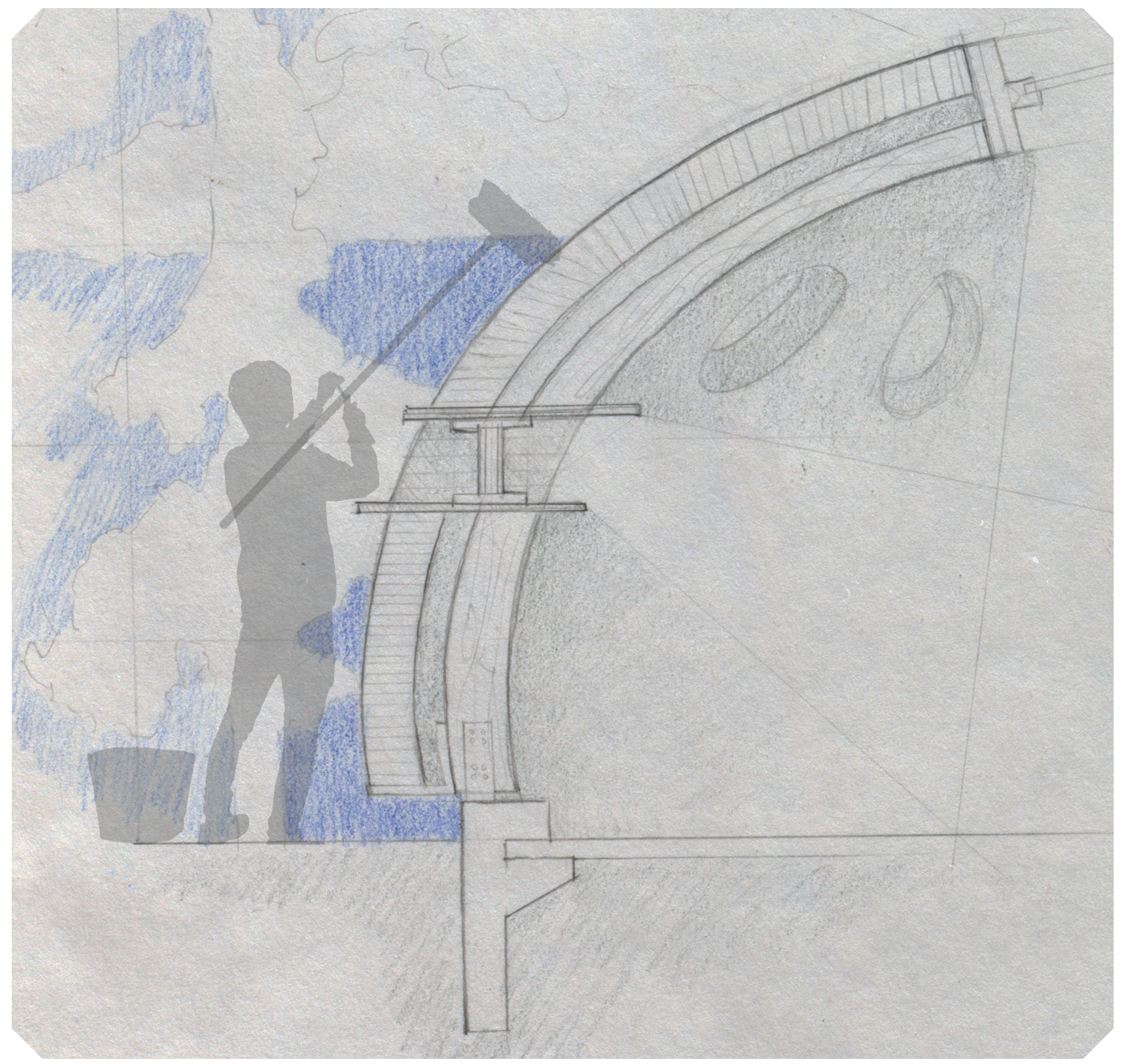

The detail above illustrates how bioplastic starch might be applied by brushes or sprayed-on, similar to the way concrete domes are poured over rubber forms. 3D printed bioplastic materials could form the initial structural components of these new constructive assemblies, after which additional coats of bioplastic might be applied by brush or hose. While any shape would arguably be feasible with this type of construction, the arch or dome offer significant structural advantages which would compliment the nature of bioplastic starch. 


\section{Figure 43 - Inhabiting Starch Structures}

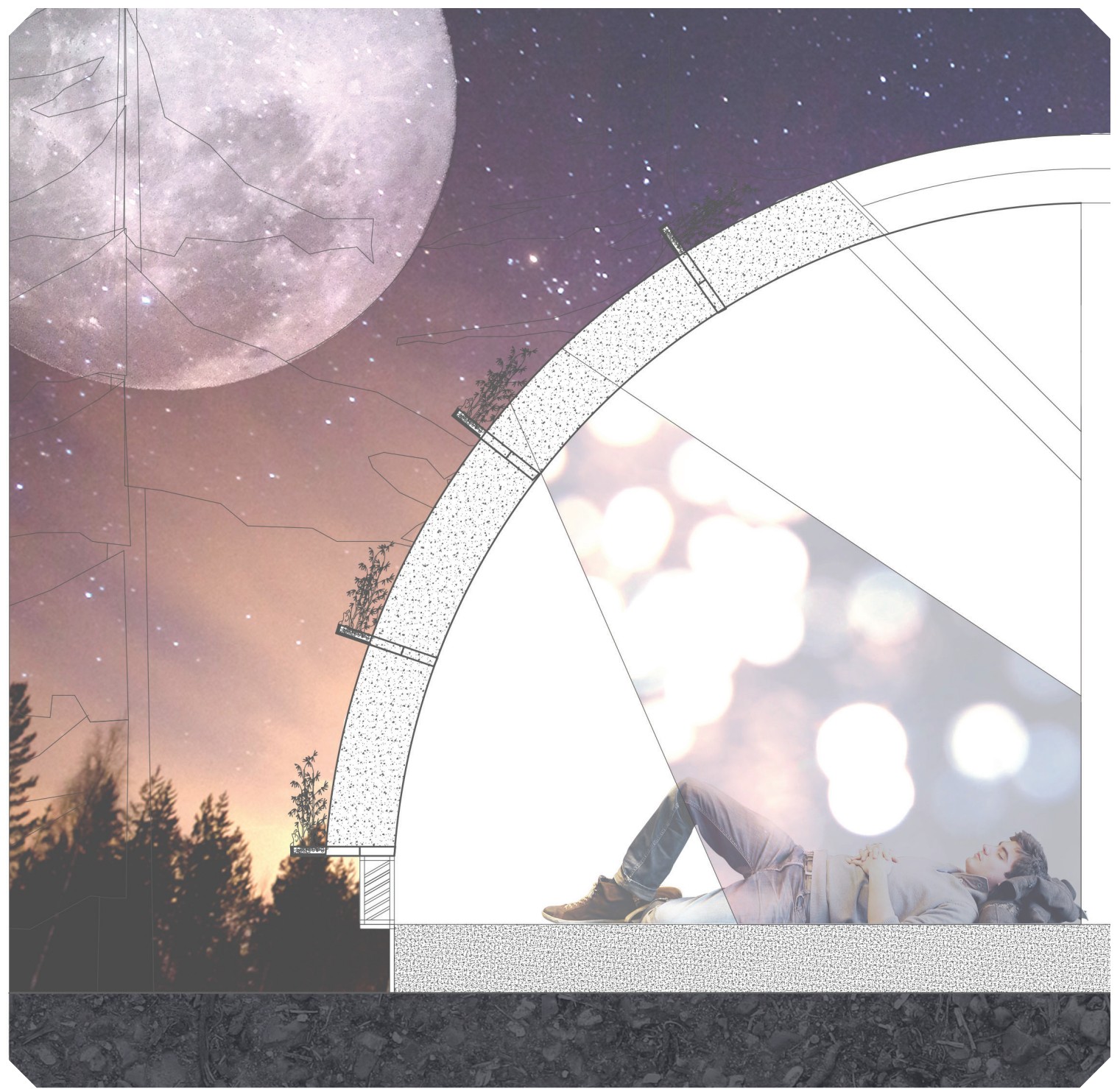

As inhabitants dwell within these new materials and methods of assembly, it is hoped that bioplastic building components would communicate the essence of sustainability through their materiality and engagement with the material imagination. Similar to the subjective evaluation of "stoniness" and the buildings of Shigeru Ban, it is hoped that inhabitants would question the use of these new materials and their construction; furthering the understanding of our place in these materials, and the motivations for their existence. 


\section{CONCLUSION}

While it is an unfortunate truth that our buildings will not last forever (despite our best intentions), we know that the manner in which we build and the materials incorporated in our dwellings ultimately dictates what materials we will have to deal with when the dwelling has exceeded its functional life span. By making thoughtful adjustments to our material palette, we have the ability to predict what waste materials we will have to deal with in the future. Novel construction techniques and innovative materials therefore present a unique opportunity for human societies to reconsider their role within proximate natural environments. To this end, the exploration of new renewable and biodegradable materials holds significant promise to satisfy the accelerating demands of continuously expanding societies by renegotiating the environmental, social, or economic costs required for persistently intensifying urban development.

New and innovative building materials are beginning to provide a feasible alternative palette for architects and engineers to provide attractive solutions to intensifying environmental issues. From fibers made of woven carbon or glass, to mycelium bricks and bioplastics, architects are engaged daily with a battery of innovative new materials which are ripe for spatial exploration and analysis. 
Specifically, bioplastics (plastic materials which are created from naturally occurring plant materials) represent an attractive option for sustainable building in the near future. Often comprised of renewable resources, cheap, easy to create, and biodegradable, bioplastics offer an environmentally responsible replacement for petroleum based plastic products. Their application is basically limited in the same manner as their petroleum counterparts, yet the social, environmental, and economic benefits of their utility heavily outweighs the costs. As such, this thesis explored the potential for bioplastic building materials in the built environment as a means of imagining an alternative future that embraces the local production of socially and environmentally sensitive buildings and materials. Through the lens of renewable and biodegradable building materials, this thesis suggests an alternative path for the architectural imagination; reconsidering our place in materials, living within the capacity of natural environments. 


\section{POST SCRIPT}

There are several distinct advantages of bioplastic starch making that are emphasized by economies of scale. While this investigation was particularly focussed on the production of starch bioplastic using readily available domestic tools and appliances, there is a significant opportunity for bioplastic starch in architecture and construction on the industrial scale. As technology continues to advance, and the lines between consumer and producer continue to blur, industrial processes could help distribute modified starch bioplastics to consumers as the necessity for environmentally sensitive plastics and building materials continues to grow. This idea is exemplified by ITKE's ArboSkin Pavilion, industrial processes and techniques which have been perfected over decades of research and practice are particularly suitable for embracing environmentally responsible raw materials to produce new and unconventional building materials. As illustrated through the arguments of William McDonnough and Michael Braungart in earlier chapters, if the industrial complex embraces environmentally sensitive materials and practices which produces responsible and biodegradable products, then the externalities of the overall system of production and consumption are likely to be positive. 


\section{BIBLIOGRAPHY}

- Abbott, Andrew P., Jesus Palazuela Conde, Stefan J. Davis, and William R. Wise. "Starch as a replacement for urea-formaldehyde in medium density fibreboard." Green Chemistry 14.11 (2012): 3067. Print.

- Knippers, Jan. "ArboSkin: Durable and Recyclable Bioplastics Facade MockUp ." Press Release. ITKE University of StuttgartÂ. University of Stuttgart, Stuttgar. 10 Feb. 2013. Address.

- Avenas, Pierre. Etymology of Main Polysaccharide Names. Springer-Verlag Wien: The European Polysaccharide Network of Excellence, 2012. Print.

- Bachelard, Gaston, and M. Jolas. The poetics of space. Boston: Beacon Press, 1994. Print.

- Barham, Peter, Leif H. Skibsted, Wender L. P. Bredie, Michael Bom Frã,st, Per MÃ,ller, Jens Risbo, Pia SnitkjÃ !r, and Louise MÃ,rch Mortensen. "Molecular Gastronomy: A New Emerging Scientific Discipline." Chemical Reviews 110.4 (2010): 2313-2365. Print.

- BeMiller, James N., and Roy Lester Whistler. Starch chemistry and technology. 3rd ed. London: Academic, 2009. Print.

- Connor, Steven. "Isobel Armstrongâ€鱼 Material Imagination." Radical Aesthetics: The Work of Isobel Armstrong. Institute for English Studies. University of London, London. 21 June 2002. Lecture.

- "Bioplastics." - Appropedia: The sustainability wiki. N.p., n.d. Web. 23 July 2014. <http://www.appropedia.org/Bioplastics>.

- Bonin, Michael. "An Investigation into the Properties of Starch-Based Foams ." School of Engineering \& Design Brunel University n/a (2010): n/a. Print.

- Borgobello, Bridget. "WikiHouse: Get ready to design, "print" and construct your own home!." GizMag 15 May 2012: n. pag. n/a. Web. 15 July 2014.

- "Climate Change 2014: Mitigation of Climate Change: Summary for Policymakers." Climate Change 2014: Mitigation of Climate Change. United Nations - International Panel on Climate Change, 1 Apr. 2014. Web. 28 Apr. 2014. <http://report.mitigation2014.org/spm/ipcc_wg3_ar5_summary-forpolicymakers_approved.pdf>. 
- Colin, Jefferey. Construction and Demolition Waste Recycling - A Literature Review. Halifax: Dalhousie Universityâ $€^{\mathrm{TM}}$ S Office of Sustainability, 2011. Print.

- "Deterioration." The Free Dictionary. Farlex, n.d. Web. 15 July 2014. <http:// www.thefreedictionary.com/deteriorations.

- Environmental silicate nano-biocomposites. London: Springer, 2012. 17. Print.

- Filiz, Klassen. "Material Innovations: Transparent, lightweight, malleable, and responsive." Ryerson University n/a (2004): n. pag. n/a. Web. 21 July 2014.

- "Global Footprint Network 2012 Annual Report." Global Footprint Network. N.p., n.d. Web. 15 July 2014. <http://www.footprintnetwork.org/images/ article_uploads/2012_Annual_Report.pdf>.

- Horwitz, Jamie, and Paulette Singley. Eating architecture. Cambridge, Mass.: MIT Press, 2004. Print.

- Human Activity and the Environment. Ottawa: Statistics Canada, 2005. Print.

- Ingold, Tim. Being alive: essays on movement, knowledge and description. London: Routledge, 2011. Print.

- Knippers, Jan. "ArboSkin: Durable and Recyclable Bioplastics Facade MockUp." ITKEÂ (InstituteÂ forÂ BuildingÂ ConstructionÂ andÂ StructuralÂA Design). University of Stuttgart, n.d. Web. 15 July 2014. <http://www.itke.uni-stuttgart. de/download.php?id=690>.

- Kohhler, C.. "Biobased plastics for exterior facades." BioPlastics Magazine 1 Apr. 2014: 12-14. Print.

- "Manufacturing of Brick." Brick Industry Association 1 (2006): 1. Print.

- McCullough, Cynthia S.. "Chapter 3: Healing Environments." Evidencebased design for healthcare facilities. Indianapolis, IN: Sigma Theta Tau International, 2010. 45. Print.

- McDonough, William, and Michael Braungart. The Upcycle: Beyond Sustainability - Designing for Abundance. New York: North Point Press, 2013. Print.

- Merina, Javier. Building 22. Ottawa: Carleton University, 2013. Print.

- Mostafa, H.M., H. Sourell, and F.J. Bockisch. "The Mechanical Properties of Some Bioplastics Under Different Soil Types for Use as a Biodegradable Drip Tubes." CIGR Journal 12.1 (2010): 50. Print.

- "Our Agenda for Action in 2002." Cement Sustainability Initiative. N.p., n.d. Web. 15 July 2014. <http://www.wbcsd.org/pages/edocument/ edocumentdetails.aspx?id=147\&nosearchcontextkey=true>.

- Scott, Gerald. Polymers and the environment. Cambridge: Royal Society of Chemistry, 1999. Print.

- Smith, Roch. Gaston Bachelard. Boston: Twayne Publishers, 1982. Print. 
- Starches: characterization, properties, and applications. Boca Raton: Taylor \& Francis, 2010. Print.

- Steele, Wendy Elizabeth, and Ilan Vizel. "Housing and the Material Imagination â€ Earth, Fire, Air and Water." Housing, Theory and Society 31.1 (2013): 1-15. Print.

- Teresa Pedrosa Silva Clerici, Maria, and Adel El-Sonbati. "Physical and/or Chemical Modifications of Starch by Thermoplastic Extrusion." Thermoplastic Elastomers. Rijeka: InTech, 2012. 39-56. Print.

- "The Case for Tall Wood." Michael Green Architects. N.p., n.d. Web. 15 July 2014. <http://wecbc.smallboxcms.com/database/rte/files/Tall\%20Wood.pdf>.

- The Cement Sustainability Initiative. Geneva: World Business Council for Sustainable Development, 2012. Print.

- "The basics of making corn starch bioplastic." Green Plastics. N.p., n.d. Web. 14 Sept. 2014. <http://green-plastics.net/posts/76/qaa-help-with-cornstarchpla-plastic-project/s.

- Valente, Marilu. "(bio)Plastic Morphologies." WeWantToLearn.net. N.p., n.d. Web. 14 Sept. 2014. <https://wewanttolearn.wordpress.com/2013/03/01/ bioplastic-morpholgies/>.

- "WikiHouse About." WikiHouse About. N.p., n.d. Web. 7 Aug. 2014. <http:// www.wikihouse.cc/about>.

- Williams, Peter A.. Renewable resources for functional polymers and biomaterials. Cambridge, UK: RSC Pub., 2011. Print.

- Wilson, Jeffrey. Ecological Footprints of Canadian Municipalities and Regions. Edmonton: Federation of Canadian Municipalities, 2005. Print.

- Wright, Frank Lloyd, and Bruce Brooks Pfeiffer. Frank Lloyd Wright collected writings. New York: Rizzoli „, 19921995. Print.

- Yeheyis, Muluken. An overview of construction and demolition waste management in Canada: a lifecycle analysis approach to sustainability. Vancouver: Clean Technology and Environmental Policy, 2012. Print.

- "Young Architects Program International." New York / Young Architects Program. N.p., n.d. Web. 7 Aug. 2014. <http://www.moma.org/interactives/ exhibitions/yap/2014ny_living.htmls. 